\title{
Phase reconfiguration of multivalent nickel sulfides in hydrogen evolution
}

\section{Yu Sun}

University of Science and Technology Beijing

\section{Jing Wu}

University of Science and Technology Beijing

\section{Zheng Zhang}

University of Science and Technology Beijing

Qingliang Liao

University of Science and Technology Beijing

\section{Suicai Zhang}

University of Science and Technology Beijing

\section{Xin Wang}

University of Science and Technology Beijing

\section{Baishan Liu}

University of Science and Technology Beijing

\section{Yunqi Zhao}

University of Science and Technology Beijing

\section{Yong Xie}

University of Science and Technology Beijing

\section{Kaikai Ma}

University of Science and Technology Beijing

\section{Zhuo Kang}

University of Science and Technology Beijing

\section{Yue Zhang ( $\nabla$ yuezhang@ustb.edu.cn )}

University of Science and Technology Beijing

https://orcid.org/0000-0002-8213-1420

\section{Article}

Keywords: Phase reconfiguration, multivalent nickel sulfides, hydrogen evolution, catalysts

Posted Date: April 14th, 2021

DOI: https://doi.org/10.21203/rs.3.rs-167398/v1 
License: (c) (i) This work is licensed under a Creative Commons Attribution 4.0 International License. Read Full License

Version of Record: A version of this preprint was published at Energy \& Environmental Science on January 1st, 2022. See the published version at https://doi.org/10.1039/D1EE02985A. 


\section{Phase reconfiguration of multivalent nickel sulfides in hydrogen evolution}

2

3 Yu Sun ${ }^{1,2,3}$, Jing $\mathrm{Wu}^{1,2,3}$, Zheng Zhang ${ }^{1,2,3}$, Qingliang Liao ${ }^{1,2}$, Suicai Zhang ${ }^{1,2}$, Xin Wang ${ }^{1,2}$,

4 Baishan Liu ${ }^{1,2}$, Yunqi Zhao ${ }^{1,2}$, Yong Xie ${ }^{1,2}$, Kaikai Ma ${ }^{1,2}$, Zhuo Kang ${ }^{\text {1,2 }}$ and Yue Zhang*1,2

${ }^{1}$ Beijing Advanced Innovation Center for Materials Genome Engineering, Beijing Key 
1 Abstract: Deciphering the dynamic evolution of catalysts' atomic and electronic structure in

2 operating conditions is pivotal for unraveling the activity origin and improving catalyst design.

3 Earth-abundant transition metal catalysts have shown efficient catalytic efficiency and are

4 attractive due to sustainable and economic considerations. However, the dynamic evolution

5 process during their whole service time remains elusive, which is greatly complicated by the

6 multiple component and valence states as well as the structural complexity of materials. Here

7 in this work, we investigated the atomic-scale evolution of multivalent nickel-based sulfides

8 (from $\mathrm{NiS}_{2}$ to $\alpha-\mathrm{NiS}, \beta-\mathrm{NiS}$ and $\mathrm{Ni}_{3} \mathrm{~S}_{4}$ ) as model catalysts for hydrogen evolution reaction

9 (HER), via operando Raman and X-ray absorption spectroscopies corroborated by theoretical

calculations. Dynamic reconstruction propagating from surface to bulk, mediated by sulphur vacancy, has been demonstrated for these materials, all with the terminated $\mathrm{Ni}_{3} \mathrm{~S}_{2}$ phase on catalyst surface being responsible for subsequent catalysis. Partial Fe substitution prompts such reconfiguration process and hence improves HER performance, which establishes the dynamic working mechanism of widely-adopted doping strategy. We unprecedentedly reveal the dynamic reconstruction with lower valence state tendency of transition metals in the catalytically terminated phase during HER, and the life-time dynamic correlation between structure and activity, providing insights into future catalyst design.

\section{Introduction}

Electrocatalytic water splitting to extract oxygen and hydrogen is expected to play an important role to replace fossil fuels in future sustainable energy supply ${ }^{1-4}$. Earth-abundant multivalent transition metal compounds have shown comparable activities to precious metal 
based catalysts, and have attracted increasing attention. Recent reports found that they are prone to involve several surface reconstruction process under complex conditions of catalytic reactions, including the crystal plane alternation ${ }^{5,6}$, atom segregation ${ }^{7,8}$, ligand dissociation ${ }^{9}$, coordination tailoring $^{10,11}$, and even the phase transition for bulk structure ${ }^{6,12,13}$. However, the multiple component and valence state, as well as the structural complexity of these materials greatly complicate the dynamic reconstruction process, inducing the ambiguity about the decisive role of active state in catalytic process. Thus, it is imperative to investigate the reaction process under catalytically relevant conditions via operando characterization technologies to reveal the corresponding evolution law, and bridge the gap between theoretical design and practical application for catalysts.

Recently, in terms of water oxidation catalysts, the dynamic reconstruction process has been well documented to transform to the catalytically authentic active state of oxyhydroxides, for layered double hydroxide ${ }^{14-18}$, spinel $^{19}$ and perovskite ${ }^{20}$ catalysts. Various engineering strategies have been designed to stimulate such phase transformation process ${ }^{21,22}$ and optimize the surface atomic ordering ${ }^{15}$ and electronic structure of resulted catalytic active phase ${ }^{23}$, together with unveiling feasible catalytic pathways ${ }^{24}$, which promote the water oxidation performance. With regard to hydrogen evolution reaction (HER) electrochemical environment, since the preliminarily noted discovery of the reconstructed $\operatorname{CoS}_{2}$ on amorphous cobalt sulfide catalyst ${ }^{25}$, the evolution of transition metal based compounds has been recognized to terminate with active structure of zero-valent metal ${ }^{26,27}$ or stoichiometrically varied compound ${ }^{28,29}$. Nevertheless, the systematic information of catalyst restructuring in whole service life, the evolution law on transition metal's valence state, and the dynamic correlation between space-resolved structure 
1 and time-resolved activity, are lacking. In addition, although the doping strategy has been

2 widely adopted, current knowledge of its working mechanism remains on the adjustment of atomic/electronic structure and defect state. Understanding element-doping affected dynamic reconstruction behavior of catalysts, and the establishment of the structure-activity correlation under various doping conditions, would be essential for the accurate design of efficient catalysts.

Here, in a class of multivalent nickel sulfides, the phase evolution throughout HER process together with valence state evolution, has been revealed via operando characterization techniques, to establish their life-time dynamic structure-activity correlation (Fig. 1). Specifically, pyrite-type $\mathrm{NiS}_{2}$ shows a spontaneous surface reconstruction into $\mathrm{Ni}_{3} \mathrm{~S}_{2}$ layer with the diffusion and accumulation of sulphur vacancy $\left(\mathrm{V}_{\mathrm{S}}\right)$, being responsible for catalysis. The reconstruction and subsequent phase transition initiated from surface further propagate into catalyst bulk during the long-term catalytic service. Moreover, partial Fe substitution improves the structure flexibility of $\mathrm{NiS}_{2}$, which grants more sulphur vacancies to removal and lower the applied potential threshold for phase variation. Such phase reconfiguration enables easier activity triggering and hence optimizes HER performance. The dynamic mechanism of doping strategy as well as the dynamic correlation between space-resolved structure and time-resolved activity have been well investigated. We also demonstrate the universality of figured evolution law for other nickel sulfide catalysts like $\alpha$-NiS, $\beta$-NiS and $\mathrm{Ni}_{3} \mathrm{~S}_{4}$, indicating its potential for expanded multivalent transition metal based catalysts. 


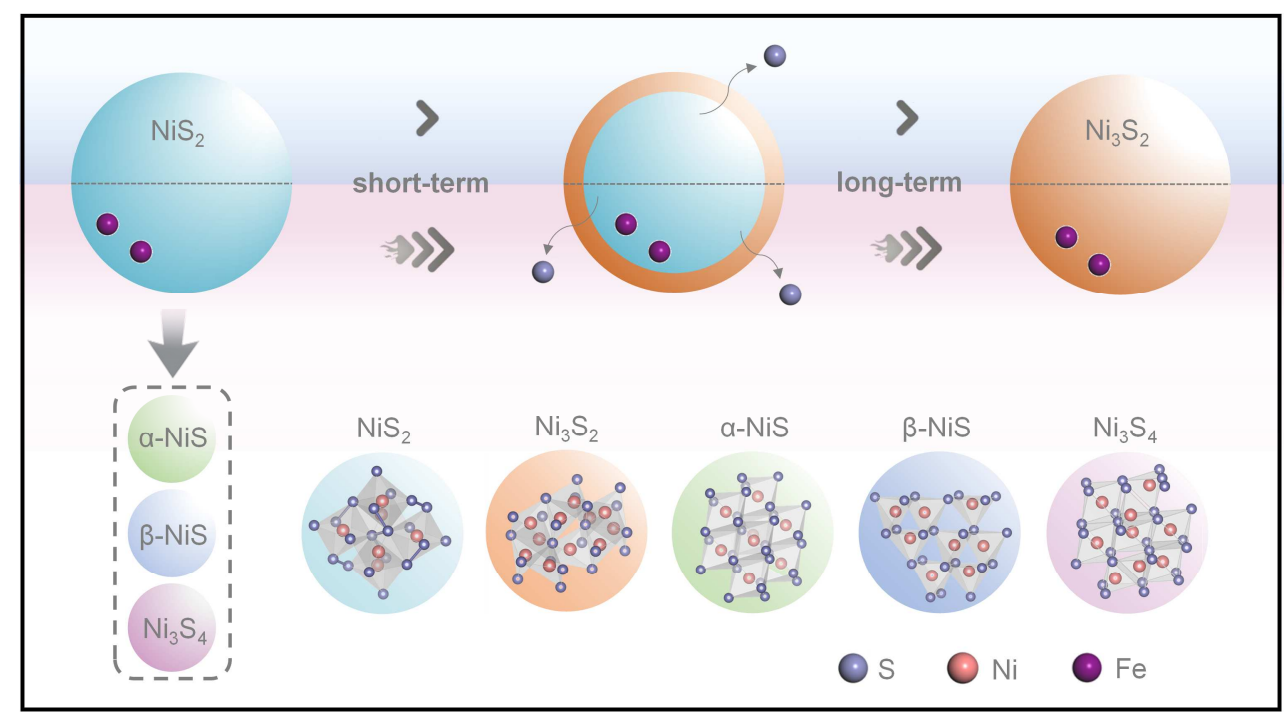

Fig. 1 | Schematic illustration of dynamic reconstruction of multivalent nickel sulfide HER catalysts.

\section{Results}

Crystal structure characterization. The pyrite-type $\mathrm{NiS}_{2}$ were achieved by annealing assynthesized $\alpha-\mathrm{Ni}(\mathrm{OH})_{2}$ nanosheets (NSs) (see Supplementary Fig. 1 and Methods for experimental details) with sulphur powder under an argon atmosphere at $400{ }^{\circ} \mathrm{C}$, and the $\mathrm{Fe}$ substitution had been well realized with the same method by partially replacing Ni atoms with Fe atoms to form $\mathrm{Ni}_{1-x} \mathrm{Fe}_{x}(\mathrm{OH})_{2} \mathrm{NSs}(x \approx 0.1 \sim 0.33)^{30,31}$. Such Fe substitution induced electronic interaction plays an important role in modulating the electronic environments of the metal $\mathrm{Ni}$ centers, potentially promoting the structural flexibility and the corresponding properties. The detailed characterization results, corroborated by theoretical calculations will be discussed in following sections.

The crystal structures of $\mathrm{Ni}_{1-x} \mathrm{Fe}_{x} \mathrm{~S}_{2}(x \approx 0 \sim 0.33)$ NSs were characterized by powder X-ray diffraction (XRD). As displayed in Fig. 2a, the diffraction peaks of as-prepared $\mathrm{Ni}_{1-x} \mathrm{Fe}_{x} \mathrm{~S}_{2}$ match with that of the standard cubic (Pa-3) pyrite-type materials (JCPDS No. 65-3325). Furthermore, the diffraction peak exhibits a shift to a large angle with increasing Fe substitution amount (inset in Fig. 2a), which is ascribed to changes in lattice parameters induced by ionic 
1 radius differential between $\mathrm{Fe}$ and $\mathrm{Ni}$ cations and suggests a solid solution property. Notably,

2 when $x \geq 0.25$, the diffraction peak appears no more shift, being attributed to the segregation of

$3 \quad \mathrm{FeS}_{2}$ (Supplementary Fig. 2). In scanning electron microscopy (SEM) and transmission electron

4 microscopy (TEM) images (Figs. 2b, c and Supplementary Fig. 3), close-up inspection of

$5 \quad \mathrm{Ni}_{0.8} \mathrm{Fe}_{0.2} \mathrm{~S}_{2} \mathrm{NSs}$ reveals nanosheets structures whose thickness-uniformly distribute between 10

6 and $20 \mathrm{~nm}$. Also, the high-resolution TEM (HRTEM) image (Fig. 2d) displays clear lattice

7 fringes with an interplanar spacing of $2.49 \AA$, indexed to the (210) plane of $\mathrm{Ni}_{0.8} \mathrm{Fe}_{0.2} \mathrm{~S}_{2} \mathrm{NSs}$,

8 which has been supported by the single-crystal-like diffraction spots from the selected-area

9 electron diffraction pattern (inset in Fig. 2d). Meanwhile, energy dispersive X-ray spectrum (EDS) elemental mappings of $\mathrm{Ni}_{0.8} \mathrm{Fe}_{0.2} \mathrm{~S}_{2} \mathrm{NSs}$ provide direct-viewing evidence for the uniform

distribution of $\mathrm{Ni}, \mathrm{Fe}$ and $\mathrm{S}$ elements in as prepared nickel sulfides (Fig. 2e).
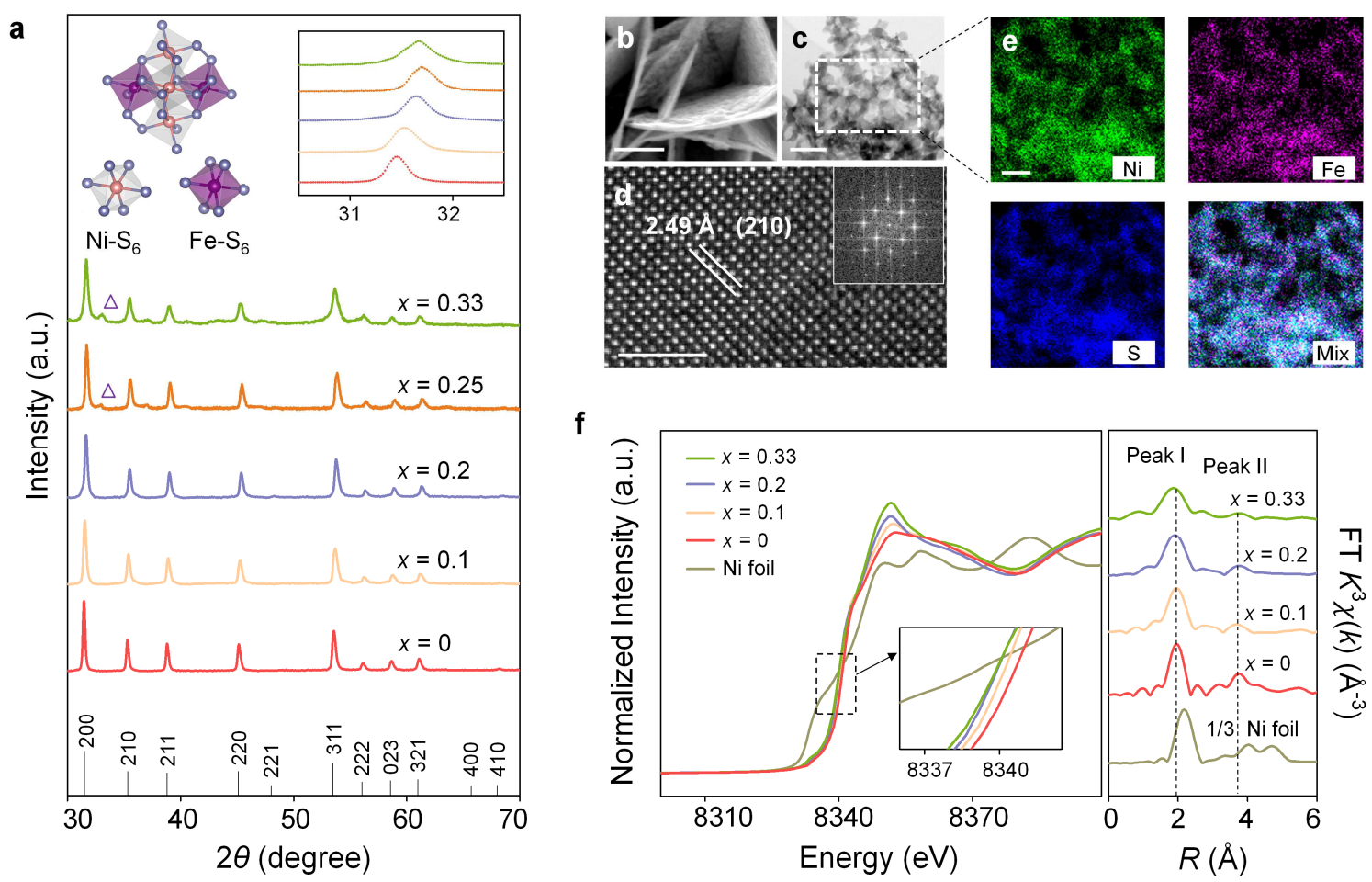

Fig. 2 | Structural characterizations of as-prepared $\mathbf{N i}_{1-x} \mathbf{F e}_{x} \mathbf{S}_{2}$ catalysts. a, Powder XRD patterns of synthesized $\mathrm{Ni}_{1-x} \mathrm{Fe}_{x} \mathrm{~S}_{2}(x \approx 0 \sim 0.33)$ samples. Inset, schematics of the composition of Fe substituted nickel disulfides and the magnified XRD patterns in the range between 30 and 33 . The triangle symbols represent diffraction peak of $\mathrm{FeS}_{2}$ structure. b, Top-view SEM image of the $\mathrm{Ni}_{0.8} \mathrm{Fe}_{0.2} \mathrm{~S}_{2}$. Scale bar, $1 \mu \mathrm{m}$. c, TEM image 
of $\mathrm{Ni}_{0.8} \mathrm{Fe}_{0.2} \mathrm{~S}_{2}$. Scale bar, $100 \mathrm{~nm}$. d, High-resolution TEM image of $\mathrm{Ni}_{0.8} \mathrm{Fe}_{0.2} \mathrm{~S}_{2}$. Scale bar, $2 \mathrm{~nm}$. The fast Fourier transform is shown in the inset of (d) confirms the crystalline nature of the bulk material. e, The corresponding EDS elemental mappings of $\mathrm{Ni}, \mathrm{Fe}, \mathrm{S}$ and the mixed elemental mapping. Scale bar, $50 \mathrm{~nm}$. f, Normalized Ni K-edge XANES analysis (left axis) of $\mathrm{Ni}_{1-x} \mathrm{Fe}_{x} \mathrm{~S}_{2}$ samples with $\mathrm{Ni}$ foil as reference, as well as the corresponding $k^{3}$-weighted Fourier transform (FT) Ni K-edge EXAFS spectra (right axis). Inset, Magnified pre-edge XANES region. Peaks I and II in the FT-EXAFS plots are assigned to Ni-S and Ni-Ni radial distances, respectively.

To gain insight into the local electronic and coordination environment of $\mathrm{Ni}_{1-x} \mathrm{Fe}_{x} \mathrm{~S}_{2}(x \approx$ 0 0.33) NSs, we performed X-ray absorption fine structure (XAFS) measurements at the nickel K edge. X-ray absorption near-edge structure (XANES) results present the Ni absorption-edge shifts to the lower-energy side as the substituted Fe concentration increasing, implying a decrease of $\mathrm{Ni}$ valence state in different components (Fig. 2f left axis inset). The K-edge position is determined by the method as described in the references ${ }^{32-34}$, and details about edge positions and nominal valence states of $\mathrm{Ni}$ and Fe are shown in Supplementary Fig. 4 and Supplementary Table 1 . The nominal Ni valence states are supported by the K-edge absorption positions with the calibration of $\mathrm{Ni}$ Foil and $\mathrm{Ni}_{2} \mathrm{O}_{3}$, which are in line with the facts of $\mathrm{Ni} 2 p 3 / 2$ X-ray photoelectron spectroscopy (XPS) peaks shifting to lower binding energies in $\mathrm{Ni}_{1-x} \mathrm{Fe}_{x} \mathrm{~S}_{2}$ (Supplementary Fig. 5 and Supplementary Table 2). Besides, Fe substitution in $\mathrm{NiS}_{2}$ also alters the local coordination environment of Ni. As observed from a different perspective in the Fourier transform (FT) Ni K-edge extended X-ray fine structure (EXAFS) analysis in Fig. 2f (right axis), two separate peaks (peaks I and II) at $\sim 1.9$ and $3.5 \AA$ are assigned to the features of Ni-S and Ni-Ni bonds. For pyrite-type $\mathrm{NiS}_{2}$, the unit cell consists of octahedral polyhedron of center nickel atom with six sulphur atoms coordinated $\left(\mathrm{Ni}-\mathrm{S}_{6}\right)$ motifs. As observed with $\mathrm{Ni}$ K-edge EXAFS (Fig. 2f right axis), the first-shell peak I is weakened by Fe substitution, suggesting a lower nickel-sulfide coordination number $(\mathrm{CN})$, more sulphur vacancies, as well 
1 as the increased lattice disorder. These results have also been verified by the least-square

2 EXAFS curve-fitting analysis for the first coordination shell of Ni. Specifically, the fitting results of $\mathrm{Ni}_{1-x} \mathrm{Fe}_{x} \mathrm{~S}_{2}(x \approx 0 \sim 0.33)$ NSs illustrate that Fe substitution reduces the average $\mathrm{CN}$ by $\sim 0.6$ and the $\mathrm{Ni}-\mathrm{S}$ bond distance by $\sim 0.4$ for $\mathrm{Ni}_{0.67} \mathrm{Fe}_{0.33} \mathrm{~S}_{2}$ (Supplementary Fig. 6 and Supplementary Table 3). Such an effect, indicating an increase in sulphur vacancy, is consistent with the lattice disorder and decreased nickel valence state for Fe doped $\mathrm{NiS}_{2}$.

Phase reconfiguration and dynamic structure-activity correlation. Nickel sulfides were then investigated by in-situ electrochemical Raman spectroscopy ${ }^{35-37}$ to gain an in-depth understanding on the dynamic reconstruction process of surface structures during HER process. According to Raman peaks of pristine pyrite-type $\mathrm{NiS}_{2}$ and heazlewoodite-type $\mathrm{Ni}_{3} \mathrm{~S}_{2}$ from Supplementary Fig. 7 and Supplementary Table 4, the corresponding characteristic peaks in Fig. 3a have been identified ${ }^{38-40}$. For the in-situ Raman measurement of $\mathrm{NiS}_{2}(x=0)$, as the applied potential increases cathodically from 0.4 to $-0.25 \mathrm{~V}$ (more negative versus the reversible hydrogen electrode, vs. RHE), the characteristic peaks assigned to $\mathrm{NiS}_{2}$ gradually decay till disappear along with the emerging and progressive growth of $\mathrm{Ni}_{3} \mathrm{~S}_{2}$ peaks. This is interpreted that $\mathrm{NiS}_{2}$ undergoes a spontaneous phase evolution process whose reconstruction potential threshold locates between 0.1 to $0.05 \mathrm{~V}$ (vs. RHE). One observation of note is the continuous redshift of $A_{\mathrm{g}}$ and $E_{\mathrm{g}}$ peaks of $\mathrm{NiS}_{2}$ with applied potentials varied from 0.4 to $0.1 \mathrm{~V}$ vs. RHE (Supplementary Fig. 8 and Supplementary Table 5). Such phenomenon suggests the softening of S-S bonds, which could be attributed to the generation and the subsequent accumulation of sulphur vacancy before the above mentioned activation of qualitative surface reconstruction ${ }^{41}$. 
1 In term of a series of $\mathrm{Ni}_{1-x} \mathrm{Fe}_{x} \mathrm{~S}_{2}$ samples $(x=0.1,0.2,0.25,0.33)$, the similar quantitative change

2 of sulphur vacancy accumulation and the following qualitative change of phase transition

3 processes have been well illustrated (Fig. 3a). Also, the quantitative changing rate and the

4 qualitative changing threshold accordingly vary with the Fe doping amount. That is to say, with

5 the incremental Fe doping in Fig. 3b, the reconstruction potential threshold range gradually

6 moves to the positive direction. However, it basically remains unchanged between $0.25 \sim 0.2 \mathrm{~V}$

7 (vs. RHE) when $x>0.2$, indicating the dominated position of the low Fe substitution levels

8 towards the reconstruction potential threshold of nickel sulfides. 

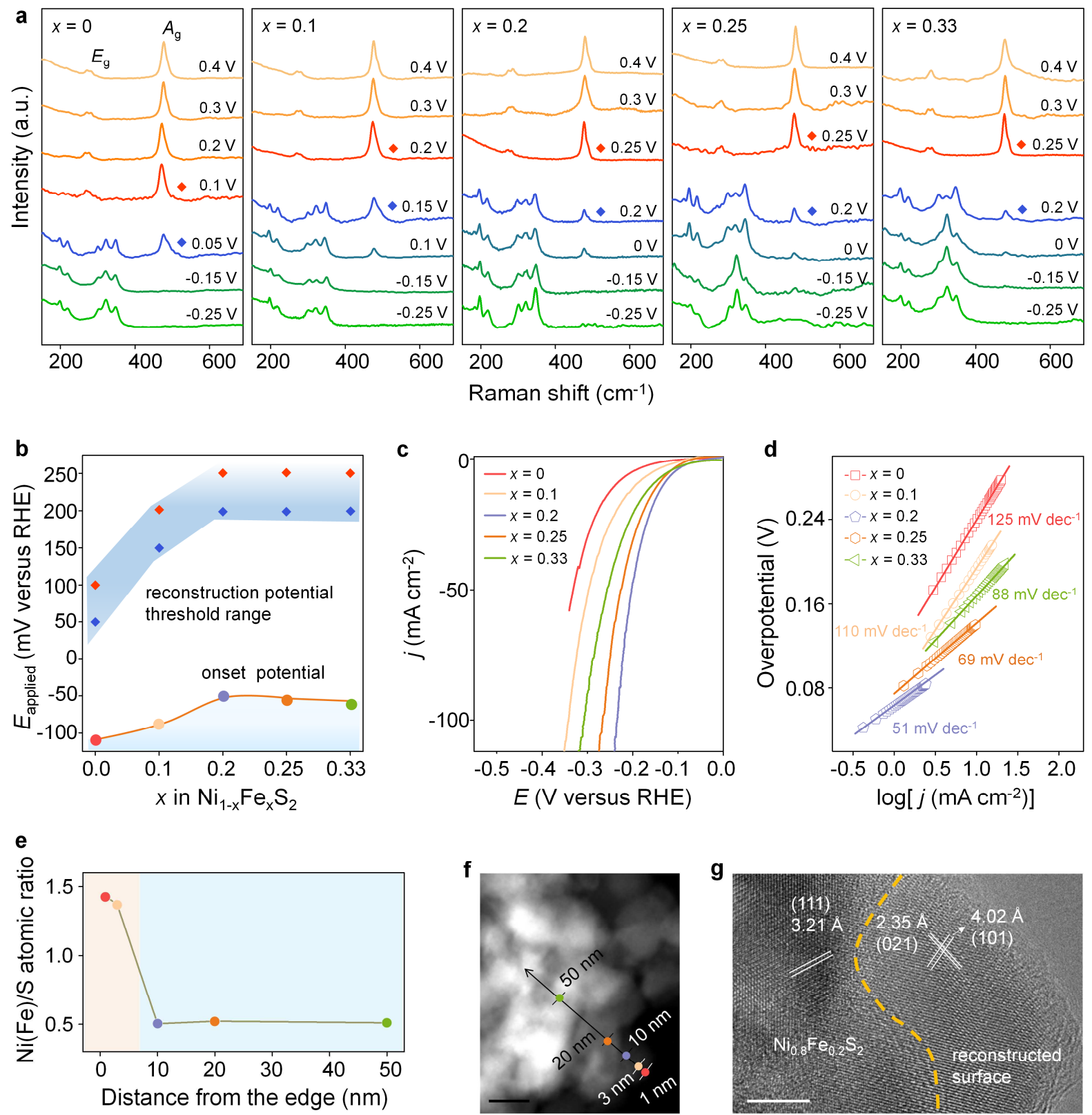

Fig. 3 | In-situ investigation of dynamic surface reconstruction process and HER performances of catalysts. a, In-situ Raman spectra of $\mathrm{Ni}_{1-x} \mathrm{Fe}_{x} \mathrm{~S}_{2}(x \approx 0 \sim 0.33)$ samples at the potentials of $0.4 \sim-0.25 \mathrm{~V}$ versus reversible hydrogen electrode (vs. RHE) in $1 \mathrm{M} \mathrm{KOH}$. b, The surface reconstruction potential threshold range for $\mathrm{Ni}_{1-x} \mathrm{Fe}_{x} \mathrm{~S}_{2}(x \approx 0 \sim 0.33)$ samples, and the corresponding onset potentials of hydrogen evolution are plotted to show the dynamic correlation of structure-activity. The red diamond dots represent the final potential of existence for Raman peaks of $\mathrm{Ni}_{1-x} \mathrm{Fe}_{x} \mathrm{~S}_{2}$ structures, and the blue diamond dots stand for the potential of emerging of $\mathrm{Ni}_{3} \mathrm{~S}_{2}$ Raman peaks. $\mathbf{c}, \mathrm{HER}$ polarization curves of $\mathrm{Ni}_{1-x} \mathrm{Fe}_{x} \mathrm{~S}_{2}$ catalysts on carbon fiber paper in $\mathrm{N}_{2}$-saturated $1 \mathrm{M} \mathrm{KOH}$ at a scan rate of $5 \mathrm{mV} \mathrm{s}^{-1}$, d, Corresponding HER Tafel plots derived from the polarization curves. e, f, Elemental composition of post-electrolysis $\mathrm{Ni}_{0.8} \mathrm{Fe}_{0.2} \mathrm{~S}_{2}$ determined from EDS at a series of spots along a line from the crystallite edge to the bulk reveals the variation in $\mathrm{Ni}(\mathrm{Fe}): \mathrm{S}$ composition across the crystallite, the marked points in (f) denote the scanning distance along the pathway in $\mathrm{nm} . \mathbf{g}$, HRTEM image of post-electrolysis $\mathrm{Ni}_{0.8} \mathrm{Fe}_{0.2} \mathrm{~S}_{2}$. The scale bars are $20 \mathrm{~nm}$ in (f), $5 \mathrm{~nm}$ in (g). 
The electrochemical HER activity of $\mathrm{Ni}_{1-x} \mathrm{Fe}_{x} \mathrm{~S}_{2}$ NSs have been systematically investigated under alkaline conditions (for detail see Methods). The steady-state linear sweep voltammetry (LSV) in $\mathrm{N}_{2}$-saturated $1 \mathrm{M} \mathrm{KOH}$, as shown in Fig. 3c, demonstrates that $\mathrm{NiS}_{2}$ exhibits an overpotential of $233 \mathrm{mV}$ at the current density of $10 \mathrm{~mA} \mathrm{~cm}{ }^{-2}$. As the Fe doping amount $x$ increases before reaching 0.2 , the corresponding overpotential @10 mA cm${ }^{-2}$ continues to decrease to $122 \mathrm{mV}$, and then it bounces back beyond 0.2 (Supplementary Fig. 9a). The Tafel slope, as a pivotal kinetic parameter, is usually used to investigate the rate determining step of an electrochemical process. Here, compared with $125 \mathrm{mV} \mathrm{dec}^{-1}$ for $\mathrm{NiS}_{2}, \mathrm{Ni}_{0.8} \mathrm{Fe}_{0.2} \mathrm{~S}_{2}(x=0.2)$ performs superior properties over other Fe-doped catalysts, with the Tafel slope as low as 51 $\mathrm{mV} \mathrm{dec}{ }^{-1}$, as shown in Fig. 3d, suggesting the Volmer-Heyrovsky mechanism as the HER pathway ${ }^{42,43}$. The activity differencial of nickel sulfides is in accordance with the electrochemical impedance spectroscopy results and the double-layer capacitance plot data. As shown in Supplementary Fig. 9b, Nyquist plots are fitted to a simplified Randles equivalent circuit model ${ }^{44}$, and the charge-transfer resistance $\left(R_{\mathrm{ct}}\right)$ of $\mathrm{Ni}_{1-x} \mathrm{Fe}_{x} \mathrm{~S}_{2}$ measured at $200 \mathrm{mV}$ overpotential decline considerably in comparison with that of $\mathrm{NiS}_{2}\left(R_{\mathrm{ct}}\right.$ is $\left.14 \Omega\right)$, and $\mathrm{Ni}_{0.8} \mathrm{Fe}_{0.2} \mathrm{~S}_{2}$ shows the smallest $R_{\mathrm{ct}}$ value of $6.5 \Omega$. These results demonstrate that an appropriate Fe doping concentration extraordinarily promotes the charge transfer, thus both improving the reaction efficiency and propelling efficient electrical integration to reduce parasitical ohmic loss. The double-layer capacitance $\left(C_{\mathrm{dl}}\right)$ scales roughly with the effective electrochemically active surface $\operatorname{area}^{45}$, and its value can be estimated from the slope of the linear relationship between the half capacitive current density $\left(\left(j_{\text {anodic }}-j_{\text {cathodic }}\right) / 2\right)$ at the middle of the applied potential range and the scan rates in Supplementary Fig. 10. Significantly, our results reveal a 
1 considerably larger $C_{\mathrm{dl}}$ of $\mathrm{Ni}_{0.8} \mathrm{Fe}_{0.2} \mathrm{~S}_{2}\left(67 \mathrm{mF} \mathrm{cm}^{-2}\right)$ compared with $\mathrm{NiS}_{2}\left(4 \mathrm{mF} \mathrm{cm}^{-2}\right)$, 2 suggesting more accessible active sites created on $\mathrm{Ni}_{0.8} \mathrm{Fe}_{0.2} \mathrm{~S}_{2}$ catalyst.

According to the LSV curve of the catalytic performance measurement, the relationship between the HER onset potentials (@ $0.5 \mathrm{~mA} \mathrm{~cm}^{-2}$ ) and the Fe doping amount has also been plotted in Fig. 3b. The exhibited synchronous trend between reconstruction potential threshold range and onset potential when $x \leq 0.2$ implicates the close correlation concerning reconstruction initiate and HER activation, further implicating the resulted $\mathrm{Ni}_{3} \mathrm{~S}_{2}$ phase at the surface should be responsible for the HER activity. Specifically, the reconstruction potential threshold of $\mathrm{Ni}_{0.8} \mathrm{Fe}_{0.2} \mathrm{~S}_{2}$ locates between $0.25 \sim 0.2 \mathrm{~V}$ (vs. RHE) while it moves into the range between $0.1 \sim 0.05 \mathrm{~V}$ (vs. RHE) for pristine $\mathrm{NiS}_{2}$. Such shift apparently verifies that appropriate Fe substitution is beneficial for reducing necessary energy consumption to ignite the phase reconfiguration process. It is attributed to the varied sulphur vacancy concentration in asprepared $\mathrm{Ni}_{1-x} \mathrm{Fe}_{x} \mathrm{~S}_{2}$ catalysts, indicated from XAFS results in Fig. 2f. When with Fe substitution in $\mathrm{NiS}_{2}$ structures, more sulphur vacancies grant the facile removal of the sulphur atoms from the surface, and at the same time enable the interdiffusion of the component atoms under working conditions ${ }^{13}$. Correspondingly, the onset potential of $\mathrm{Ni}_{0.8} \mathrm{Fe}_{0.2} \mathrm{~S}_{2}$ declines by about 50 $\mathrm{mV}$ as comparison with $\mathrm{NiS}_{2}$. The cyclic voltammetry (CV) curves in Supplementary Fig. 11 also suggest consistent results. The reduction peak in the first cycle appears at $\sim 0.1 \mathrm{~V}$ (vs. RHE) for $\mathrm{Ni}_{0.8} \mathrm{Fe}_{0.2} \mathrm{~S}_{2}$, while an obvious negative peak shift is observed for $\mathrm{NiS}_{2}(\sim 0.0 \mathrm{~V}$ vs. RHE), which suggest that Fe substitution facilitates the pre-reduction of $\mathrm{Ni}$ as well as subsequent surface reconstruction initiate.

In addition, the irreversible morphology change on catalyst surface during HER 
1 measurement was monitored (Figs. 3 e, f, g and Supplementary Fig. 12). The catalysts sprayed

2 on $\mathrm{Cu}$ grids, which were attached to $\mathrm{Au}$ electrode with conductive carbon tape, have been

3 polarized in $\mathrm{N}_{2}$ saturated 0.01 $\mathrm{M} \mathrm{NaPi}$ electrolyte (sodium phosphate, $\mathrm{pH} 7.2$ ) at $-0.45 \mathrm{~V}$ (vs.

4 RHE) for $2 \mathrm{~h}$. EDS results display that the $\mathrm{Ni}(\mathrm{Fe})$ : $\mathrm{S}$ atomic ratio is $1.43: 1.0$ at the edge of the

5 nanosheet, and this ratio rapidly increases to $1.0: 2.0$ as the scan proceeds to the interior,

6 reflecting the bulk stoichiometry. Also, the $5 \mathrm{~nm}$ thick reconstructed phase shell, indexed to the

7 (101) and (021) planes of $\mathrm{Ni}_{3} \mathrm{~S}_{2}$, were observed on the surface of bulk $\mathrm{Ni}_{0.8} \mathrm{Fe}_{0.2} \mathrm{~S}_{2}$ catalyst.

8 These visualization results again support the undergoing reconstruction of pre-catalyst.
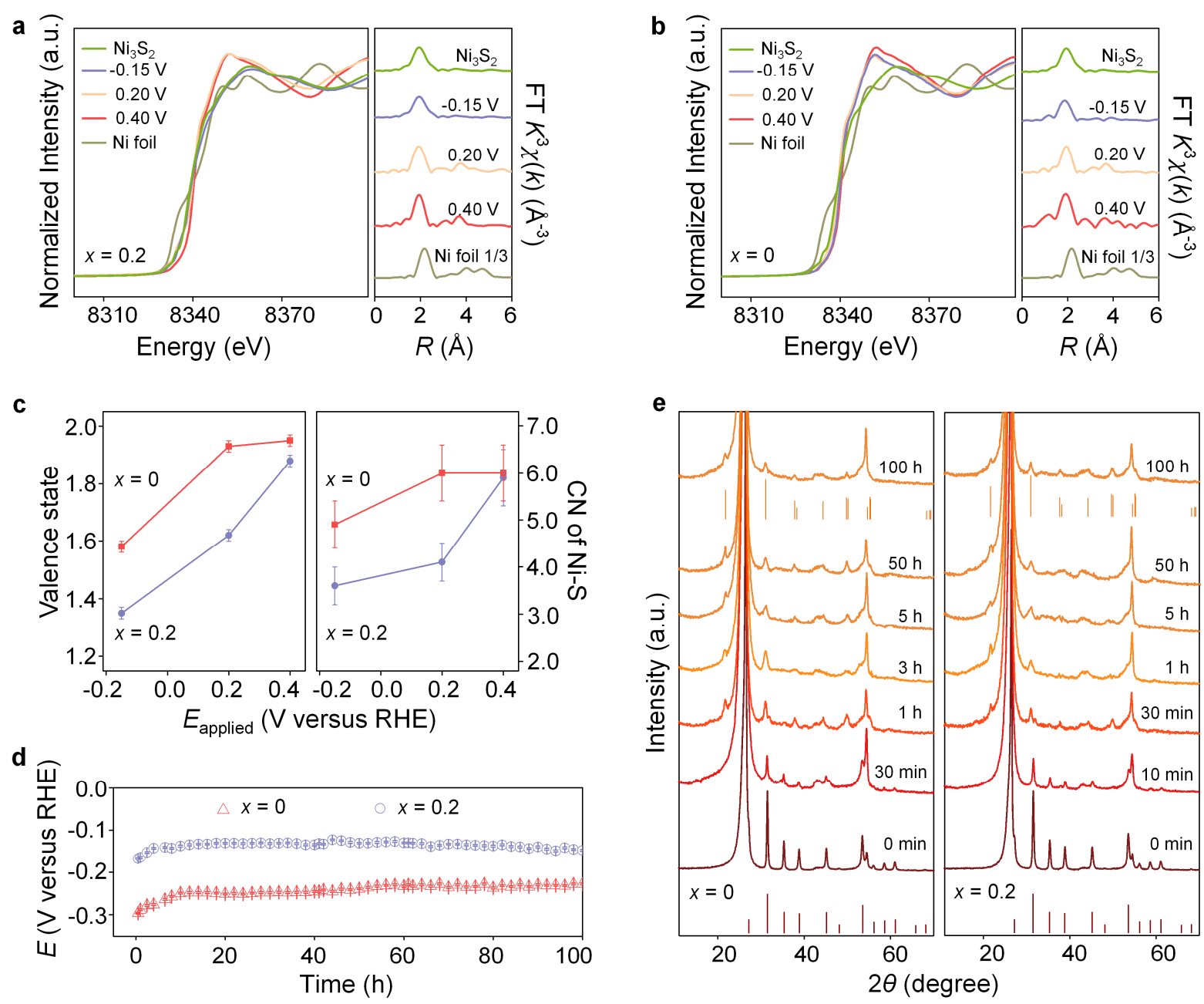

Fig. 4 | Operando XAFS spectra and long-term operation characterization of catalysts. a, b, Normalized operando Ni K-edge XANES analysis (left axis) at 0.40, 0.20, and -0.15 V (vs. RHE) with Ni Foil and standard $\mathrm{Ni}_{3} \mathrm{~S}_{2}$ powder (Alfa Aesar) as reference, as well as the corresponding operando $\mathrm{FT} k^{3}$-weighted Ni 
K-edge EXAFS (right axis): $\mathrm{Ni}_{0.8} \mathrm{Fe}_{0.2} \mathrm{~S}_{2}$ (a) and $\mathrm{NiS}_{2}$ (b). c, Left axis, the fitted average valence states of nickel element from XANES spectra for $\mathrm{NiS}_{2}$ and $\mathrm{Ni}_{0.8} \mathrm{Fe}_{0.2} \mathrm{~S}_{2}$. Error bars represent the standard deviation from at least three independent measurements. The right axis show the changes of coordination number $(\mathrm{CN})$ for Ni-S corresponding to the applied potentials. d, Chronopotentiometric curves obtained with $\mathrm{Ni}_{0.8} \mathrm{Fe}_{0.2} \mathrm{~S}_{2}$ and $\mathrm{NiS}_{2}$ at constant current density of $10 \mathrm{~mA} \mathrm{~cm}^{-2}$. e, XRD patterns of catalysts after the operation of HER instantly at $10 \mathrm{~mA} \mathrm{~cm}{ }^{-2}$ during $100 \mathrm{~h}$. The $2 \theta$ peaks of $\sim 26.5^{\circ}$ and $54.5^{\circ}$ stand for the carbon fiber paper substrates.

Thereafter, attention was directed to the dynamic evolution of electronic structure and local coordination environment via operando XAFS for as-prepared nickel sulfides during the practical electrochemical reaction. Figs. $4 \mathrm{a}, \mathrm{b}$ illustrate the operando XANES and the FTEXAFS spectra in $R$-space of $\mathrm{Ni}_{0.8} \mathrm{Fe}_{0.2} \mathrm{~S}_{2}$ and $\mathrm{NiS}_{2}$ recorded at $0.4 \mathrm{~V}, 0.2 \mathrm{~V}$ and $-0.15 \mathrm{~V}$ (vs. RHE). Note that in left axis of Figs. $4 a$ and b, absorption K-edges of both samples gradually shift to a lower energy position with the potential increase cathodically during HER process. This clearly explains the reduced valence state of nickel, which is attributed to the reconstruction in nickel sites. The corresponding nominal valence states of $\mathrm{Ni}$ in both samples under each applied potential are shown in Fig. 4c left based on the results from Supplementary Fig. 4. The average valence state of $\mathrm{Ni}$ in $\mathrm{Ni}_{0.8} \mathrm{Fe}_{0.2} \mathrm{~S}_{2}$ at $0.40 \mathrm{~V}$ (vs. RHE) is approximately +1.88 , and it decreases to +1.62 and +1.35 at 0.20 and $-0.15 \mathrm{~V}$ (vs. RHE), respectively. While for $\mathrm{NiS}_{2}$, the average valence state has a negligible decrease at $0.20 \mathrm{~V}$ compared with $0.4 \mathrm{~V}$ (vs. RHE), and it reaches +1.58 at $-0.15 \mathrm{~V}$ (vs. RHE). This demonstrates the promotion effect on $\mathrm{Ni}$ reduction originated from Fe substitution, which is in accord with the results of phase transition and effectively supports the rational inference regarding its contribution on reconfiguration process.

In the case of local coordination environment, similar results are acquired from the FTEXAFS spectra in $R$-space (right axis of Figs. $4 \mathrm{a}, \mathrm{b}$ ). Compared with the profiles collected at 
$0.4 \mathrm{~V}$ vs. RHE, the Ni-S bond peak in both samples decrease at $-0.15 \mathrm{~V}$ vs. RHE, indicating Ni atom accumulation in $\mathrm{Ni}-\mathrm{S}_{4}$ tetrahedral coordination resulted from reconstruction. More precisely for fitting results (right axis in Fig. 4c), the Ni-S CN decreases to $4.1 \pm 0.4$ and $3.5 \pm$ 0.4 for $\mathrm{Ni}_{0.8} \mathrm{Fe}_{0.2} \mathrm{~S}_{2}$ at 0.20 and $-0.15 \mathrm{~V}$ vs. RHE from $5.9 \pm 0.6$ at $0.4 \mathrm{~V}$ vs. RHE. While for $\mathrm{NiS}_{2}$, the decline trend is obviously delayed (Supplementary Figs. 13, 14 and Supplementary Table 3). Notably, the absorption edge and $\mathrm{CN}$ of $\mathrm{Ni}_{0.8} \mathrm{Fe}_{0.2} \mathrm{~S}_{2}$ at $-0.15 \mathrm{~V}$ (vs. RHE) is closer to that of standard $\mathrm{Ni}_{3} \mathrm{~S}_{2}$ sample (the average valence state of $\mathrm{Ni}$ in standard $\mathrm{Ni}_{3} \mathrm{~S}_{2}$ is about +1.20 , in Supplementary Fig. 15), further verifying a more thorough reconstruction process with the distorted Ni tetrahedral structure enabled by Fe doping.

The lower tendency of both Ni valence state and $\mathrm{CN}$ in the cathodic process on nickel sulfides surface could be viewed as a desulphurization process, and the delayed Ni reduction for pristine $\mathrm{NiS}_{2}$ suggests a relatively limited desulphurization process. This elucidates that Fe substitution activate the structure to facilitate quantitative accumulation of sulphur vacancy and the interdiffusion of component atoms, as well to subsequently germinate the phase transition with unsaturated nickel-sulphur sites, reconfirming that the phase evolution together with the lower valence state evolution tendency are strongly correlated with the sulphur atom behavior.

Therefore, the surface of pyrite-type nickel sulfide catalyst is inclined to reconstruct soon after desulphurization, to generate the $\mathrm{Ni}_{3} \mathrm{~S}_{2}$ structure. Such critical process, consisting of the quantitative (sulphur vacancy accumulation) to qualitative alternation (phase transition), is effectively facilitated by introduction of proper sulphur vacancy, to empower the catalytic HER activity easier to be triggered. To sum up, the phase reconfiguration process, indicated by the evolution law of phase transition and valence state, is dominated by Fe doping with a sulphur 
vacancy mediated mechanism.

In order to investigate the long-term structure-activity correlation at catalyst during the whole HER service life, the stability test for the nickel sulfide/carbon fiber paper electrodes at a fixed current density of $10 \mathrm{~mA} \mathrm{~cm}^{-2}$ was conducted. As shown in Fig. 4d, the exhibited negligible activity decay even over $100 \mathrm{~h}$ demonstrates their superior stability under the alkaline environment. To follow the phase transition from their as-synthesized pre-state into the practically true state of the whole catalyst, XRD analysis was employed (Fig. 4e). The diffraction peaks of $\mathrm{NiS}_{2}$ gradually fade away with $\mathrm{Ni}_{3} \mathrm{~S}_{2}$ peaks emerging to finally reach a total phase transition throughout the electrolysis duration, demonstrating the terminated stable phase of $\mathrm{Ni}_{3} \mathrm{~S}_{2}$. Simultaneously considering in-situ Raman results, as well as the corresponding surface chemical states of Ni probed by the XPS data during the long-term operation are provided in Supplementary Fig. 16 and Supplementary Table 2, it is confirmed that the phase transition initially starts from the catalyst surface and subsequently extends to the bulk structure. The life-time dynamic structure-activity correlation during HER service of nickel-based sulfide compounds is further established by comprehensively considering the transient reconstruction triggered activity and the long-term bulk phase transition maintained stability.

Dynamic mechanism of phase reconfiguration. To further validate the dominant sulphur vacancy as inner driving force for phase reconfiguration and the effective tuning capability of proper Fe substitution, density functional theory (DFT) calculations were conducted. The computational models for $\mathrm{Ni}_{1-x} \mathrm{Fe}_{x} \mathrm{~S}_{2}(x=0$ and 0.2$)$ are presented in Fig. 5a. The projected density of state (PDOS) of $\mathrm{Ni}_{1-x} \mathrm{Fe}_{x} \mathrm{~S}_{2}$ and their band center energies are given in Fig. $5 \mathrm{~b}$ (for 
1 more details see Supplementary Table 6). When Fe is substituted in $\mathrm{NiS}_{2}, \mathrm{~S} 3 p$ band center

2 energy is raised to be closer to the Fermi level, allowing for the reduction of energy penalty to

3 create sulphur vacancy, which is beneficial for the formation of sulphur vacancy in nickel

4 sulfide $^{46}$. Similar inference is reached based on lower sulphur vacancy formation enthalpy $(0.75$

$5 \mathrm{eV}$ for $\mathrm{Ni}_{0.8} \mathrm{Fe}_{0.2} \mathrm{~S}_{2}$ and $0.86 \mathrm{eV}$ for $\mathrm{NiS}_{2}$ ) from Fig. $5 \mathrm{c}$ and details in Supplementary Tables 1

6 and 7, thus resulting in the highest sulphur vacancy concentration $(\delta)$ approximate 0.13 with

$7 \quad 0.2 \mathrm{Fe}$ substitution. The catalyst structural flexibility, enabled by initial high anion vacancy

8 concentration, is believed to be capable of accommodating even more anion vacancies during

9 the electrocatalysis ${ }^{21,22}$. This capacitates the easy migrating and leaching of sulphur atoms from

10 nickel sulfide surface, while simultaneously aiding interdiffusion of the constituent atoms, via

11 the sulphur vacancy mediated mechanism under operation condition. 
a
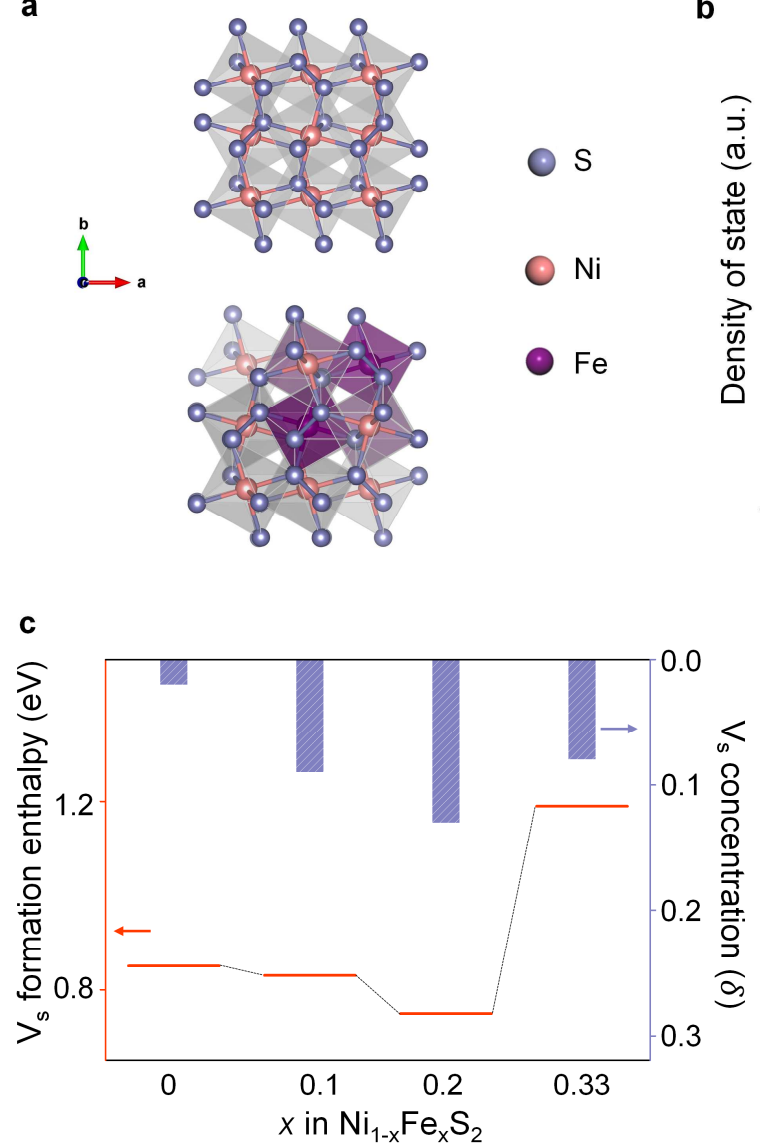

b

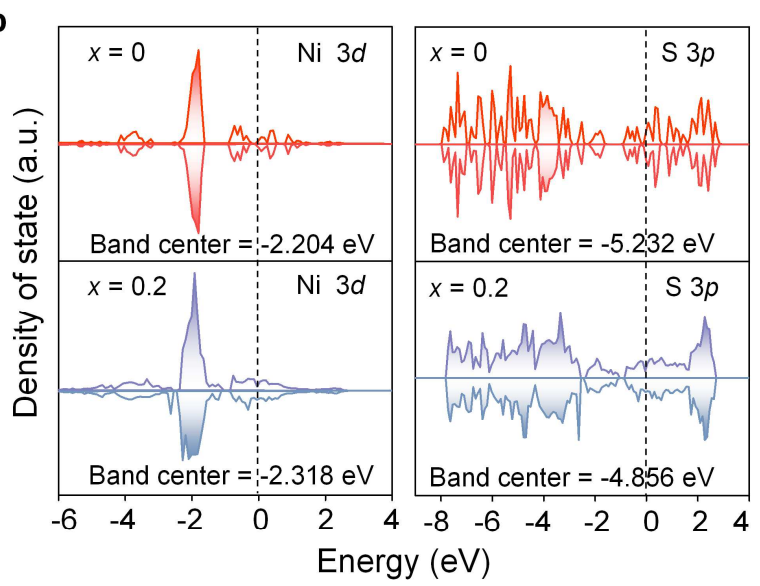

d

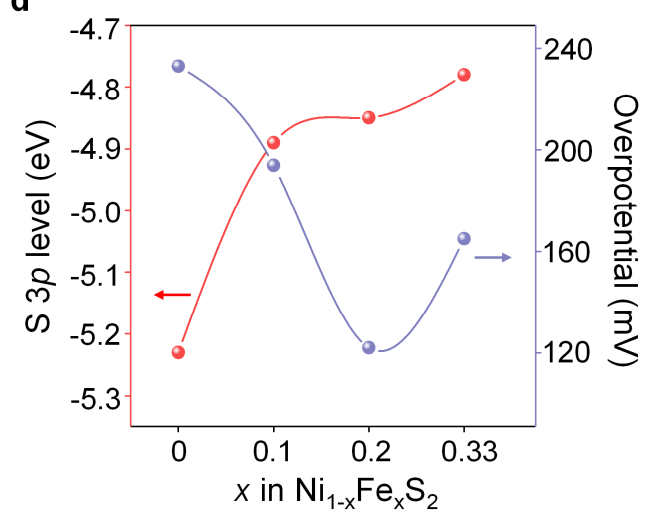

Fig. 5 Electronic interpretation of the effect of Fe substitution on catalyst evolution. a, Computational models of $\mathrm{Ni}_{1-x} \mathrm{Fe}_{x} \mathrm{~S}_{2}$ : top, $x=0$; bottom, $x=0.2$. b. Computed Ni $3 d$, $\mathrm{S} 3 p$ PDOS of $\mathrm{Ni}_{1-x} \mathrm{Fe}_{x} \mathrm{~S}_{2}(x=0.0,0.2)$. c, Calculated sulphur vacancy $\left(\mathrm{V}_{\mathrm{S}}\right)$ formation enthalpy and sulphur vacancy concentration $(\delta)$ of the samples for $\mathrm{Ni}_{1-x} \mathrm{Fe}_{x} \mathrm{~S}_{2}(x=0.0,0.1,0.2,0.33)$. d, Computed $\mathrm{S} 3 p$ PDOS related to the overpotential of $\mathrm{Ni}_{1-x} \mathrm{Fe}_{x} \mathrm{~S}_{2}(x$ $=0.0,0.1,0.2,0.33) @ 10 \mathrm{~mA} \mathrm{~cm}^{-2}$.

Furthermore, as the Ni $3 d$ band expands gradually with the incremental Fe substitution amount, its overlap with the S $3 p$ band becomes larger, verifying the enhanced Ni-S covalency due to the increased hybridization between Ni $3 d$ and S $3 p$ orbital. In Supplementary Table 6, when $x$ ranges from 0 to 0.33 , the Ni $3 d$-S $3 p$ exhibits an obvious diminishment, indicating that the Ni $3 d$-S $3 p$ hybridization is enhanced by increasing Fe substitution amount. This benefits the sulphur redox reaction and the mutual diffusion when a cathodic potential is applied. The sulphur atom in the lattice is easier to be leached to create more sulphur vacancies to subsequently boost the qualitative phase transition. This trend is in consistent with the HER 
1 activity in terms of overpotential when $x \leq 0.2$ in Fig. 5d. However, as for $x=0.33$, its

2 overpotential unexpectedly rises, which originated from the inhibition of further sulphur

3 vacancy creating with excessive $\mathrm{Fe}-\mathrm{S}$ bonds. This phenomenon is also explained by the

4 increased enthalpy of sulphur vacancy formation in Fig. 5c. Additionally, the calculated

5 formation energy differential for reconstruction (Supplementary Table 8) again confirms the

6 superiorities of Fe substitution towards phase reconfiguration.

Universality of catalyst evolution. Besides $\mathrm{NiS}_{2}$, the above demonstrated phase evolution to $\mathrm{Ni}_{3} \mathrm{~S}_{2}$ has been extended to $\alpha$-NiS, $\beta$-NiS and $\mathrm{Ni}_{3} \mathrm{~S}_{4}$ HER catalysts. Their crystal structure and local chemical state characterization results are illustrated in Supplementary Fig. 17 and Supplementary Tables 2, 4. According to the in-situ Raman data from Fig. 6a and Supplementary Table 9, their reconstruction potential thresholds locate in varied regions of $0.1 \sim 0.05 \mathrm{~V}, 0.15 \sim 0.1 \mathrm{~V}$ and $0.1 \sim 0.05 \mathrm{~V}$ (vs. RHE), respectively, illustrating different energy barriers to overcome during reconstruction. And this is consistent with corresponding reduction peaks in the cycles for restructuring process at surface (Fig. 6b). Comparatively, the reduction peak in the first cycle appears at $\sim 0.03 \mathrm{~V}$ (vs. RHE) for $\beta$-NiS, while negative shifts are observed for $\alpha-\mathrm{NiS}$ and $\mathrm{Ni}_{3} \mathrm{~S}_{4}$. Considering about $50 \mathrm{mV}$ lower restructuring potential for $\beta-\mathrm{NiS}$, it could 
1 be speculated that its lower $\mathrm{CN}$ of $\mathrm{Ni}-\mathrm{S}_{5}$ motif is responsible for easier transition to the $\mathrm{Ni}-\mathrm{S}_{4}$

2 motif of $\mathrm{Ni}_{3} \mathrm{~S}_{2}{ }^{6}$. The overpotential (@ $\left.10 \mathrm{~mA} \mathrm{~cm}{ }^{-2}, \eta_{10}\right)$ of $\beta$-NiS is about $70 \mathrm{mV}$ and $20 \mathrm{mV}$

3 lower compared with $\alpha-\mathrm{NiS}$ and $\mathrm{Ni}_{3} \mathrm{~S}_{4}$, respectively. Such correlation between the

4

6

7

8

reconstruction potential threshold differential and HER performance variation signalizes the dominance of phase evolution during HER catalytic reaction.
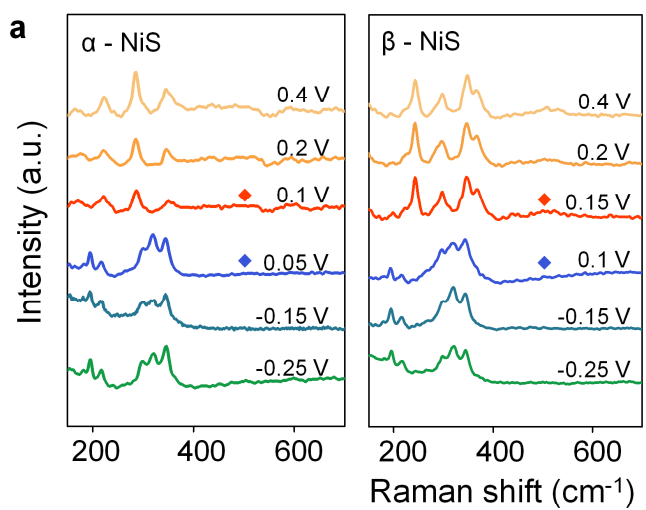

b

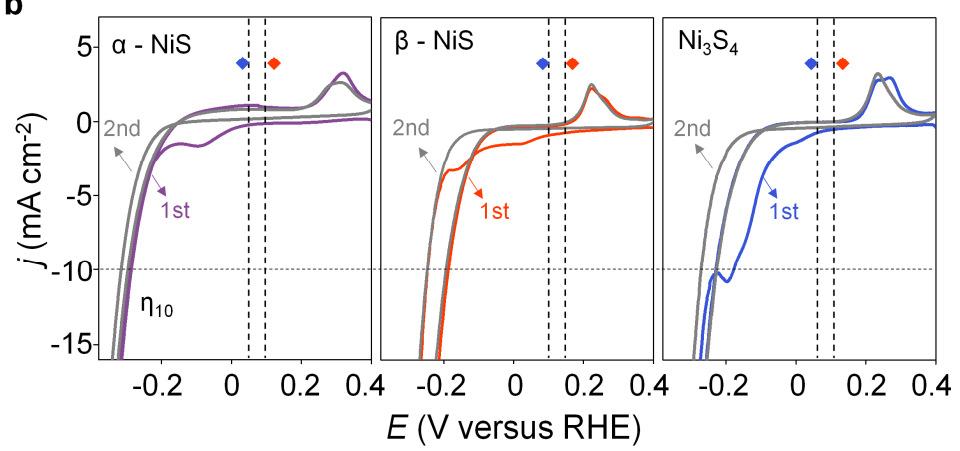

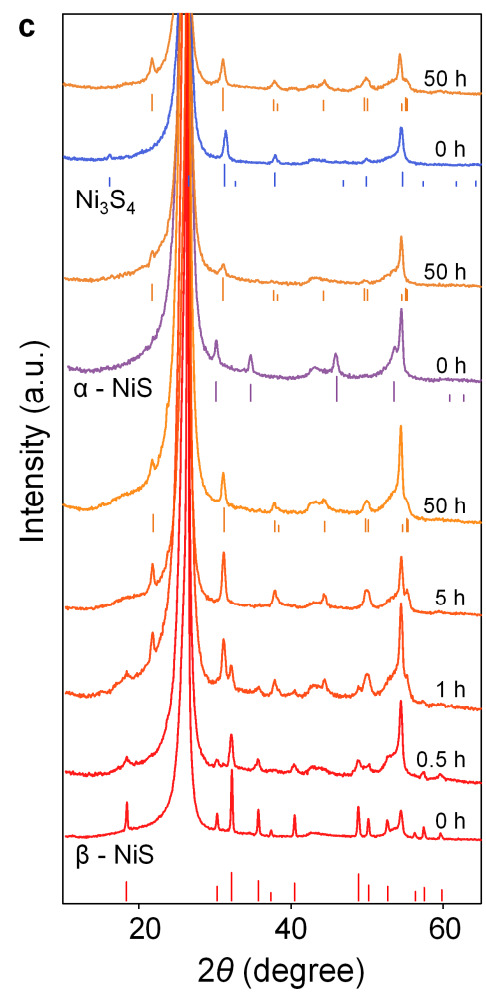

Fig. 6 | Dynamic structural evolution characterization of $\alpha$-NiS, $\beta$-NiS and $\mathrm{Ni}_{3} \mathrm{~S}_{4}$ catalysts. a, In-situ Raman spectra of nickel sulfides at the potentials of $0.4 \sim-0.25 \mathrm{~V}$ (vs. RHE) in $1 \mathrm{M} \mathrm{KOH}$ for $\alpha-\mathrm{NiS}, \beta-\mathrm{NiS}$ and $\mathrm{Ni}_{3} \mathrm{~S}_{4}$. b, Cyclic voltammetry curves of $\alpha$-NiS, $\beta$-NiS and $\mathrm{Ni}_{3} \mathrm{~S}_{4}$ in $\mathrm{N}_{2}$-saturated $1 \mathrm{M} \mathrm{KOH}$ with a scan rate of $2 \mathrm{mV} \mathrm{s}^{-1}$ between 0.4 and $-0.4 \mathrm{~V}$ (vs. RHE). The red diamond dots represent the final potential of existence for $\alpha-\mathrm{NiS}, \beta-\mathrm{NiS}$ and $\mathrm{Ni}_{3} \mathrm{~S}_{4}$ Raman peaks, and the blue diamond dots stand for the potential of emerging of $\mathrm{Ni}_{3} \mathrm{~S}_{2}$ Raman peaks. $\mathbf{c}$, XRD patterns of catalysts after the operation of HER instantly at constant current density of $10 \mathrm{~mA} \mathrm{~cm}^{-2}$.

For XRD patterns during the long-term service in Fig. $6 \mathrm{c}$, the intensity of $\mathrm{Ni}_{3} \mathrm{~S}_{2}$ peaks rise slightly along with the gradual disappearance of $\beta$-NiS peaks for the first hour. And the bulk phase transformation was realized basically after $5 \mathrm{~h}$ electrolysis. Similar for $\alpha-\mathrm{NiS}$ and $\mathrm{Ni}_{3} \mathrm{~S}_{4}$, the terminated bulk phases are both confirmed as $\mathrm{Ni}_{3} \mathrm{~S}_{2}$. In short, nickel sulfides including $\mathrm{NiS}_{2}$, 
$\alpha$-NiS, $\beta$-NiS and $\mathrm{Ni}_{3} \mathrm{~S}_{4}$ are all demonstrated to perform phase evolution process with unified and terminated $\mathrm{Ni}_{3} \mathrm{~S}_{2}$ structure. These results indicate the electrochemical universality of structural evolution for nickel sulfide catalysts, and figure a lower valence state evolution tendency of nickel in the catalytically terminated phase of HER, which implicates a general phenomenon during the restructuring of multivalent transition metal based catalysts.

(1)

\section{Conclusions}

In summary, the spontaneous phase evolution phenomena as well as the dynamic structureactivity correlations for the whole service life of a class of multivalent nickel sulfides during their HER service have been investigated from multiple dimensions including variations of phase, valence state and coordination environment via operando electrochemical spectroscopy techniques. The diffused and accumulated sulphur vacancies on nickel sulfide catalyst lead to surface reconstruction and phase transition with terminated $\mathrm{Ni}_{3} \mathrm{~S}_{2}$ structure responsible for subsequent catalysis. Such quantitative to qualitative alternation is prompted with Fe doping which enables the structural flexibility to accommodate more sulphur vacancies for the phase reconfiguration, and hence improves HER performance at an optimal dopant amount of $20 \%$. Based on this, we also established the dynamic mechanism of doping strategy, which is widely adopted for promoting catalytic activity but has only been understood in the static level. Beyond propagation from surface into bulk after prolonged service, the phase evolution has also been universally confirmed from $\mathrm{NiS}_{2}$ to $\alpha-\mathrm{NiS}, \beta-\mathrm{NiS}$ and $\mathrm{Ni}_{3} \mathrm{~S}_{4}$. The findings indicate a general law of lower valence state evolution tendency along with the phase evolution of multivalent transition metal catalyst under HER condition, evidence a fundamental idea that the dynamic 
evolution of catalysts dominates the finalized catalytic activity, and provide an alternative strategy of phase reconfiguration for developing superior catalysts.

\section{Methods}

Material synthesis. $\mathrm{Ni}_{1-x} \mathrm{Fe}_{x} \mathrm{~S}_{2}(x=0,0.1,0.2,0.25,0.33)$ powders were prepared by a typical procedure. In a first step, nickel (II) nitrate hexahydrate $\left(\mathrm{Ni}\left(\mathrm{NO}_{3}\right)_{2} \cdot 6 \mathrm{H}_{2} \mathrm{O}\right.$, Sigma-Aldrich, 98.5\%) and iron(II) sulfate heptahydrate $\left(\mathrm{FeSO}_{4} \cdot 7 \mathrm{H}_{2} \mathrm{O}\right.$, Sinopharm Chemical Reagent Co., Ltd, $99 \%$ ) in specific molar ratio were dissolved in deionized water, followed by the addition of urea (Aladdin, 99\%) and ammonium fluoride (Aladdin, 98\%). After stirred for $30 \mathrm{~min}$, the suspension was transferred to a $50 \mathrm{~mL}$ Teflon-lined stainless-steel autoclave and heated at $120{ }^{\circ} \mathrm{C}$ for $10 \mathrm{~h}$ before cooling to room temperature. The resultant precipitate was centrifuged and washed by deionized water and ethanol and dried at $60{ }^{\circ} \mathrm{C}$ for $1 \mathrm{~h}$. The as prepared $\mathrm{NiFeO}_{x} \mathrm{H}_{y}$ LDH was sufficiently mixed with sulphur powder (Alfa Aesar, 100 mesh, 99.5\%, 1:5) by grinding for $30 \mathrm{~min}$. The mixture was then placed in the center of a quartz tube in an aluminum oxide boat, and heated at $400{ }^{\circ} \mathrm{C}$ for $1 \mathrm{~h}$ in an argon atmosphere to obtain pyrite $\mathrm{Ni}_{1-x} \mathrm{Fe}_{x} \mathrm{~S}_{2}$. Finally, the obtained compounds were ultrasonicated, washed several times and dried under vacuum overnight. For the $\mathrm{Ni}_{3} \mathrm{~S}_{4}$ and $\beta$-NiS, the hydrothermal method was used in the solution of carbon disulfide $\left(\mathrm{CS}_{2}\right.$, Aladdin, $\left.99 \%\right)$ and sodium sulfide nonahydrate $\left(\mathrm{Na}_{2} \mathrm{~S} \cdot 9 \mathrm{H}_{2} \mathrm{O}\right.$, Aladdin, $98 \%$ ) in a $50 \mathrm{~mL}$ Teflon-lined stainless-steel autoclave at $200{ }^{\circ} \mathrm{C}$ for $10 \mathrm{~h}$ with $\mathrm{NiCl}_{2} \cdot 6 \mathrm{H}_{2} \mathrm{O}$ and $\mathrm{Ni}(\mathrm{OH})_{2} \mathrm{LDH}$, respectively. $\alpha-\mathrm{NiS}$ was obtained using thiourea $\left(\left(\mathrm{NH}_{2}\right)_{2} \mathrm{CS}\right.$, Alfa Aesar, $\left.98.5 \%\right)$ and $\mathrm{NiCl}_{2} \cdot 6 \mathrm{H}_{2} \mathrm{O}$ (Aladdin, 98\%) in a $50 \mathrm{~mL}$ Teflon-lined stainless-steel autoclave filled with hydrazine hydrate $\left(\mathrm{N}_{2} \mathrm{H}_{4} \cdot \mathrm{H}_{2} \mathrm{O}, 50\right.$ wt.\% content, J\&K$)$ at $120{ }^{\circ} \mathrm{C}$ for $24 \mathrm{~h}$. The nickel sulfides 
on carbon fiber paper (CFP, TORAY, thickness of $0.18 \mathrm{~mm}$ ) were also prepared through the above method just adding CFP in the solution.

Characterizations. The XRD patterns of bulk nickel sulfides were recorded on a Rigaku TTR3 diffractometer at a scanning rate of $2^{\circ} \mathrm{min}^{-1}$, using $\mathrm{Cu}-\mathrm{K} \alpha$ radiation $(\lambda=1.5418 \AA)$. XPS data were obtained using an ESCALab250 electron spectrometer from Thermo Fisher Scientific Corporation with monochromatic $150 \mathrm{~W}$ AlK $\alpha$ radiation. Pass energy for the narrow scan is 30 $\mathrm{eV}$. The base pressure was about $6.5 \times 10^{-10}$ mbar. The binding energies were referenced to the C1s line at $284.8 \mathrm{eV}$ from alkyl or adventurous carbon.

The nickel sulfide morphologies were characterized by SEM (FEI Quanta 3D) at an accelerating voltage of $5 \mathrm{kV}$. The crystal structures and detailed information about the morphologies and element compositions were obtained using TEM (JEM-120F) and the energy dispersive X-ray spectroscopy (EDS) (JEOL JED-2300 Analysis Station) with an accelerating voltage of $200 \mathrm{kV}$. The nickel sulfide catalysts samples were drop cast onto Cu TEM grids and then attached to the Au electrode with conductive carbon tape polarized in $\mathrm{N}_{2}$ saturated $0.01 \mathrm{M}$ NaPi electrolyte, $\mathrm{pH}$ 7.2. The treated samples were rinsed with reagent grade water, dried in a stream of $\mathrm{N}_{2}$. The EDS scans were collected at various positions in the sample extending from the surface layer to the interior of the samples.

Electrochemical measurements. All electrochemical measurements were carried out in a typical three-electrode system with an electrochemical workstation (CHI 660E, Shanghai Chenhua, China) at room temperature, and using a platinum plate as the counter electrode and 
1 saturated $\mathrm{Ag} / \mathrm{AgCl}$ as the reference electrode. The prepared Ni-based sulfide/CFP $\left(0.5 \mathrm{~cm}^{2}\right)$

2 used as the working electrode. For HER, cathodic linear sweep voltammetry with a $5 \mathrm{mV} \mathrm{s}^{-1}$

3 scan rate was performed in $\mathrm{N}_{2}$-saturated 1.0 M KOH (pH 13.6, Aladdin, 95\%). Electrochemical

4 impedance spectroscopy measurements were carried out by applying an a.c. voltage with 10

$5 \mathrm{mV}$ amplitude in a frequency range from $100 \mathrm{kHz}$ to $10 \mathrm{mHz}$ at an overpotential of $200 \mathrm{mV}$.

$6 \quad$ All potentials were calibrated versus RHE using

$7 \quad E(\mathrm{RHE})=E(\mathrm{Ag} / \mathrm{AgCl})+0.197 \mathrm{~V}+0.0592 \times \mathrm{pH}$

8 For all polarization curves presented in the paper, the $i R$ values were manually corrected with

9 the series resistance $\left(R_{\mathrm{s}}\right)$ on the basis of the equation:

$E(\mathrm{RHE})=E(\mathrm{Ag} / \mathrm{AgCl})+0.197 \mathrm{~V}+0.0592 \times \mathrm{pH}-i R_{\mathrm{S}}$

The compensated ohmic $R_{\mathrm{s}}$ values were obtained from the fittings of electrochemical impedance spectra.

In-situ Raman spectroscopy. Raman spectroscopy was carried out with a Horiba Jobin-Yvon

Labram HR 800 Micro-Raman instrument and Labspec software. All Raman spectra were acquired with $532 \mathrm{~nm}$ excitation from a $250 \mathrm{~mW}$ diode laser. The incident laser power was decreased by a factor of 100 to avoid sample damage. A $50 \times$ magnification long working distance $(8 \mathrm{~mm})$ objective was used. Raman frequencies were calibrated using Si wafer (520.7 $\mathrm{cm}^{-1}$ ). The measurements of in-situ Raman spectra were carried out in a home-built cell (Supplementary Fig. 18) filled with $1 \mathrm{M} \mathrm{KOH}$ electrolyte, with $\mathrm{Ag} / \mathrm{AgCl}$ and platinum foil as reference and counter electrodes, respectively. Acquisition of spectra at steady-state conditions was performed after holding the catalyst at the desired potential for $5 \mathrm{~min}$. To prepare the 
working electrode, $4 \mathrm{mg}$ electrocatalyst and $20 \mu \mathrm{l}$ Nafion solution (5 wt \%, Sigma-Aldrich) were ultrasonically dispersed in $1 \mathrm{ml}$ water/ethanol ( $\mathrm{vol} / \mathrm{vol}=3: 1)$ solution to form a homogeneous ink. The electrocatalyst suspension $(10 \mu \mathrm{l})$ was loaded onto glass carbon $(3 \mathrm{~mm})$ as the working electrode.

(1)

Operando X-ray absorption measurements. The Ni K-edge (8333 eV) XAFS spectra were measured at the 1W2B beamline of Beijing Synchrotron Radiation Facility (BSRF), China. The storage ring of BSRF was operated at $2.5 \mathrm{GeV}$ with a maximum electron current of $250 \mathrm{~mA}$. Operando XAFS measurements were performed with catalyst-coated carbon paper using a home-built cell (Supplementary Fig. 19). The catalyst was spray onto carbon paper taped with Kapton film on the back as the working electrode $(\sim 1 \mathrm{~cm} \times 1 \mathrm{~cm})$ to ensure all of the electrocatalyst reacted with $\mathrm{KOH}$ electrolyte at a geometric metal loading of $\sim 1 \mathrm{mg} \mathrm{cm}^{-2}$. The operando XAFS spectra were collected through the fluorescence mode to monitor the changes during the HER process, cathodic voltages at $0.40,0.20$ and $-0.15 \mathrm{~V}$ (vs. RHE) were applied for $5 \mathrm{~min}$ in $1 \mathrm{M} \mathrm{KOH}$ as the conditioning step.

During XAFS measurements, we calibrated the position of the absorption edge $\left(\mathrm{E}_{0}\right)$ using Ni foil, and all the XAFS data were collected during one period of beam time. The standard samples of $\mathrm{Ni}$ foil, $\mathrm{Ni}_{3} \mathrm{~S}_{2}$ (Alfa Aesar, 99.9\%) and $\mathrm{Ni}_{2} \mathrm{O}_{3}$ (Macklin, 99.5\%) were measured in the transmission mode. The position of $\mathrm{E}_{0}$ is defined as the point corresponding to the maximum value in the derivative curves of the XANES spectra. The obtained XAFS data was processed in Athena (version 0.9.25) for background, pre-edge line and post-edge line calibrations. Then Fourier transformed fitting was carried out in Artemis (version 0.9.25) (7) $^{4}$ The $k^{3}$ weighting, $k$ - 
1 range of $3 \sim 11 \AA^{-1}$ and $R$ range of $1 \sim 3 \AA$ were used for the fitting. The model of bulk Ni, NiS 2 ,

$2 \mathrm{NiS}$ and $\mathrm{Ni}_{3} \mathrm{~S}_{2}$ were used to calculate the simulated scattering paths. The four parameters, coordination number, bond length, Debye-Waller factor and $\mathrm{E}_{0}$ shift $\left(\mathrm{CN}, R, \sigma^{2}, \Delta E_{0}\right)$ were fitted without anyone was fixed, constrained, or correlated.

DFT calculations. The ab initio simulations mentioned in this work that related to density functional theory (DFT) was conducted using the Vienna ab initio simulation package (VASP) ${ }^{48}$. Projector augmented wave (PAW) potentials was chosen to treat ion-electron interactions, and the exchange-correlation contributions were approximated by the generalized gradient approximation (GGA) method, the Perdew-Burke-Ernzerhof(PBE) functional ${ }^{49}$. In the process of optimizing lattice structure of $\mathrm{NiS}_{2}$, conjugate gradient algorithm with a force tolerance of $0.01 \mathrm{eV} / \AA$ and a kinetic energy cutoff $500 \mathrm{eV}$ was as convergence criteria. The Gamma k-point sampling was set to be $9 \times 9 \times 9$ for materials. The optimized $\mathrm{NiS}_{2}$ crystalline cell was built into supercell along (111) direction and Fe doped $\mathrm{NiS}_{2}$ models were achieved by replacing $\mathrm{Ni}$ atoms with $\mathrm{Fe}$ atoms randomly in $\mathrm{NiS}_{2}$ supercell model. For these supercells, the k-point mesh was set as $5 \times 5 \times 1$, and all the other simulation parameters remain unchanged in the selfconsistent calculations. The vacancy formation energy was calculated by the equation of $E_{\text {vacancy_formation }}=E_{\mathrm{S}_{-} \text {defect }}-\left(E_{\text {perfect }}-E_{\mathrm{S}_{-} \text {element }}\right), E_{\text {perfect }}$ is the total energy of perfect $\mathrm{NiS}_{2}, E_{\mathrm{S} \_ \text {defect }}$ is the total energy of $\mathrm{NiS}_{2}$ with sulphur vacancy, $E_{\mathrm{S} \_ \text {element }}$ is the averaged total energy for each sulphur atom in its most stale elemental form (i.e. Rhombic sulphur).

\section{Data Availability}


1 The data supporting the findings of this study are available within this article and its

2 Supplementary Information, or from the corresponding author upon reasonable request.

3

$4 \quad$ References

1. Turner, J. A. A realizable renewable energy future. Science 285, 687-689 (1999).

2. Gasteiger, H. A. \& Marković, N. M. Just a dream-or future reality? Science 324, 48-49

7 (2009).

3. Seh, Z. W. et al. Combining theory and experiment in electrocatalysis: Insights into materials design. Science 355, eaad4998 (2017).

4. Chu, S., Cui, Y. \& Liu, N. The path towards sustainable energy. Nat. Mater. 16, 16-22 (2017).

5. Hansen, T. W. et al. Atomic-resolution in situ transmission electron microscopy of a promoter of a heterogeneous catalyst. Science 294, 1508-1510 (2001).

6. Yan, B. et al. Surface restructuring of nickel sulfide generates optimally coordinated active sites for oxygen reduction catalysis. Joul 1, 600-612 (2017).

7. Tian, X. et al. Engineering bunched Pt-Ni alloy nanocages for efficient oxygen reduction in practical fuel cells. Science 366, 850-856 (2019).

8. Nong, H. N. et al. A unique oxygen ligand environment facilitates water oxidation in holedoped IrNiOx core-shell electrocatalysts. Nat. Catal. 1, 841-851 (2018).

9. Shi, Y., Yu, Y., Liang, Y., Du, Y. \& Zhang, B. In situ electrochemical conversion of ultrathin Tannin-NiFe complex film as an efficient oxygen-evolving electrocatalyst. Angew. Chem. Int. Ed. 58, 3769-3773 (2019). 
10. Cao, L. et al. Identification of single-atom active sites in carbon-based cobalt catalysts during electrocatalytic hydrogen evolution. Nat. Catal. 2, 134-141 (2019).

11. Li, S. et al. Operando revealing dynamic reconstruction of NiCo carbonate hydroxide for high-rate energy storage. Joule 4, 1-15 (2020).

12. Sun, D. et al. Ordered intermetallic $\mathrm{Pd}_{3} \mathrm{Bi}$ prepared by an electrochemically induced phase transformation for oxygen reduction electrocatalysis. ACS Nano 13, 10818-10825 (2019).

13. Wang, D. et al. Spontaneous incorporation of gold in palladium-based ternary nanoparticles makes durable electrocatalysts for oxygen reduction reaction. Nat. Commun. 7, 11941 (2016).

14. Klaus, S., Cai, Y., Louie, M. W., Trotochaud, L. \& Bell, A. T. Effects of Fe electrolyte impurities on $\mathrm{Ni}(\mathrm{OH})_{2} / \mathrm{NiOOH}$ structure and oxygen evolution activity. J. Phys. Chem. C 119, 7243-7254 (2015).

15. Lee, S., Bai, L. \& Hu, X. Deciphering iron-dependent activity in oxygen evolution catalyzed by nickel iron layered double hydroxide. Angew. Chem. Int. Ed. 59, 8072-8077 (2020).

16. Jiang, J. et al. Atomic-level insight into super-efficient electrocatalytic oxygen evolution on iron and vanadium co-doped nickel (oxy)hydroxide. Nat. Commun. 9, 2885 (2018).

17. Bergmann, A. et al. Unified structural motifs of the catalytically active state of Co(oxyhydr)oxides during the electrochemical oxygen evolution reaction. Nat. Catal. 1, 711-719 (2018).

18. Dionigi, F. et al. In-situ structure and catalytic mechanism of NiFe and CoFe layered double hydroxides during oxygen evolution. Nat. Commun. 11, 2522 (2020).

19. Peña, N. O. et al. Morphological and structural evolution of $\mathrm{Co}_{3} \mathrm{O}_{4}$ nanoparticles revealed 
by in situ electrochemical transmission electron microscopy during electrocatalytic water oxidation. ACS Nano 13, 11372-11381 (2019).

20. Hwang, J. et al. Perovskites in catalysis and electrocatalysis. Science 358, 751-756 (2017).

21. Fabbri, E. et al. Dynamic surface self-reconstruction is the key of highly active perovskite nano-electrocatalysts for water splitting. Nat. Mater. 16, 925-931 (2017).

22. $\mathrm{Wu}, \mathrm{T}$. et al. Iron-facilitated dynamic active-site generation on spinel $\mathrm{CoAl}_{2} \mathrm{O}_{4}$ with selftermination of surface reconstruction for water oxidation. Nat. Catal. 2, 763-772 (2019).

23. Zhang, B. et al. Homogeneously dispersed multimetal oxygen-evolving catalysts. Science 352, 333 (2016).

24. Huang, Z.-F. et al. Chemical and structural origin of lattice oxygen oxidation in Co- $\mathrm{Zn}$ oxyhydroxide oxygen evolution electrocatalysts. Nat. Energy 4, 329-338 (2019).

25. Kornienko, N. et al. Operando spectroscopic analysis of an amorphous cobalt sulfide hydrogen evolution electrocatalyst. J. Am. Chem. Soc. 137, 7448-7455 (2015).

26. Hu, C. et al. In situ electrochemical production of ultrathin nickel nanosheets for hydrogen evolution electrocatalysis. Chem 3, 122-133 (2017).

27. Zhu, Y. et al. Operando Unraveling of the structural and chemical stability of P-substituted $\mathrm{CoSe}_{2}$ electrocatalysts toward hydrogen and oxygen evolution reactions in alkaline electrolyte. ACS Energy Lett. 4, 987-994 (2019).

28. Zhai, L. et al. In Situ phase transformation on nickel-based selenides for enhanced hydrogen evolution reaction in alkaline medium. ACS Energy Lett. 5, 2483-2491 (2020).

29. Zhang, Y., Gao, L., Hensen, E. J. M. \& Hofmann, J. P. Evaluating the stability of $\mathrm{Co}_{2} \mathrm{P}$ electrocatalysts in the hydrogen evolution reaction for both acidic and alkaline electrolytes. 
ACS Energy Lett. 3, 1360-1365 (2018).

30. Gamsjäger, H., Bugajski, J., Gajda, T., Lemire, R. J. \& Preis, W. Chemical Thermodynamics of Nickel (Elsevier Press, 2004).

31. Vaughan, D. J. \& Craig, J. R. Mineral Chemistry of Metal Sulfides (Cambridge Univ. Press, 1978).

32. Gu, W., Wang, H. \& Wang, K. Extended X-ray absorption fine structure and multiplescattering simulation of nickel dithiolene complexes $\mathrm{Ni}\left[\mathrm{S}_{2} \mathrm{C}_{2}\left(\mathrm{CF}_{3}\right)_{2}\right]_{2}{ }^{\mathrm{n}}(\mathrm{n}=-2,-1,0)$ and an olefin adduct $\mathrm{Ni}\left[\mathrm{S}_{2} \mathrm{C}_{2}\left(\mathrm{CF}_{3}\right)_{2}\right]_{2}$ (1-hexene). J. Synchrotron Rad. 22, 124-129 (2015).

33. Arčon, I., Mirtič, B. \& Kodre, A. Determination of valence states of chromium in calcium chromates by using X-ray absorption near-edge structure (XANES) spectroscopy. J. Am. Ceram. Soc. 81, 222-224 (1998).

34. Dau, H., Liebisch, P. \& Haumann, M. X-ray absorption spectroscopy to analyze nuclear geometry and electronic structure of biological metal centers-potential and questions examined with special focus on the tetra-nuclear manganese complex of oxygenic photosynthesis. Anal. Bioanal. Chem. 376, 562-583 (2003).

35. Handoko, A. D., Wei, F., Jenndy, Yeo, B. S. \& Seh, Z. W. Understanding heterogeneous electrocatalytic carbon dioxide reduction through operando techniques. Nat. Catal. 1, 922934 (2018).

36. Deng, Y. et al. Operando Raman spectroscopy of amorphous molybdenum sulfide $\left(\mathrm{MoS}_{x}\right)$ during the electrochemical hydrogen evolution reaction: Identification of sulphur atoms as catalytically active sites for $\mathrm{H}^{+}$reduction. ACS Catal. 6, 7790-7798 (2016).

37. Chen, D.-J. \& Tong, Y. Y. J. In situ Raman spectroscopic measurement of near-surface 
proton concentration changes during electrochemical reactions. Chem. Commun. 51, 5683$5686(2015)$.

38. de las Heras, C. \& Agulló-Rueda, F. Raman spectroscopy of $\mathrm{NiSe}_{2}$ and $\mathrm{NiS}_{2-x} \mathrm{Se}_{x}(0<x<2)$ thin films. J. Phys. Condens. Matter. 12, 5317-5324 (2000).

39. Fateley, W. G., McDevitt, N. T., \& Bentley, F. F. Infrared and Raman selection rules for lattice vibrations: The correlation method. Appl. Spectrosc. 25, 155-173 (1971).

40. Cheng, Z., Abernathy, H. \& Liu, M. Raman spectroscopy of nickel sulfide $\mathrm{Ni}_{3} \mathrm{~S}_{2}$. J. Phys. Chem. C 111, 17997-18000 (2007).

41. Li, H. et al. Activating and optimizing $\mathrm{MoS}_{2}$ basal planes for hydrogen evolution through the formation of strained sulphur vacancies. Nat. Mater. 15, 364 (2016).

42. Jiao, Y., Zheng, Y., Davey, K. \& Qiao, S.-Z. Activity origin and catalyst design principles for electrocatalytic hydrogen evolution on heteroatom-doped graphene. Nat. Energy 1, 16130 (2016).

43. Voiry, D., Shin, H. S., Loh, K. P. \& Chhowalla, M. Low-dimensional catalysts for hydrogen evolution and $\mathrm{CO}_{2}$ reduction. Nat. Rev. Chem. 2, 0105 (2018).

44. Vrubel. H., Moehl, T., Grätzel, M. \& Hu, X. Revealing and accelerating slow electron transport in amorphous molybdenum sulphide particles for hydrogen evolution reaction. Chem. Commun. 49, 8985-8987 (2013).

45. Wei, C. et al. Recommended practices and benchmark activity for hydrogen and oxygen electrocatalysis in water splitting and fuel cells. Adv. Mater. 31, 1806296 (2019). 
46. Deml, A. M., Stevanović, V., Muhich, C. L., Musgrave, C. B. \& O'Hayre, R. Oxide enthalpy of formation and band gap energy as accurate descriptors of oxygen vacancy formation energetics. Energy Environ. Sci. 7, 1996-2004 (2014).

47. Newville, M. IFEFFIT: interactive XAFS analysis and FEFF fitting. J. Synchrotron Radiat. 8, 322-324 (2001).

48. Kresse, G. \& Hafner, J. Ab initio molecular-dynamics simulation of the liquid-metalamorphous-semiconductor transition in germanium. Phys. Rev. B 49, 14251-14269 (1994).

49. Perdew, J. P., Burke, K. \& Ernzerhof, M. Generalized gradient approximation made simple. Phys. Rev. Lett. 77, 3865-3868 (1996).

\section{Acknowledgments}

This work was supported by the National Key Research and Development Program of China (Nos. 2018YFA0703503 and 2016YFA0202701), Overseas Expertise Introduction Projects for Discipline Innovation (111 project, B14003), National Natural Science Foundation of China (Nos. 51991340, 51991342, 52072031, 51527802, 51702014, 51722203, 51672026), State Key Laboratory for Advanced Metals and Materials (Nos. 2018Z-03, 2019Z-04), Fundamental Research Funds for the Central Universities (Nos. FRF-AS-17-002, FRF-TP-19-005A2, and FRF-TP-20-008A3), and the Natural Science Foundation of Beijing Municipality (Grant No. Z180011). This work has also benefited from the use of the 1W2B beamlines at the Beijing Synchrotron Radiation Facility (BSRF) and we thank Lirong Zheng for assistance.

\section{Author contributions}


1 Z.K. and Y.Z. designed and proposed the research direction, initiated and supervised the

2 project. Y.S. performed the experiments. J.W. carried out the DFT simulations. Y.S. and Z.Z.

3 designed and analysed the in-situ Raman and XAFS measurements. X.W., B.L. and Y.X.

4 assisted with XAFS experiments and discussions about DFT simulations. J.W. and Z.K.

5 contributed to the analysis of electrochemical performance. Q.L., S.Z., Y.Q.Z. and K.M.

6 assisted in carrying out the XRD, SEM, XPS, TEM and EDS measurements. All the authors

7 discussed the results and participated in writing the manuscript.

8

9 Competing interests

10 The authors declare no competing interests. 


\section{Supplementary Information}

\section{Phase reconfiguration of multivalent nickel sulfides in hydrogen evolution}

Yu Sun ${ }^{1,2,3}$, Jing $\mathrm{Wu}^{1,2,3}$, Zheng Zhang ${ }^{1,2,3}$, Qingliang Liao ${ }^{1,2}$, Suicai Zhang ${ }^{1,2}$, Xin Wang ${ }^{1,2}$, Baishan Liu ${ }^{1,2}$, Yunqi Zhao ${ }^{1,2}$, Yong Xie ${ }^{1,2}$, Kaikai Ma ${ }^{1,2}$, Zhuo Kang ${ }^{* 1,2}$ and Yue Zhang ${ }^{* 1,2}$

${ }^{1}$ Beijing Advanced Innovation Center for Materials Genome Engineering, Beijing Key Laboratory for Advanced Energy Materials and Technologies, University of Science and Technology Beijing, Beijing 100083, China

${ }^{2}$ State Key Laboratory for Advanced Metals and Materials, School of Materials Science and Engineering, University of Science and Technology Beijing, Beijing 100083, China

${ }^{3}$ These authors contributed equally: Yu Sun, Jing Wu, Zheng Zhang.

*e-mail: zhuokang@ustb.edu.cn; yuezhang@ustb.edu.cn

\section{Table of Contents:}

1. Supplementary Fig. 1 to 19

2. Supplementary Tables 1 to 9 


\section{Supplementary Figures}
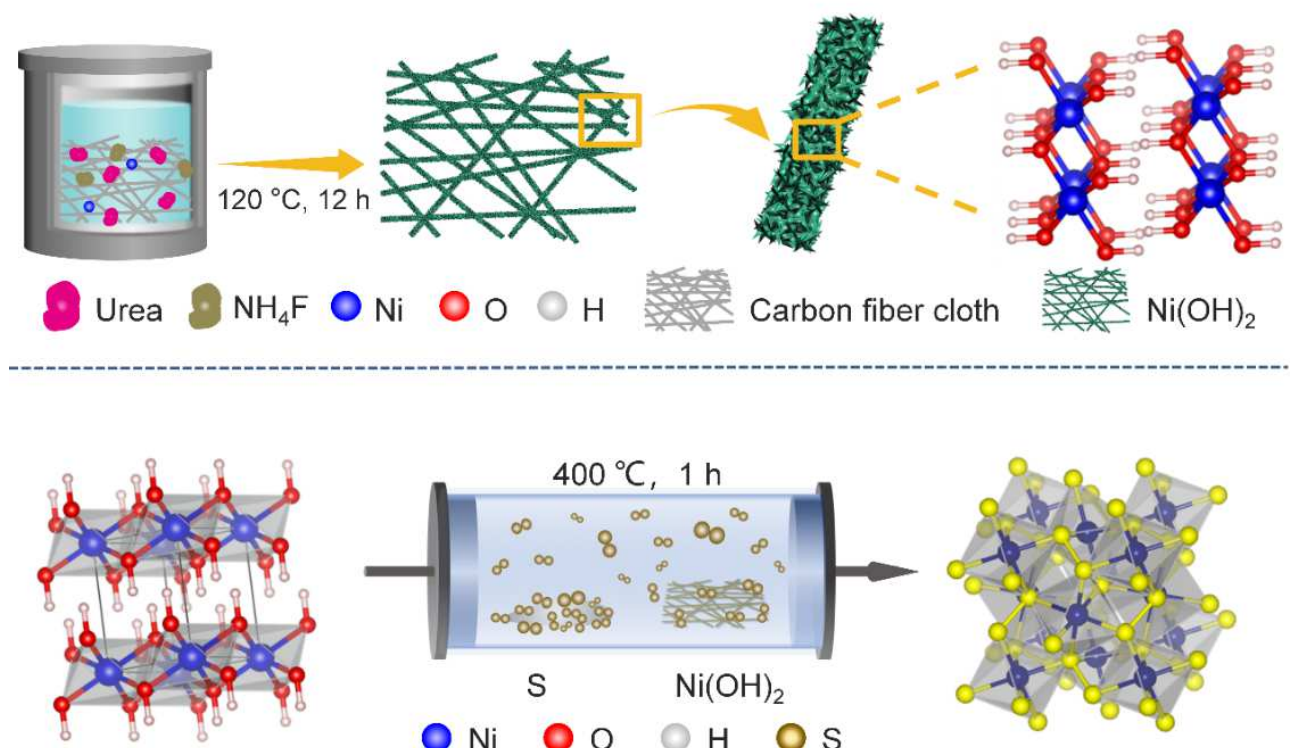

$\mathrm{Ni}(\mathrm{OH})_{2}$

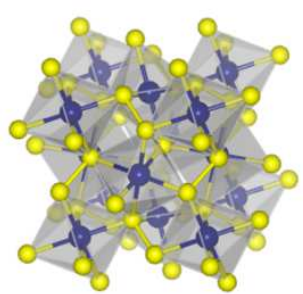

$\mathrm{NiS}_{2}$

Supplementary Fig. 1. Fabrication of $\mathrm{Ni}_{1-x} \mathrm{Fe}_{x} \mathrm{~S}_{2} / \mathrm{CFP} \mathrm{H}$-evolving electrodes. Schematic illustration of the fabrication procedure by directly growing $\mathrm{Ni}_{1-x} \mathrm{Fe}_{x} \mathrm{~S}_{2} \mathrm{NSs}$, and the sulfurization process at $400{ }^{\circ} \mathrm{C}$.

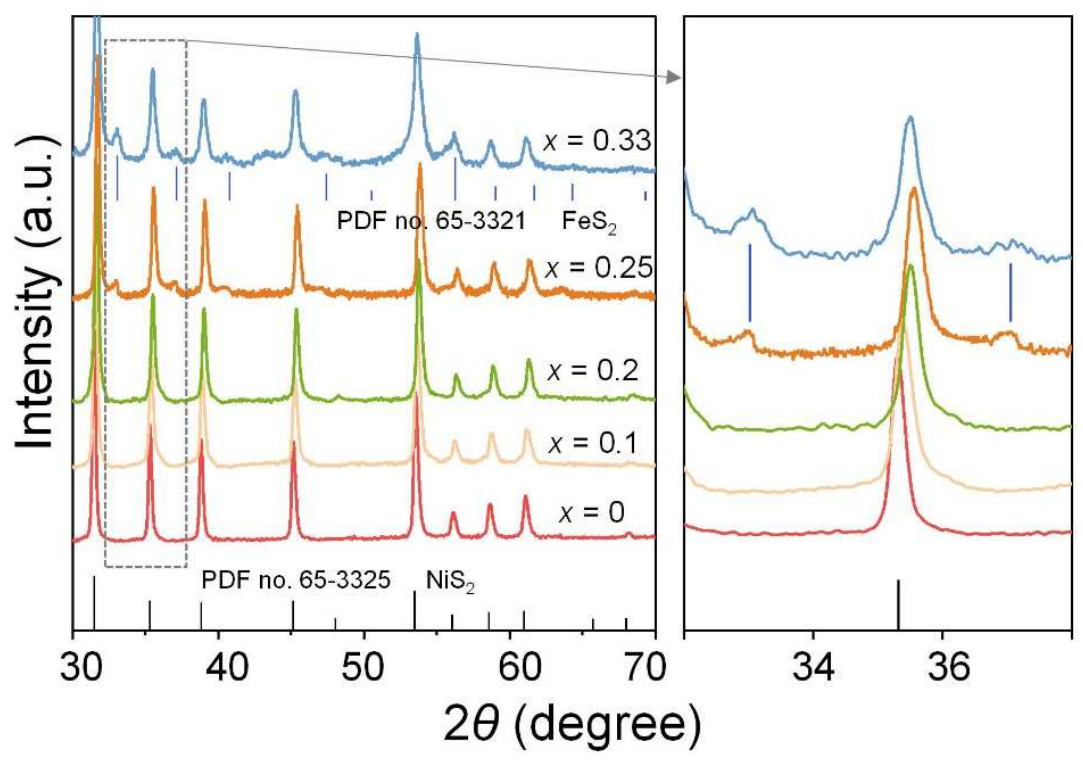

Supplementary Fig. 2. PXRD patterns of synthesized $\mathrm{Ni}_{1-x} \mathrm{Fe}_{x} \mathrm{~S}_{2}(x \approx 0-0.33)$. The right axis show the unit cell of cubic metal disulfides and the magnified PXRD patterns in the range between 32 and 38 . 
a

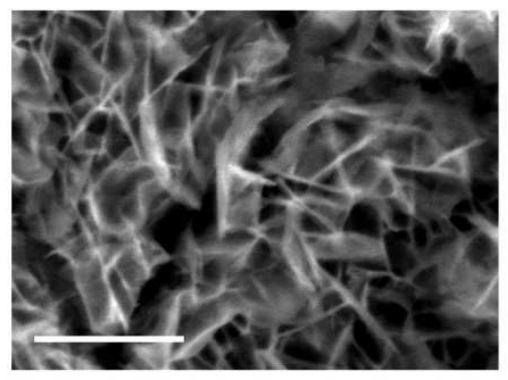

b

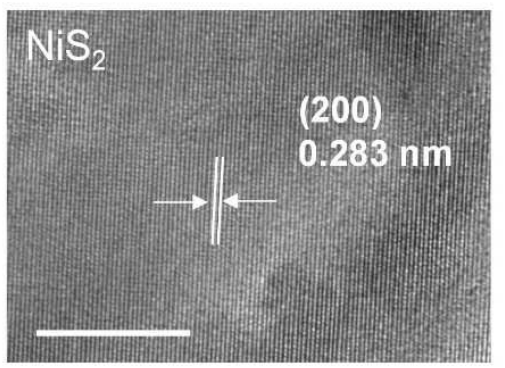

C

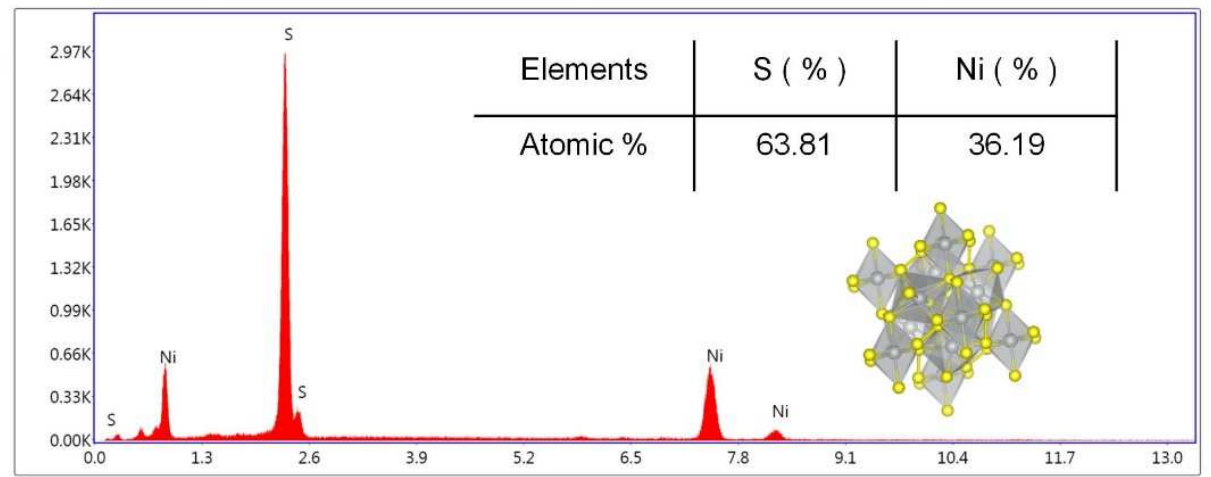

Lsec: 30.00 Cnts 0.000 keV Det: Octane Plus Det

\section{d}

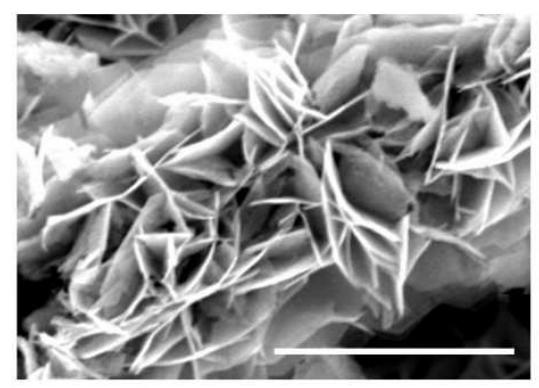

e

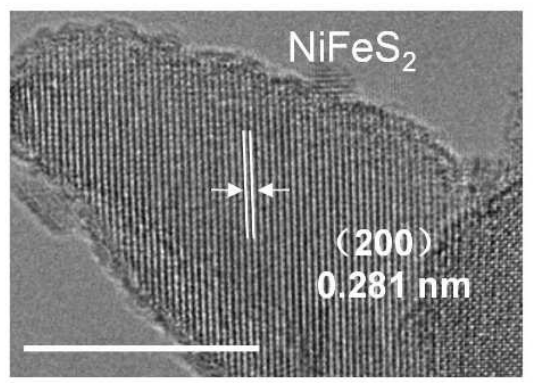

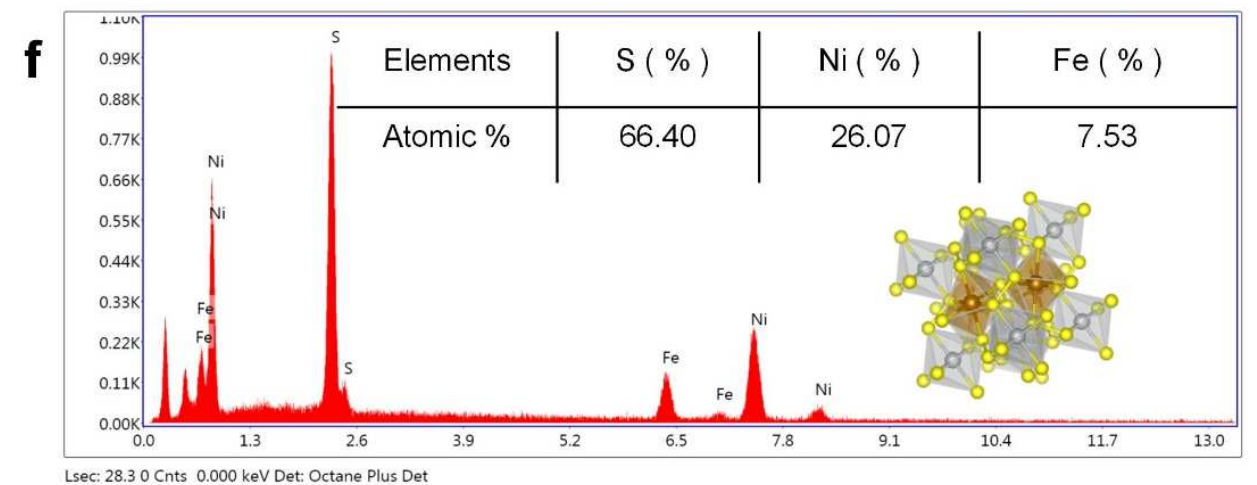

Supplementary Fig. 3. SEM-EDX elemental analysis and the TEM images of the as-prepared $\mathrm{Ni}_{1}$ ${ }_{x} \mathrm{Fe}_{x} \mathrm{~S}_{2}$ electrode. a, SEM images of the carbon fiber coated with $\mathrm{NiS}_{2}$. Scale bar, $1 \mu \mathrm{m}$. b, TEM images of $\mathrm{NiS}_{2} \mathrm{NSs}$. Scale bar, $5 \mathrm{~nm}$. c, The corresponding EDX elemental atomic ratio of Ni and S elements. d, Topview SEM images of the carbon fiber coated with $\mathrm{Ni}_{0.8} \mathrm{Fe}_{0.2} \mathrm{~S}_{2}$ NSs. Scale bar, $10 \mu \mathrm{m}$. e, TEM images of $\mathrm{Ni}_{0.8} \mathrm{Fe}_{0.2} \mathrm{~S}_{2} \mathrm{NSs}$. Scale bar, $10 \mathrm{~nm}$. f, The corresponding EDX elemental atomic ratio of Ni, Fe and S elements. Inset of $\mathrm{c}$ and $\mathrm{f}$ is the corresponding weight and atomic ratio of $\mathrm{Ni}, \mathrm{Fe}$ and $\mathrm{S}$ elements and the lattice structure of $\mathrm{Ni}_{1-x} \mathrm{Fe}_{x} \mathrm{~S}_{2}$. 

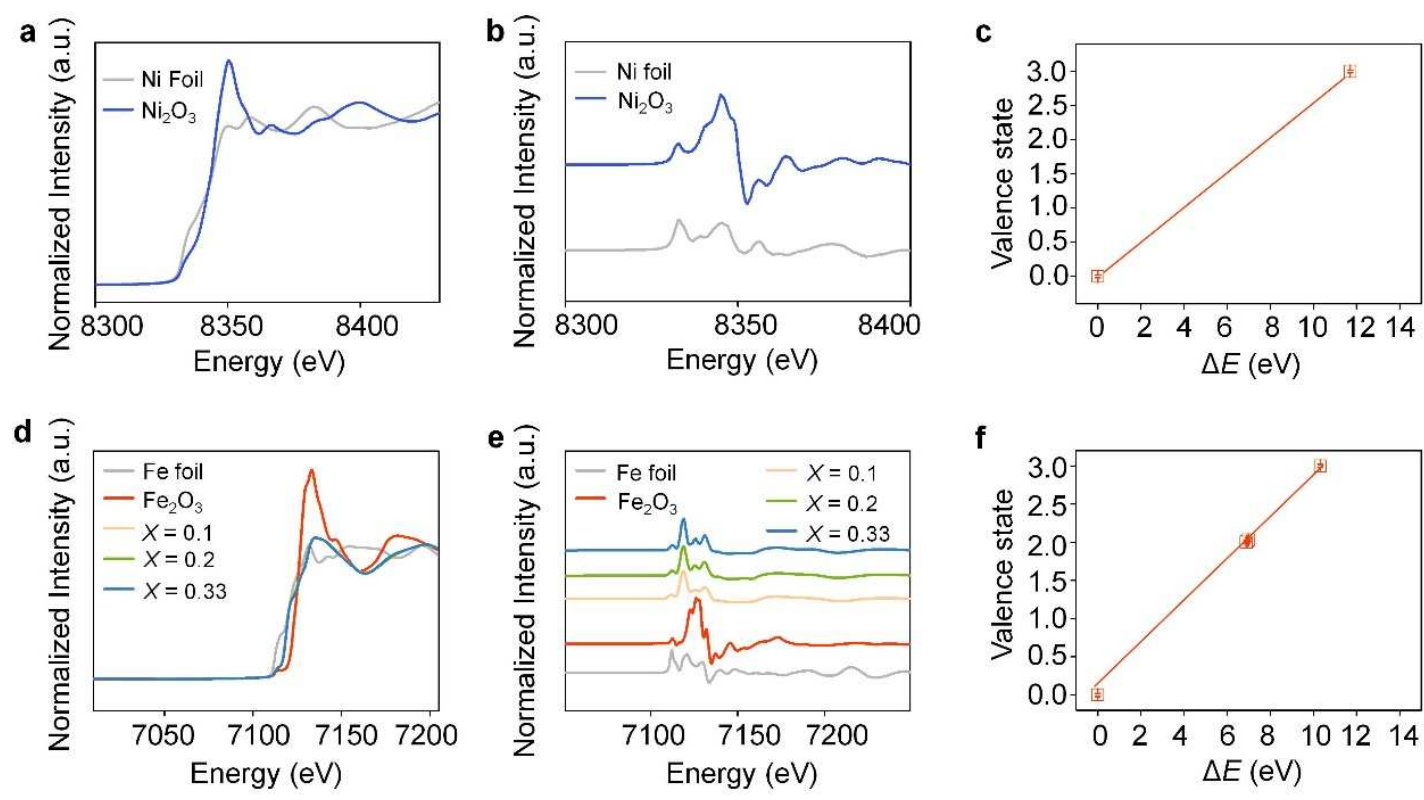

Supplementary Fig. 4. XAFS measurements. a, XANES spectra recorded at the Ni K-edge of nickel foil, $\mathrm{Ni}_{2} \mathrm{O}_{3}$. b, Normalized difference spectra for Ni K-edge XANES. c, The fitted average valence states of $\mathrm{Ni}$ from XANES spectra. Ni Foil is approximately close to $0, \mathrm{Ni}_{2} \mathrm{O}_{3}$ is approximately close to $3+$. d, XANES spectra recorded at the $\mathrm{Fe} \mathrm{K}$-edge of Iron foil, $\mathrm{Fe}_{2} \mathrm{O}_{3}$. e, Normalized difference spectra for Fe K-edge XANES. $\mathrm{f}$, The fitted average valence states of $\mathrm{Fe}$ from XANES spectra. Fe Foil is approximately close to $0, \mathrm{Fe}_{2} \mathrm{O}_{3}$ is approximately close to $3+$. Error bars represent the standard deviation from at least three independent measurements.

The Ni and Fe valence states of the samples were estimated by means of the absorption edge energy $E_{0}$, which is defined as the energy at the highest first derivative of the absorbance as shown in Supplementary Fig. 4 b, e. Correspondingly, the absorption edge energy $E_{0}$ of $\mathrm{Ni}$ foil with $\mathrm{Ni}^{0}$ valence state is determined as $8333 \mathrm{eV}$ as shown in Supplementary Fig. 4b. Similarly, the Ni K-edge EXAFS spectra show that the absorption edge energies $E_{0}$ of the $\mathrm{NiS}_{2}, \mathrm{Ni}_{0.9} \mathrm{Fe}_{0.1} \mathrm{~S}_{2}, \mathrm{Ni}_{0.8} \mathrm{Fe}_{0.2} \mathrm{~S}_{2}$, and $\mathrm{Ni}_{0.67} \mathrm{Fe}_{0.33} \mathrm{~S}_{2}$ and $\mathrm{Ni}_{2} \mathrm{O}_{3}$ were located at $8360.68,8340.35,8340.12$, and 8340.27 and $8344.61 \mathrm{eV}$, respectively. The Fe K-edge EXAFS spectra show that the absorption edge energies $E_{0}$ of the Fe Foil, $\mathrm{Ni}_{0.9} \mathrm{Fe}_{0.1} \mathrm{~S}_{2}, \mathrm{Ni}_{0.8} \mathrm{Fe}_{0.2} \mathrm{~S}_{2}$, and $\mathrm{Ni}_{0.67} \mathrm{Fe}_{0.33} \mathrm{~S}_{2}$ and $\mathrm{Fe}_{2} \mathrm{O}_{3}$ were located at 7112, 7118.92, 7118.98, 7118.89 and $7122.32 \mathrm{eV}$, respectively.

The obtained energy shifts $(\Delta E)$, as a function of the valence state, are shown in Supplement Fig. 4c, f, together with a model linear function, which have been determined as a best fit to the data from the reference samples. The nickel and iron valence states in the synthesized Fe substituted nickel sulfides are calculated from the linear function. These data are listed in Supplementary Table 1. 

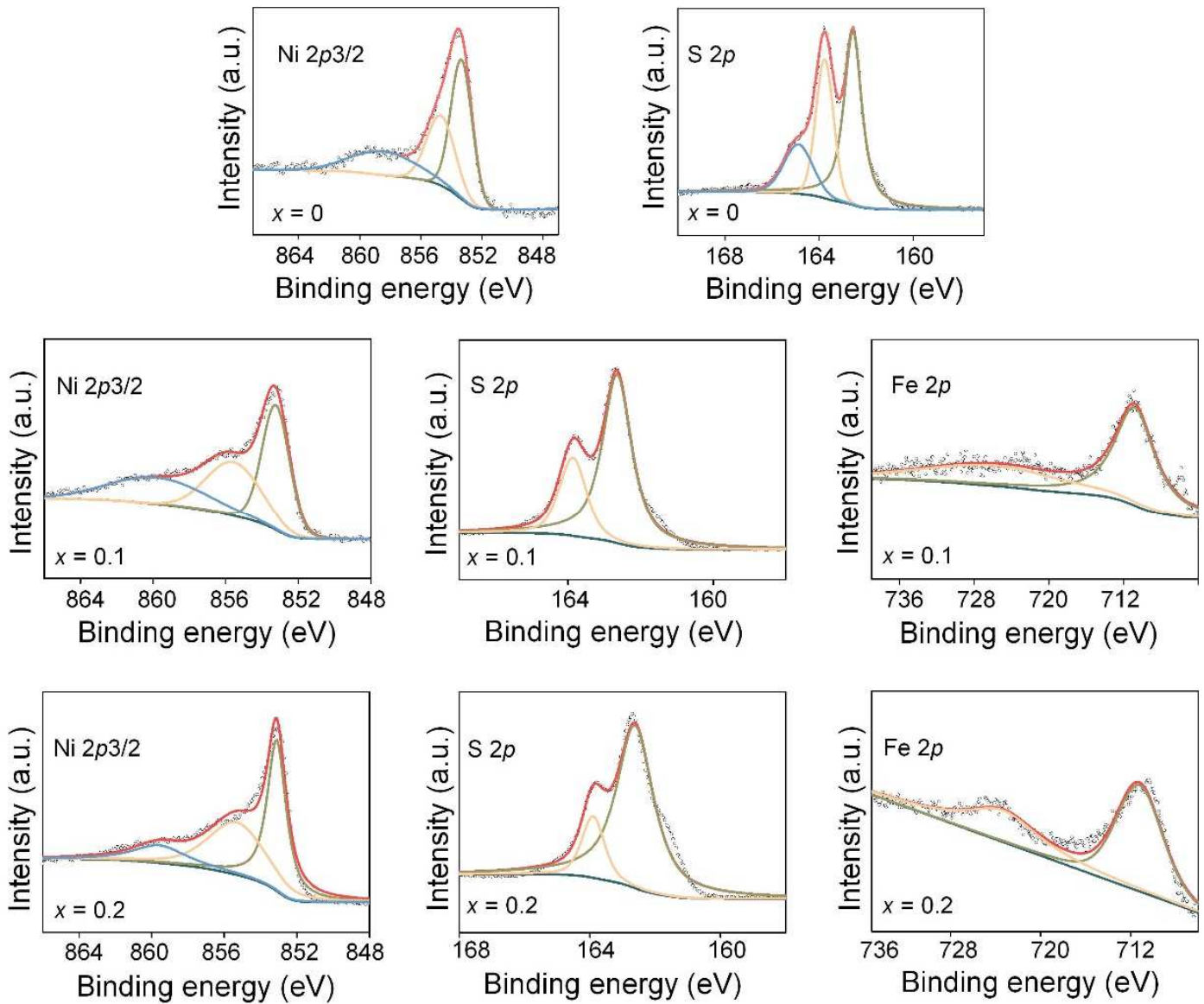

2

Supplementary Fig. 5. XPS Characterization of $\mathrm{Ni}_{1-x} \mathrm{Fe}_{x} \mathrm{~S}_{2}(x=0,0.1,0.2)$ for the $\mathrm{Ni} 2 p 3 / 2, \mathrm{~S} 2 p$ and $\mathrm{Fe}$ $2 p$ regions. The broad S $2 p$ XPS peak is fitted into two main peaks. The peaks located at 162.6 and 163.8 $\mathrm{eV}$ are attributed to the $\mathrm{S} 2 p 3 / 2$ and $\mathrm{S} 2 p 1 / 2$ orbitals of bridging $\mathrm{S}_{2}{ }^{2-}$.

5

6

8

9

10

11

12

13 

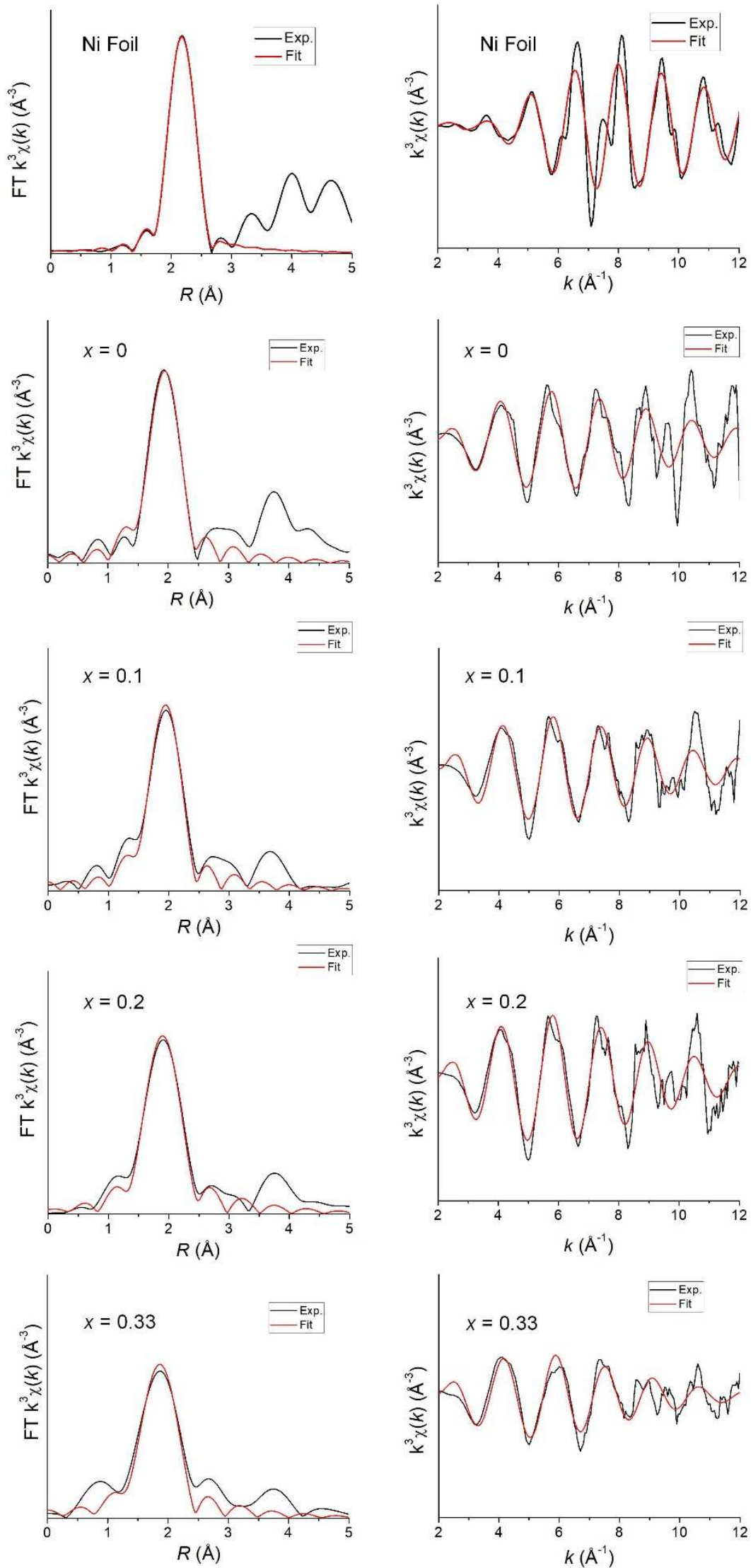

Supplementary Fig. 6. Ni K-edge EXAFS analysis of samples in $R$ and $k$ spaces. FT-EXAFS spectra and 3 fits of $\mathrm{Ni} \mathrm{K}$-edges from $\mathrm{Ni}$ foil and $\mathrm{Ni}_{1-x} \mathrm{Fe}_{x} \mathrm{~S}_{2}(x=0,0.1,0.2,0.33)$ catalysts. The black lines represent the 4 experiment data and the red lines represent the fitting values. 

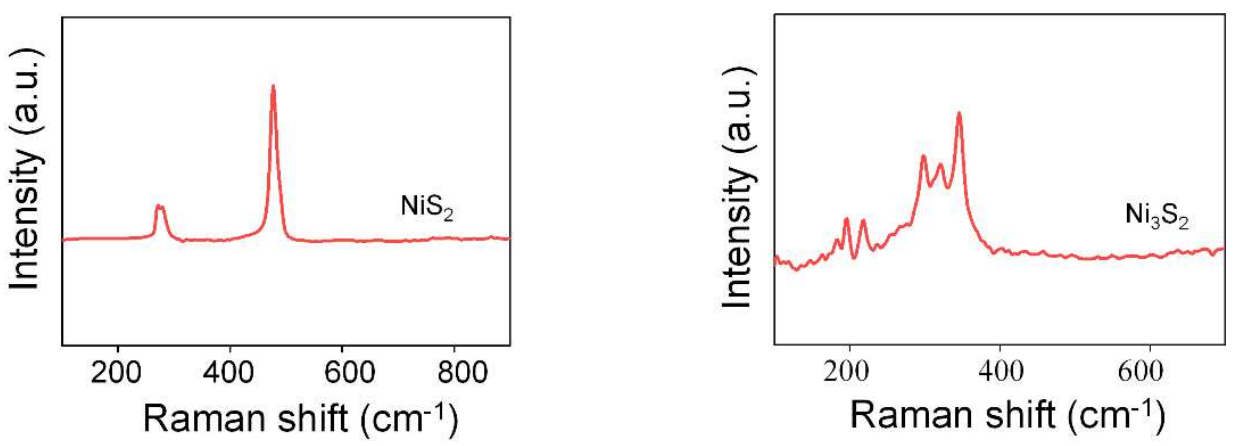

Supplementary Fig. 7. Raman spectrum of $\mathrm{NiS}_{2}$ and $\mathrm{Ni}_{3} \mathrm{~S}_{2}$. The peaks at $274.4\left(T_{\mathrm{g}}\right), 284.8\left(E_{\mathrm{g}}\right), 479.3\left(A_{\mathrm{g}}\right)$ $\mathrm{cm}^{-1}$ previously attributed to $\mathrm{NiS}_{2}$, peaks at $187.6\left(A_{1}(2)\right), 202.1(E(4)), 223.6(E(3)), 303.6(E(2)), 324.6$ $\left(A_{1}(1)\right), 350.3(E(1)) \mathrm{cm}^{-1}$ were correlated respectively with two $A_{1}$ stretching and four $E$ bending vibration of Ni-S in the heazlewoodite-phase $\mathrm{Ni}_{3} \mathrm{~S}_{2}$, the peaks are shown in Supplementary Table 4.

6

7

8

9
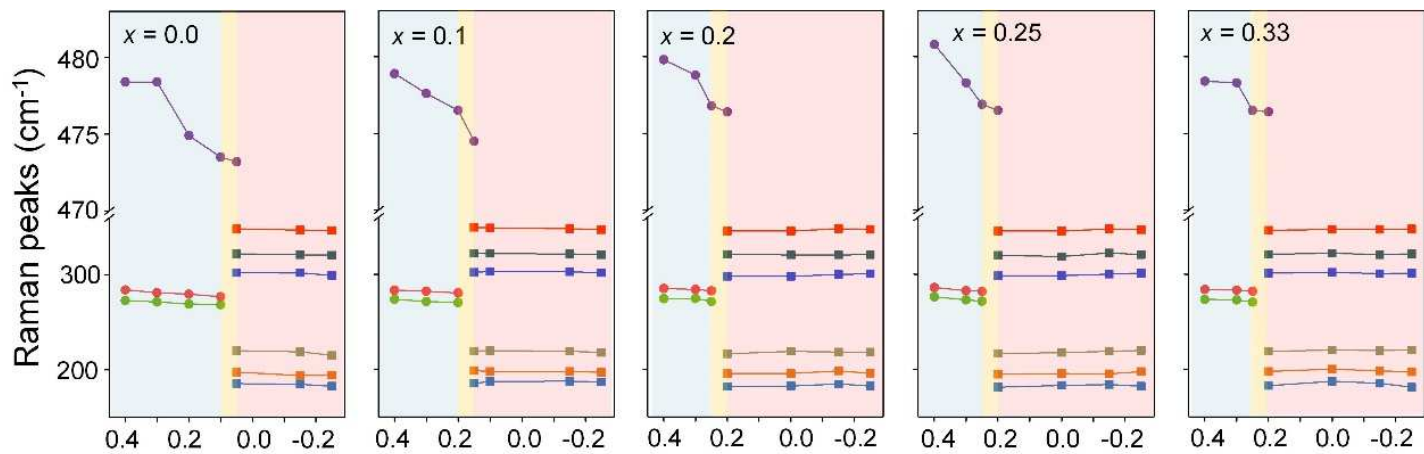

Applied potential ( $\mathrm{V}$ vs RHE)
10

Supplementary Fig. 8. Frequency of the vibrational modes versus the applied potential obtained from the in-situ Raman spectra for $\mathrm{Ni}_{1-x} \mathrm{Fe}_{x} \mathrm{~S}_{2}$. 5 

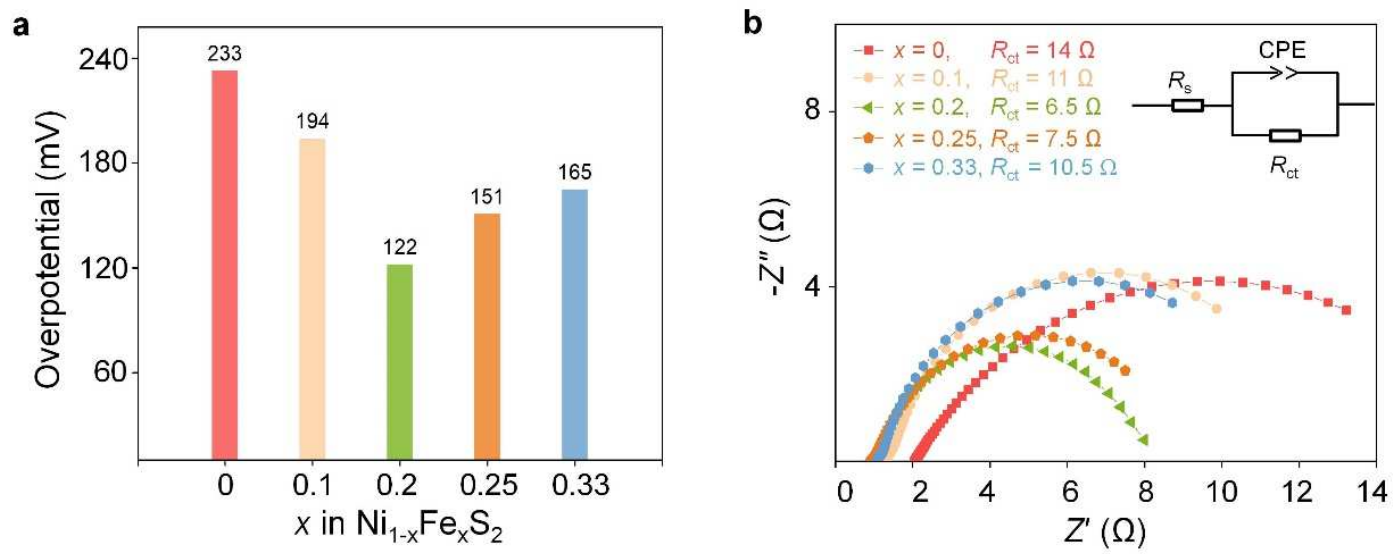

2 Supplementary Fig. 9. Electrochemical characterization of $\mathrm{Ni}_{1-x} \mathrm{Fe}_{x} \mathrm{~S}_{2}$. a, Overpotential of the nickel sulfide 3 catalysts at the current density of $10 \mathrm{mAcm}^{-2}$, b, Nyquist plots of the catalyst electrode@200 mV 4 overpotential in $1 \mathrm{M} \mathrm{KOH}$. Inset of (b) is the simplified Randles equivalent circuit model. The intercept in 5 the high frequency zone are attributed to the internal charge-transfer resistances or the system resistance $\left(R_{\mathrm{s}}\right)$ 6 of electrodes, and the semicircles represent the charge transfer resistances $\left(R_{\mathrm{ct}}\right)$ at the electrode/electrolyte 7 interface. The charge-transfer resistances $\left(R_{\mathrm{ct}}\right)$ measured at $200 \mathrm{mV}$ overpotential are 14, 11, 6.5, 7.5 and $810.5 \Omega$ for the CFP-supported pure $\mathrm{NiS}_{2}, \mathrm{Ni}_{0.9} \mathrm{Fe}_{0.1} \mathrm{~S}_{2}, \mathrm{Ni}_{0.8} \mathrm{Fe}_{0.2} \mathrm{~S}_{2}, \mathrm{Ni}_{0.75} \mathrm{Fe}_{0.25} \mathrm{~S}_{2}$ and $\mathrm{Ni}_{0.67} \mathrm{Fe}_{0.33} \mathrm{~S}_{2}$, 9 respectively. 

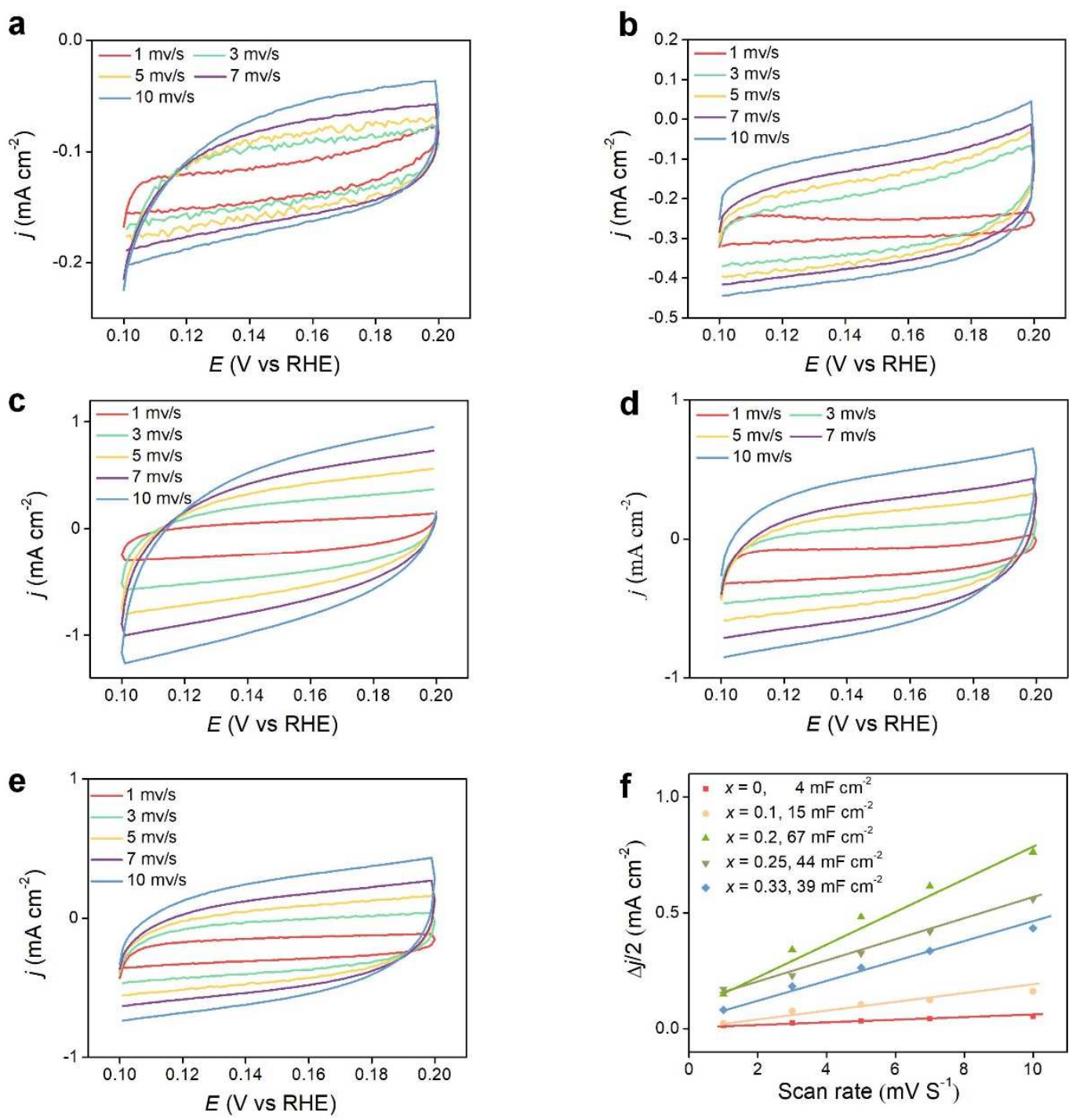
5

Supplementary Fig. 10. Cyclic voltammograms of the as-fabricated nickel sulfide catalysts. Cyclic voltammograms at different scan rates of in the non-Faradaic potential region ( 0.1 to $0.2 \mathrm{~V}$ versus RHE) for the $\mathrm{Ni}_{1-x} \mathrm{Fe}_{x} \mathrm{~S}_{2}(\mathrm{a}, x=0 ; \mathrm{b}, x=0.1 ; \mathrm{c}, x=0.2 ; \mathrm{d}, x=0.25 ; \mathrm{e}, x=0.33)$ catalysts in $1 \mathrm{M} \mathrm{KOH}$ at different scan rates $\left(1,3,5,7,10 \mathrm{mV} \mathrm{s}^{-1}\right)$. f, Charging current density differences at $0.15 \mathrm{~V}$ versus RHE plotted against scan rate. The value of $C_{\mathrm{dl}}$ was estimated from the slope of the linear relationship between the half capacitive current density $\left(\left(j_{\text {anodic }}-j_{\text {cathodic }}\right) / 2\right)$ at the middle of the applied potential range and the scan rates. Significantly,

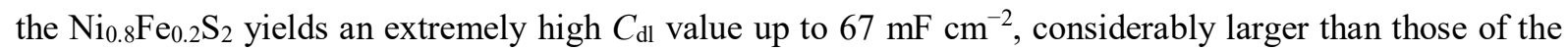
$\mathrm{NiS}_{2}\left(4 \mathrm{mF} \mathrm{cm}{ }^{-2}\right), \mathrm{Ni}_{0.9} \mathrm{Fe}_{0.1} \mathrm{~S}_{2}\left(15 \mathrm{mF} \mathrm{cm}{ }^{-2}\right), \mathrm{Ni}_{0.75} \mathrm{Fe}_{0.25} \mathrm{~S}_{2}\left(44 \mathrm{mF} \mathrm{cm}{ }^{-2}\right)$ and $\mathrm{Ni}_{0.67} \mathrm{Fe}_{0.33} \mathrm{~S}_{2}\left(39 \mathrm{mF} \mathrm{cm}{ }^{-2}\right)$, which indicates that an appropriate concentration of $\mathrm{Fe}$ doping can substantially extend the electrochemical active area and render more catalytic active sites. 

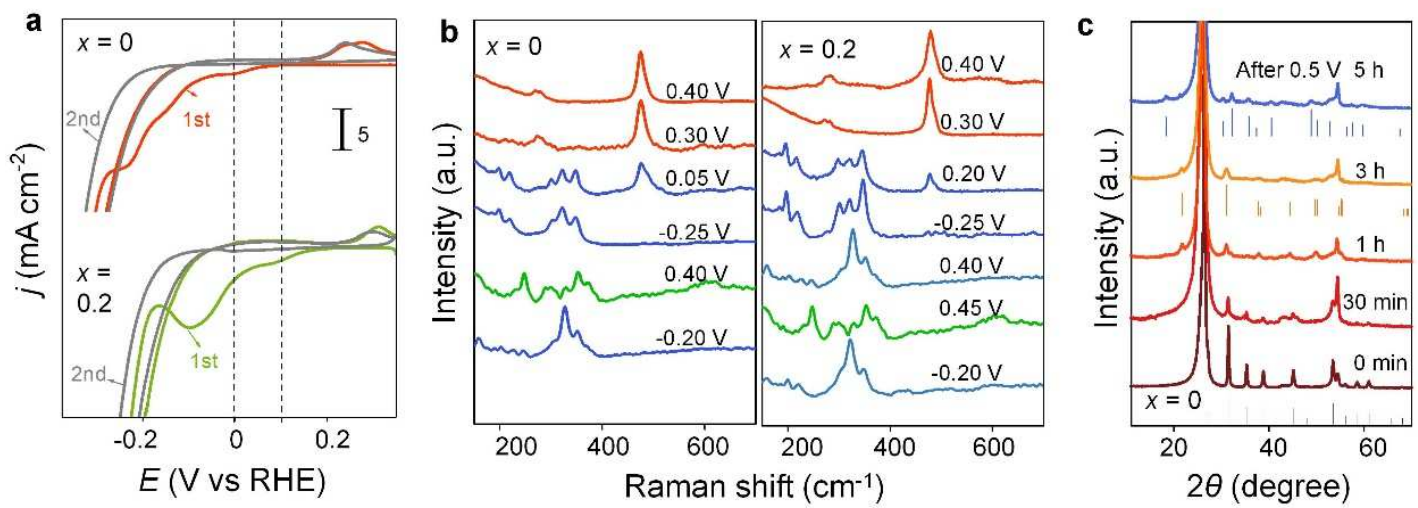

Supplementary Fig. 11. a, Cyclic Voltammetry curves of $\mathrm{Ni}_{1-x} \mathrm{Fe}_{x} \mathrm{~S}_{2}(x=0.0,0.2)$ in $\mathrm{N}_{2}$-saturated $1 \mathrm{M} \mathrm{KOH}$ with a scan rate of $2 \mathrm{mV} \mathrm{s}^{-1}$ between 0.4 and $-0.4 \mathrm{~V}$ (vs. RHE) to show the pseudocapacitive behavior preceding to HER. b, In-situ Raman spectra of $\mathrm{Ni}_{1-x} \mathrm{Fe}_{x} \mathrm{~S}_{2}(x=0$ and 0.2$)$ at the potentials of $0.45 \mathrm{~V} \sim-0.25 \mathrm{~V}$ (RHE) in $1 \mathrm{M} \mathrm{KOH.} \mathrm{c,} \mathrm{XRD} \mathrm{patterns} \mathrm{of} \mathrm{catalyst} \mathrm{after} \mathrm{the} \mathrm{operation} \mathrm{of} \mathrm{HER} \mathrm{instantly} \mathrm{at} \mathrm{constant} \mathrm{current}$ density of $-10 \mathrm{~mA} \mathrm{~cm}^{-2}$ and constant potential $0.5 \mathrm{~V}$ (RHE) $5 \mathrm{~h}$. We can interpret that $\mathrm{NiS}_{2}$ have a phase transition to $\mathrm{Ni}_{3} \mathrm{~S}_{2}$ under the proper conditions, and it will have a reversible phase transition to $\beta$-NiS.

For the CV curves of oxidation scan, nickel sulfides all have an anodic peak. In-situ Raman spectra and XRD patterns prove the structure will have a phase transition to $\beta$-NiS structure with the potential increase. The anodic peak of $\mathrm{Ni}_{0.8} \mathrm{Fe}_{0.2} \mathrm{~S}_{2}$ is higher than that of $\mathrm{NiS}_{2}$ in the $\mathrm{CVs}$, which means the more stability in the $\mathrm{Fe}$ substitution. . 5 6 
a

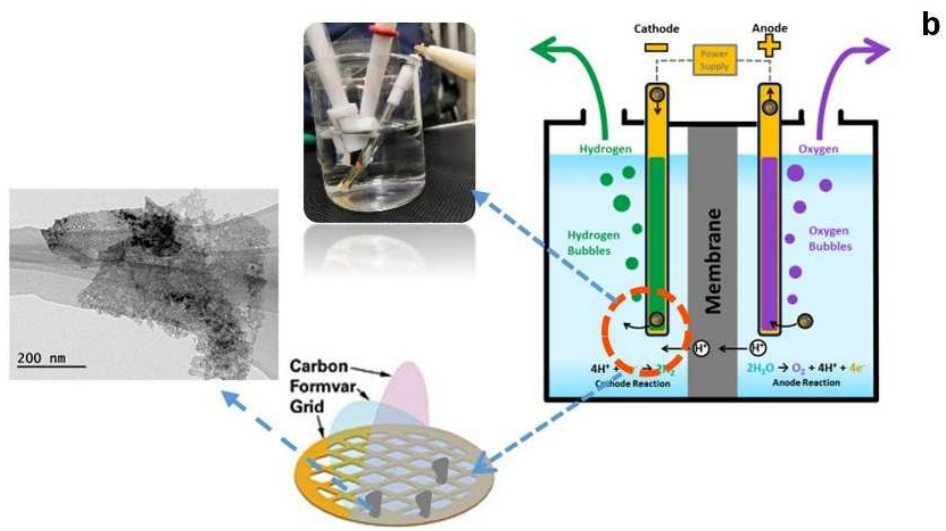

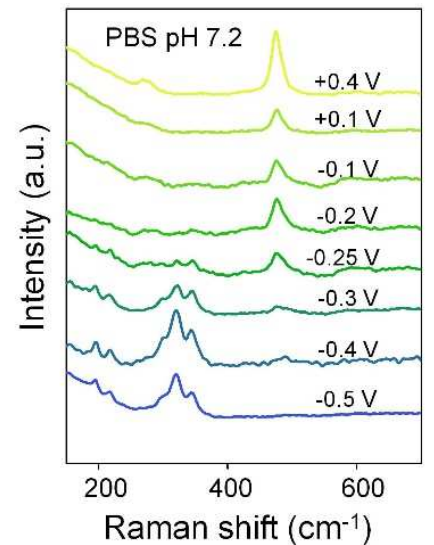

1

2

3

4

5

6

7

8

9

10

11

Supplementary Fig. 12. TEM characterization of surface-restructured nickel sulfide after the process of HER. a, Schematic process of HRTEM of nickel sulfide. b, In-situ Raman spectra of $\mathrm{NiS}_{2}$ at the potentials of $0.4 \mathrm{~V} \sim-0.5 \mathrm{~V}$ (RHE) in 0.01M PBS (NaPi, pH7.2).

The catalysts sprayed on the $\mathrm{Cu}$ grids, which were attached to the Au electrode with conductive carbon tape, polarized in $\mathrm{N}_{2}$ saturated $0.01 \mathrm{M} \mathrm{NaPi}$ electrolyte ( $\mathrm{pH}$ 7.2) at the potential of $-0.45 \mathrm{~V}$ (vs RHE) for $2 \mathrm{~h}$. As we can see the results from different condition of electrolyte, reconstruction potential range turned on, which is $-0.25 \sim-0.3 \mathrm{~V}$ for $0.01 \mathrm{M} \mathrm{NaPi}$. 

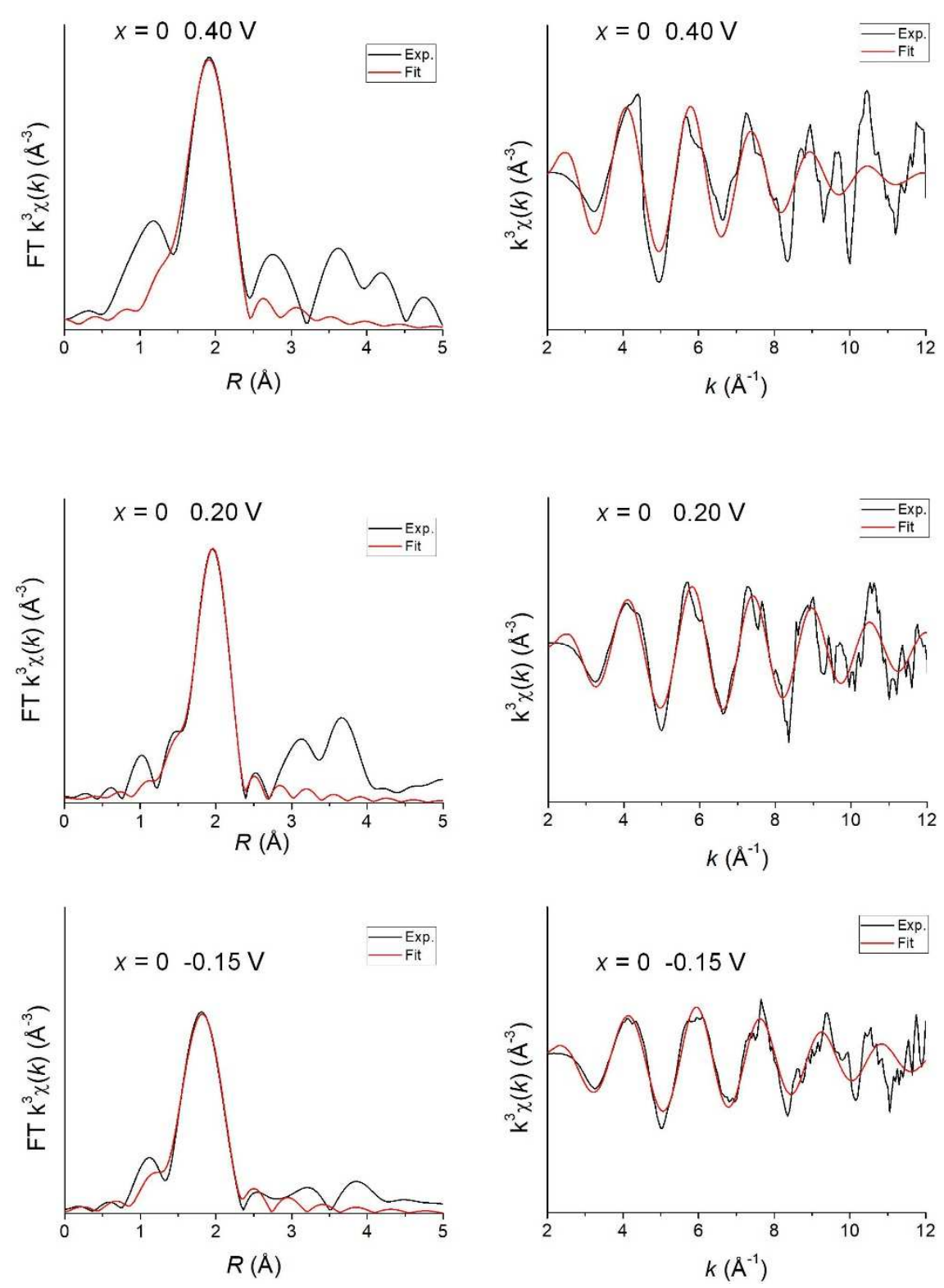

3 Supplementary Fig.13. Ni K-edge EXAFS analysis of nickel sulfide in $R$ and $k$ spaces. FT-EXAFS spectra 4 and fits of Ni K-edges from $\mathrm{NiS}_{2}$ (in $-0.15 \mathrm{~V}, 0.20 \mathrm{~V}$ and $0.40 \mathrm{~V}$ vs RHE test). The black lines represent the 5 experiment data and the red lines represent the fitting values. 

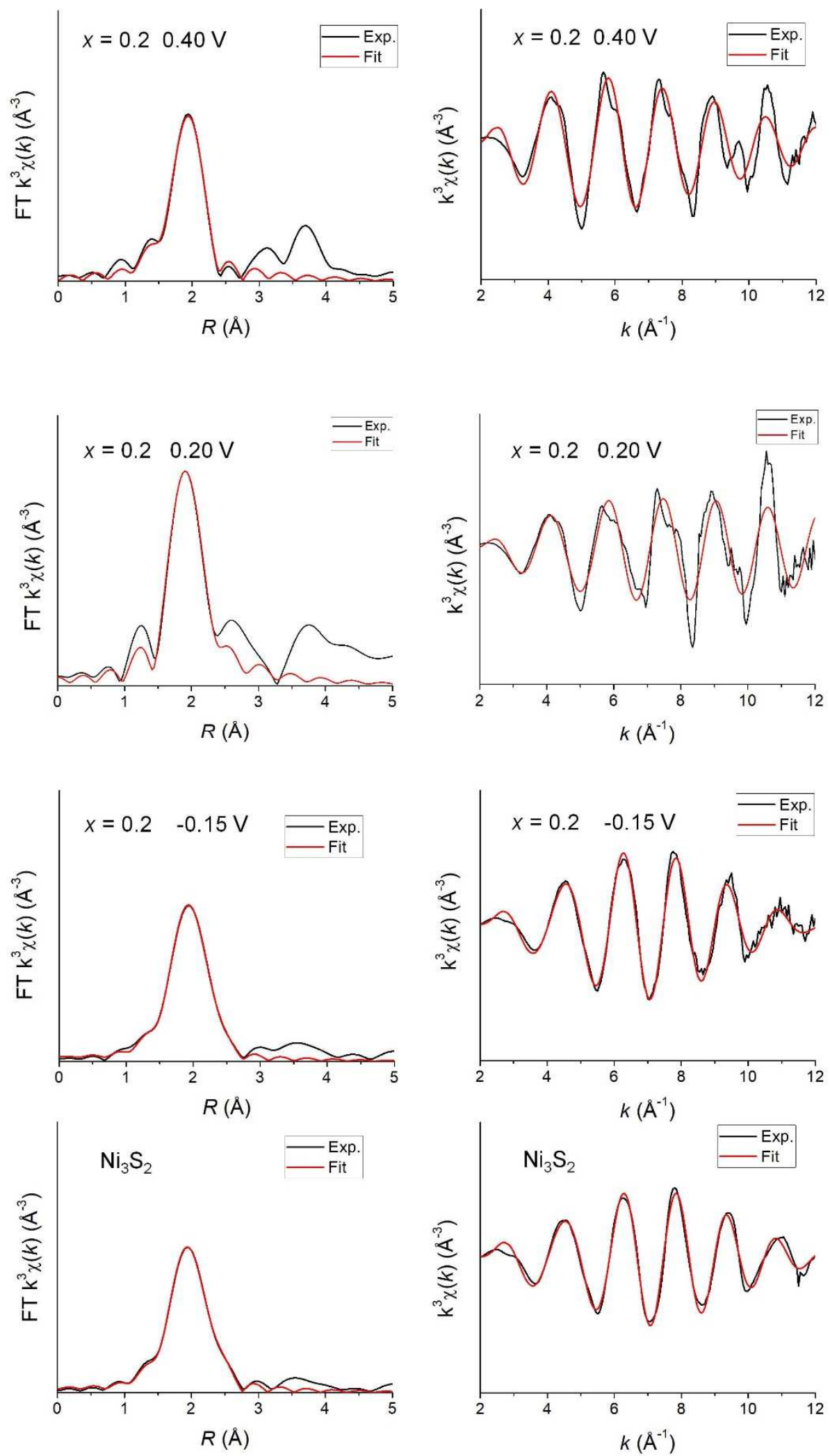

Supplementary Fig. 14. Ni K-edge EXAFS analysis of nickel sulfide in $R$ and $k$ spaces. FT-EXAFS spectra and fits of $\mathrm{Ni} \mathrm{K}$-edges from $\mathrm{Ni}_{3} \mathrm{~S}_{2}$ catalysts and $\mathrm{Ni}_{0.8} \mathrm{Fe}_{0.2} \mathrm{~S}_{2}$ (in $-0.15 \mathrm{~V}, 0.20 \mathrm{~V}$ and $0.40 \mathrm{~V}$ vs RHE test). The black lines represent the experiment data and the red lines represent the fitting values. 

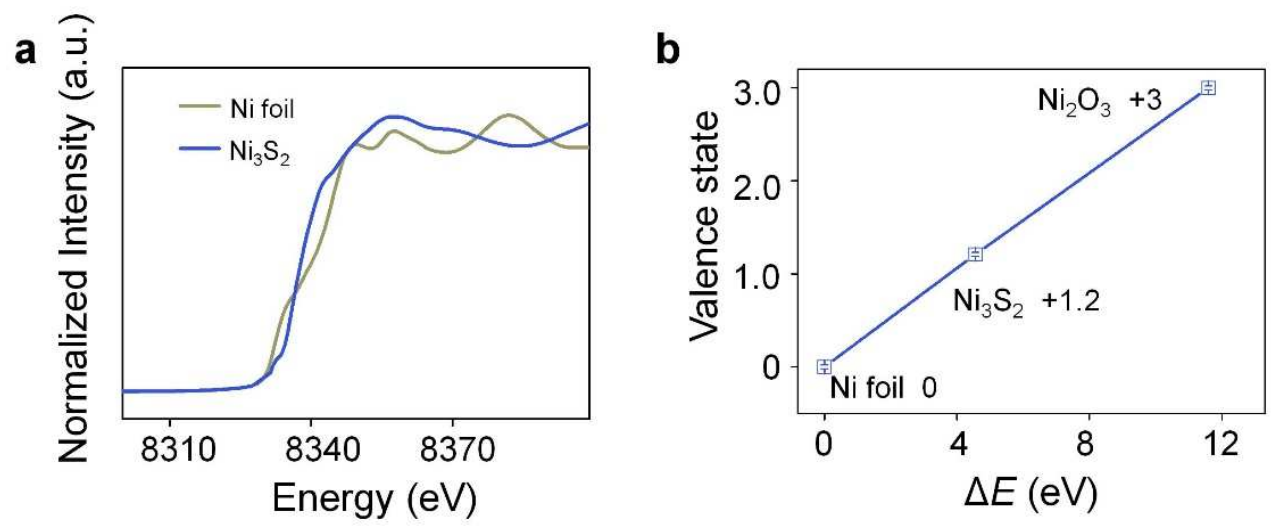

1

2 Supplementary Fig. 15. XAFS measurements. $\mathrm{a}, \mathrm{b}$ is the $\mathrm{Ni}_{3} \mathrm{~S}_{2}$ XANES spectra and the corresponding 3 valence state of $\mathrm{Ni}$ in $\mathrm{Ni}_{3} \mathrm{~S}_{2}$ according to the linear relationship described in $\mathrm{b}$. Error bars represent the 4 standard deviation from at least three independent measurements. The average valence state of nickel foil 5 and $\mathrm{Ni}_{2} \mathrm{O}_{3}$ is fitted to 0 and +3 by the Nickel K-edge XANES in Supplementary Fig. 4. Applying the linear 6 correlation, it is found that the average valence state of $\mathrm{Ni}$ for $\mathrm{Ni}_{3} \mathrm{~S}_{2}$ is approximately +1.20 .

7

8

9

10

11

12

13

14

15 

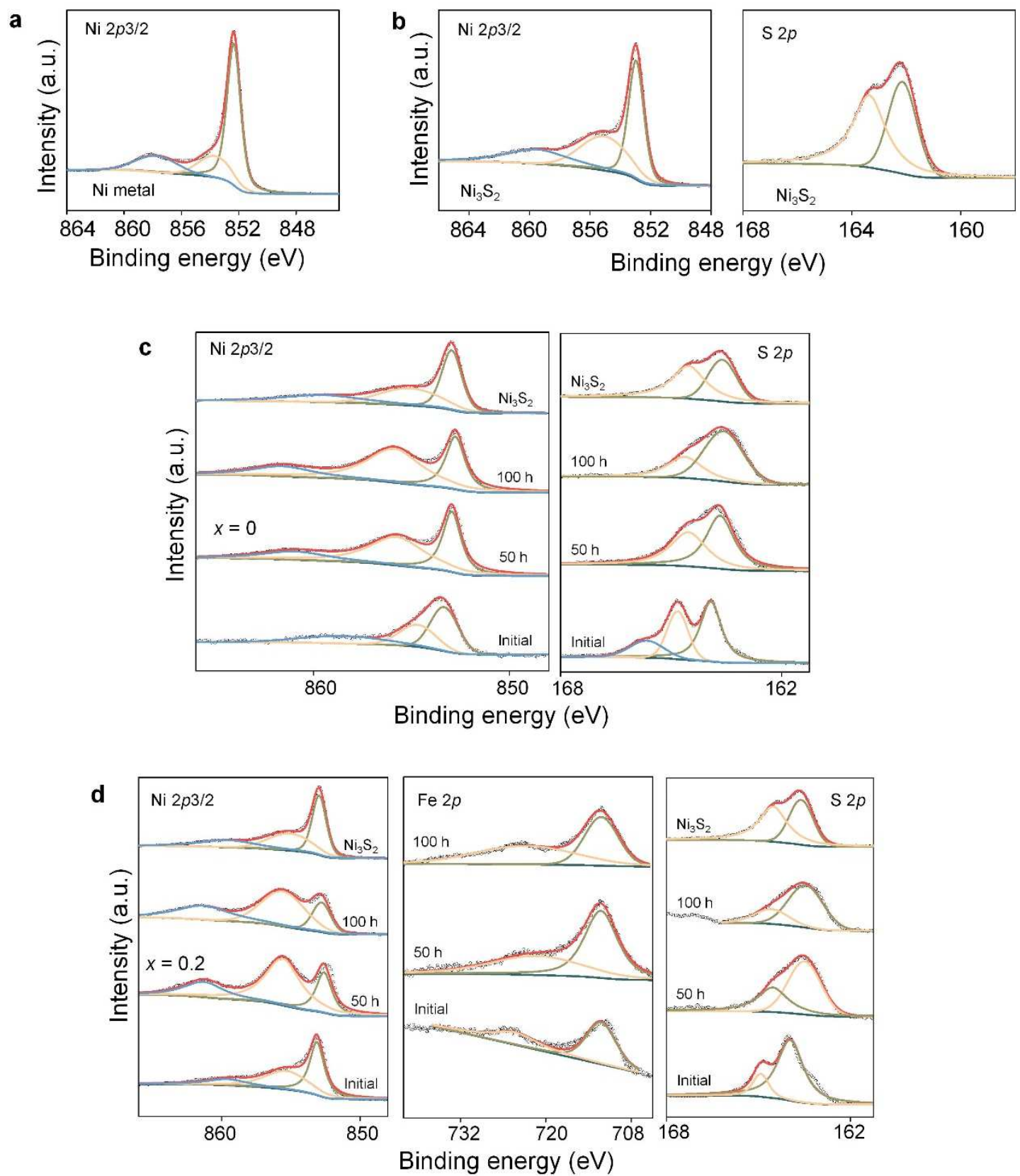

2 Supplementary Fig. 16. XPS Characterization. a, Ni Metal of Ni $2 p 3 / 2$ regions. b, Ni $2 p 3 / 2$ and S $2 p$ regions 3 of $\mathrm{Ni}_{3} \mathrm{~S}_{2}$. The $\mathrm{Ni}$ metal peak at $852.30 \mathrm{eV}$, and the $\mathrm{Ni}$ peak of $\mathrm{Ni}_{3} \mathrm{~S}_{2}$ is about at $852.85 \mathrm{eV}$. c, d, XPS analysis 4 of the electrodes after long time test as the work electrode to identify the binding energy and ratio of the surface element for $\mathrm{NiS}_{2}$ (c) and $\mathrm{Ni}_{0.8} \mathrm{Fe}_{0.2} \mathrm{~S}_{2}$ (d). At $50 \mathrm{~h}$ and $100 \mathrm{~h}$, the Ni $2 p 3 / 2$ binding energy is 6 approaching to $\mathrm{Ni}$ in $\mathrm{Ni}_{3} \mathrm{~S}_{2}$, while for $\mathrm{Fe}$, the binding energy is slightly changed.

7 For the $\mathrm{Ni} 2 p 2 / 3$, the peaks after $50 \mathrm{~h}$ and $100 \mathrm{~h}$ are all verge on the corresponding peaks of the $\mathrm{Ni}_{3} \mathrm{~S}_{2}$ crystal, 8 thus implying the finalized phase of the long-term service also close to $\mathrm{Ni}_{3} \mathrm{~S}_{2}$ structure. 

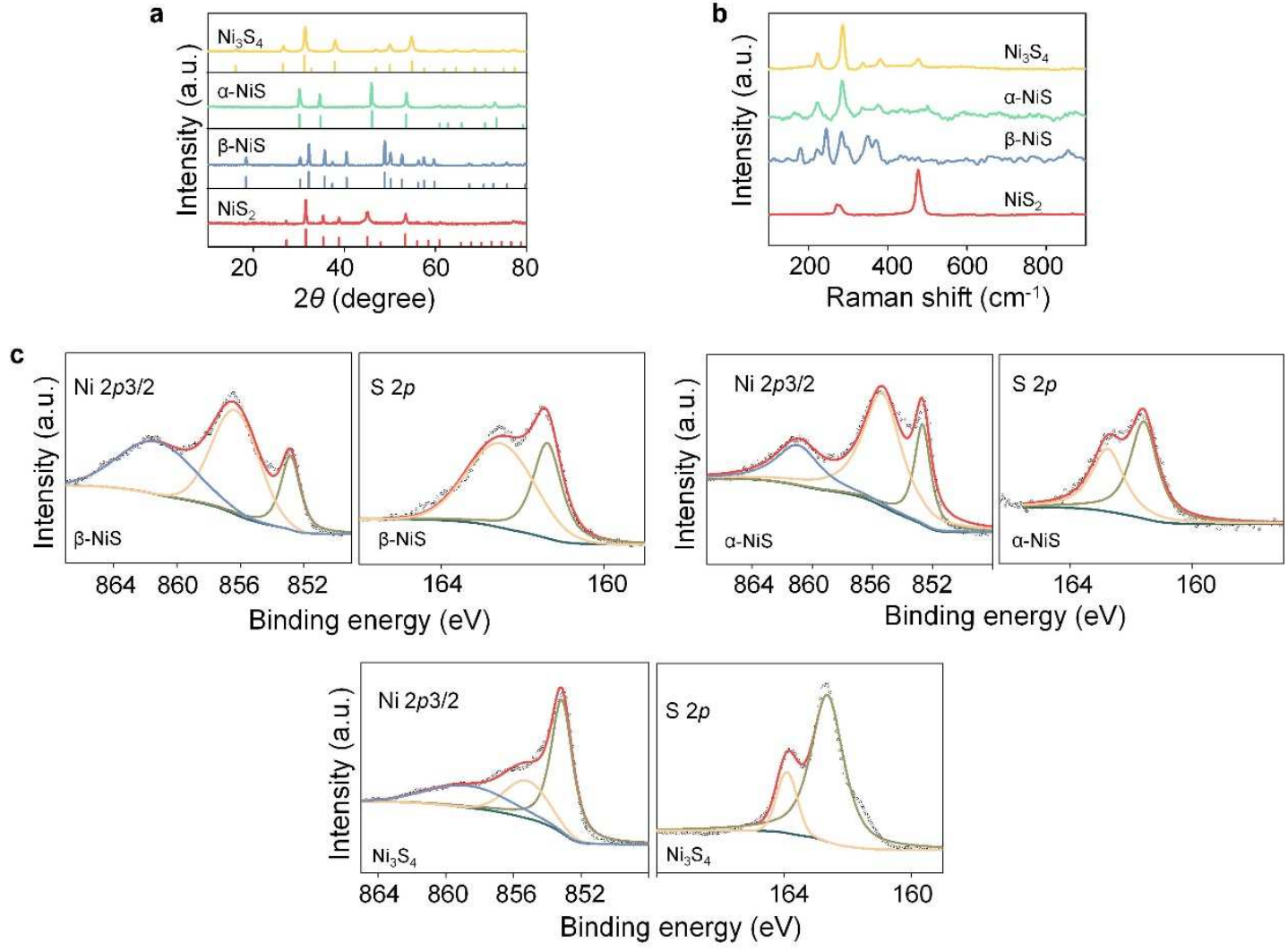

d
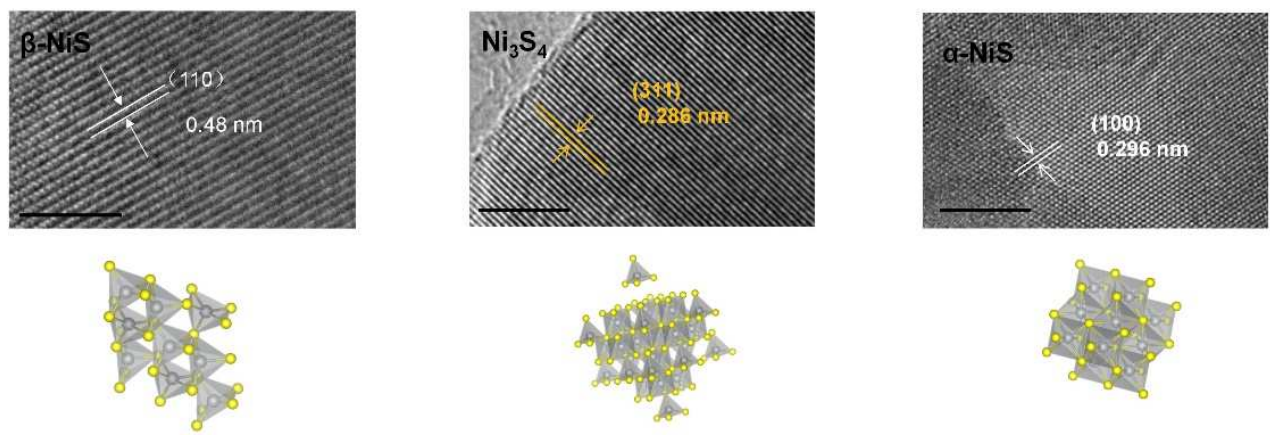

Supplementary Fig. 17. Structure Characterization of $\alpha-\mathrm{NiS}, \beta-\mathrm{NiS} \mathrm{Ni}_{3} \mathrm{~S}_{4}$. a PXRD, b Raman spectra. The PDF number of $\beta$-NiS is $12-0041$, the PDF number of $\alpha$-NiS is $02-1280$, the PDF number of $\mathrm{Ni}_{3} \mathrm{~S}_{4}$ is 43 1469; the Raman peaks are shown in Table 4. c, XPS analysis of the electrodes of $\alpha$-NiS, $\beta-\mathrm{NiS}$ and $\mathrm{Ni}_{3} \mathrm{~S}_{4}$. d, HRTEM characterization of $\alpha-\mathrm{NiS}, \beta-\mathrm{NiS}$ and $\mathrm{Ni}_{3} \mathrm{~S}_{4}$ and the lattice structure of each Nickel sulfides. Scale bars, $5 \mathrm{~nm}$. For spinel structure of $\mathrm{Ni}_{3} \mathrm{~S}_{4}$, there is two arrangement of $\mathrm{Ni}$ atom and $\mathrm{S}$ atom to consist octahedron polyhedral of $\mathrm{Ni}$ with six $\mathrm{S}$ around and tetrahedron polyhedral of $\mathrm{Ni}$ with four $\mathrm{S}$. For $\beta$-NiS, there is five $\mathrm{S}$ around $\mathrm{Ni}$ atom to consist pyramidal polyhedral. For the $\alpha$-NiS, the Ni atom is around with six $\mathrm{S}$ atom to consist octahedron polyhedral. 
a

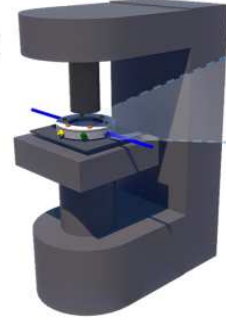

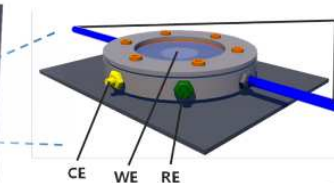

CE WE RE

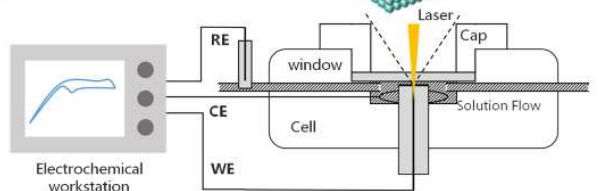

b

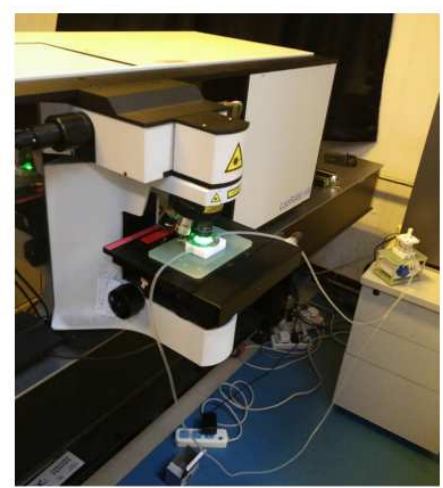

2 Supplementary Fig. 18. Equipment used for in-situ Raman measurements. a, Schematic for the equipment 3 used for in-situ Raman. b, Digital photo taken during in-situ Raman.

4

5

6

8

9

10 a

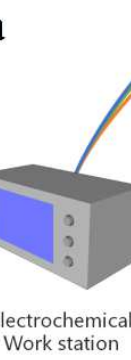

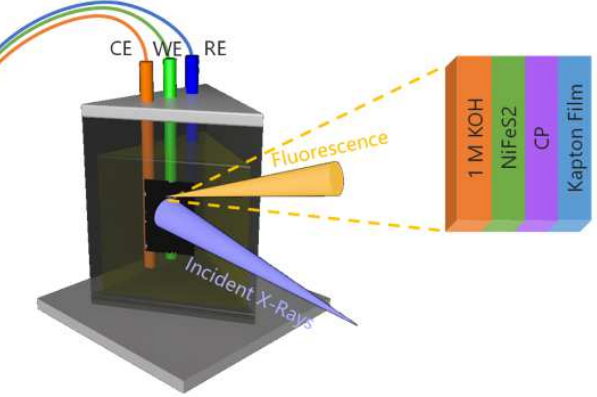

b

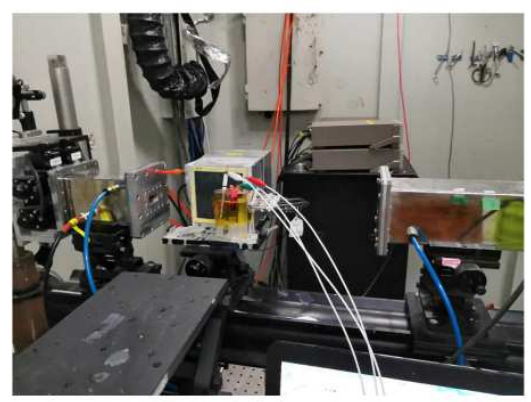

Supplementary Fig. 19. Equipment used for operando XAFS measurements. a, Schematic for the equipment used for operando XAFS measurements. b, Digital photo taken during operando XAFS measurement. 


\section{Supplementary Tables}

2

3 Supplementary Table 1. The Ni and Fe K-edge positions, nominal $\mathrm{Ni}$ and $\mathrm{Fe}$ valence state and the nominal 4 sulphur vacancy concentration $(\delta)$ in $\mathrm{Ni}_{1-x} \mathrm{Fe}_{x} \mathrm{~S}_{2-\delta}$.

\begin{tabular}{|c|c|c|c|c|c|c|}
\hline \multirow[t]{2}{*}{ Samples } & \multicolumn{2}{|c|}{ Fe k-edge } & \multirow[t]{2}{*}{ Samples } & \multicolumn{2}{|c|}{ Ni k-edge } & \multirow{2}{*}{$\begin{array}{c}\text { Nominal } \\
\text { sulphur } \\
\text { vacancy } \\
\text { concentration } \\
\text { (ס) }\end{array}$} \\
\hline & $\begin{array}{c}\text { Edge } \\
\text { energy } \\
(\mathrm{eV})\end{array}$ & $\begin{array}{c}\text { Nominal } \\
\text { Valence } \\
\text { state }\end{array}$ & & $\begin{array}{c}\text { Edge } \\
\text { energy } \\
(\mathrm{eV})\end{array}$ & $\begin{array}{c}\text { Nominal } \\
\text { Valence } \\
\text { state }\end{array}$ & \\
\hline Fe foil & 7112.00 & 0.00 & Ni foil & 8333.00 & 0.00 & \\
\hline \multirow[t]{2}{*}{$\mathrm{Fe}_{2} \mathrm{O}_{3}$} & 7122.32 & 3.00 & $\mathrm{Ni}_{2} \mathrm{O}_{3}$ & 8344.61 & 3.00 & \\
\hline & & & $x=0$ & 8340.68 & 1.98 & $\begin{array}{c}\delta=0.02 \\
\left(\mathrm{NiS}_{1.98}\right)\end{array}$ \\
\hline$x=0.1$ & 7118.92 & 2.01 & $x=0.1$ & 8340.35 & 1.90 & $\begin{array}{c}\delta=0.09 \\
\left(\mathrm{Ni}_{0.9} \mathrm{Fe}_{0.1} \mathrm{~S}_{1.91}\right)\end{array}$ \\
\hline$x=0.2$ & 7118.98 & 2.03 & $x=0.2$ & 8340.12 & 1.84 & $\begin{array}{c}\delta=0.13 \\
\left(\mathrm{Ni}_{0.8 \mathrm{Fe}} \mathrm{F}_{0.21 .87}\right)\end{array}$ \\
\hline$x=0.33$ & 7118.89 & 2.00 & $x=0.33$ & 8340.27 & 1.88 & $\begin{array}{c}\delta=0.08 \\
\left(\mathrm{Ni}_{0.66} \mathrm{Fe}_{0.33} \mathrm{~S}_{1.92}\right)\end{array}$ \\
\hline
\end{tabular}

5

6 The nominal sulphur vacancy concentration was calculated on the basis of the nominal valence state of $\mathrm{Ni}$, 7 Fe and $\mathrm{S}$. 
1 Supplementary Table 2. XPS fitting parameters of binding energies for the as-prepared nickel sulfide 2 catalysts.

\begin{tabular}{|c|c|c|c|c|c|c|}
\hline \multirow{2}{*}{ Catalyst } & \multicolumn{5}{|c|}{ Binding energy $(\mathrm{eV})$} & \multirow{2}{*}{$\begin{array}{c}\text { Element } \\
\text { Ratio (\%) } \\
\mathrm{Ni}:(\mathrm{Fe}): \mathrm{S}\end{array}$} \\
\hline & $\mathrm{Ni} 2 p 3 / 2$ & $\mathrm{~S} 2 p 3 / 2$ & S $2 p 1 / 2$ & $\mathrm{Fe} 2 p 3 / 2$ & $\mathrm{Fe} 2 p 1 / 2$ & \\
\hline Ni Metal & 852.30 & - & - & - & - & - \\
\hline $\mathrm{Ni}_{3} \mathrm{~S}_{2}$ & 852.82 & 162.18 & 163.36 & - & - & $23.85: 27.57$ \\
\hline $\mathrm{NiS}_{2}$ & 853.56 & 162.58 & 163.79 & - & - & $4.01: 10.26$ \\
\hline $\mathrm{Ni}_{0.9} \mathrm{Fe}_{0.1} \mathrm{~S}_{2}$ & 853.13 & 162.7 & 163.8 & 710.87 & 726.92 & $\begin{array}{l}\text { 8.69: (1.03): } \\
20.24\end{array}$ \\
\hline $\mathrm{Ni}_{0.8} \mathrm{Fe}_{0.2} \mathrm{~S}_{2}$ & 853.16 & 162.63 & 163.92 & 710.65 & 722.85 & $\begin{array}{c}10.52:(1.47) \\
21.05\end{array}$ \\
\hline $\mathrm{NiS}_{2}, 50 \mathrm{~h}$ & 852.89 & 162.26 & 163.43 & - & - & $26.03: 16.33$ \\
\hline $\mathrm{NiS}_{2}, 100 \mathrm{~h}$ & 852.68 & 162.25 & 163.80 & - & - & $22.92: 13.28$ \\
\hline $\mathrm{Ni}_{0.8} \mathrm{Fe}_{0.2} \mathrm{~S}_{2}, 50 \mathrm{~h}$ & $\begin{array}{l}852.59 / \\
855.56\end{array}$ & 162.25 & 163.48 & 711.05 & 722.08 & $\begin{array}{l}\text { 20.09: (1.16): } \\
10.27\end{array}$ \\
\hline $\mathrm{Ni}_{0.8} \mathrm{Fe}_{0.2} \mathrm{~S}_{2}, 100 \mathrm{~h}$ & $\begin{array}{l}852.77 / \\
855.50\end{array}$ & 162.10 & 163.47 & 711.12 & 722.28 & $\begin{array}{c}\text { 21.02: }(0.95): \\
16.20\end{array}$ \\
\hline$\alpha-\mathrm{NiS}$ & $\begin{array}{l}852.71 / \\
855.38\end{array}$ & 161.59 & 162.79 & - & - & $16.42: 10.84$ \\
\hline$\beta-\mathrm{NiS}$ & $\begin{array}{l}852.89 / \\
856.52\end{array}$ & 161.41 & 162.60 & - & - & $10.36: 14.93$ \\
\hline $\mathrm{Ni}_{3} \mathrm{~S}_{4}$ & $\begin{array}{l}853.17 / \\
855.32\end{array}$ & 162.68 & 163.90 & - & - & $13.32: 35.22$ \\
\hline
\end{tabular}

3 
1 Supplementary Table 3. EXAFS fitting parameters at the Ni K-edge various samples $\left(S_{0}{ }^{2}=0.82\right)$

\begin{tabular}{|c|c|c|c|c|c|c|}
\hline Sample & Path & $\mathrm{CN}^{\mathrm{a}}$ & $R(\AA)^{b}$ & $\sigma^{2} \times 10^{-3}\left(\AA^{2}\right)^{c}$ & $\Delta E(\mathrm{eV})^{\mathrm{d}}$ & $R$ factor \\
\hline Ni foil & $\mathrm{Ni}-\mathrm{Ni}$ & $12 *$ & $2.48 \pm 0.01$ & $6.1 \pm 0.2$ & $6.7 \pm 0.3$ & 0.001 \\
\hline$x=0$ & $\mathrm{Ni}-\mathrm{S}$ & $6.0 \pm 0.7$ & $2.40 \pm 0.01$ & $7.4 \pm 1.8$ & $2.0 \pm 1.9$ & 0.015 \\
\hline$x=0.1$ & Ni-S & $5.9 \pm 0.6$ & $2.39 \pm 0.01$ & $8.2 \pm 1.5$ & $3.5 \pm 1.5$ & 0.010 \\
\hline$x=0.2$ & $\mathrm{Ni}-\mathrm{S}$ & $5.8 \pm 0.6$ & $2.38 \pm 0.01$ & $8.2 \pm 2.1$ & $1.4 \pm 1.8$ & 0.007 \\
\hline$x=0.33$ & Ni-S & $5.4 \pm 0.6$ & $2.36 \pm 0.02$ & $10.9 \pm 3.2$ & $1.6 \pm 2.7$ & 0.016 \\
\hline \multirow{2}{*}{$\mathrm{Ni}_{3} \mathrm{~S}_{2}$} & Ni-S & $3.9 \pm 0.4$ & $2.27 \pm 0.02$ & $6.8 \pm 2.4$ & $3.8 \pm 1.6$ & \multirow{2}{*}{0.001} \\
\hline & $\mathrm{Ni}-\mathrm{Ni}$ & $2.0 \pm 1.1$ & $2.52 \pm 0.03$ & $6.2 \pm 4.0$ & $4.6 \pm 4.6$ & \\
\hline $\begin{array}{l}x=0.2 \\
0.40 \mathrm{~V}\end{array}$ & $\mathrm{Ni}-\mathrm{S}$ & $5.9 \pm 0.6$ & $2.38 \pm 0.01$ & $7.3 \pm 0.9$ & $1.3 \pm 1.1$ & 0.008 \\
\hline $\begin{array}{l}x=0.2 \\
0.20 \mathrm{~V}\end{array}$ & $\mathrm{Ni}-\mathrm{S}$ & $4.1 \pm 0.4$ & $2.36 \pm 0.01$ & $2.5 \pm 1.6$ & $0.9 \pm 2.2$ & 0.011 \\
\hline \multirow{2}{*}{$\begin{array}{l}x=0.2 \\
-0.15 \mathrm{~V}\end{array}$} & $\mathrm{Ni}-\mathrm{S}$ & $3.5 \pm 0.4$ & $2.26 \pm 0.02$ & $6.2 \pm 2.5$ & $2.4 \pm 2.2$ & \multirow{2}{*}{0.001} \\
\hline & $\mathrm{Ni}-\mathrm{Ni}$ & $2.8 \pm 1.6$ & $2.51 \pm 0.03$ & $7.7 \pm 4.5$ & $0.1 \pm 5.9$ & \\
\hline $\begin{array}{c}x=0 \\
0.40 \mathrm{~V}\end{array}$ & $\mathrm{Ni}-\mathrm{S}$ & $6.0 \pm 0.7$ & $2.39 \pm 0.01$ & $4.6 \pm 1.3$ & $1.5 \pm 1.8$ & 0.018 \\
\hline $\begin{array}{c}x=0 \\
0.20 \mathrm{~V}\end{array}$ & $\mathrm{Ni}-\mathrm{S}$ & $6.0 \pm 0.6$ & $2.38 \pm 0.01$ & $6.1 \pm 1.4$ & $1.4 \pm 1.1$ & 0.016 \\
\hline $\begin{array}{c}x=0 \\
-0.15 \mathrm{~V}\end{array}$ & Ni-S & $4.9 \pm 0.5$ & $2.30 \pm 0.01$ & $8.7 \pm 1.7$ & $-3.7 \pm 1.9$ & 0.013 \\
\hline
\end{tabular}

$2 \quad{ }^{a} \mathrm{CN}$ : coordination number; ${ }^{b} R$ : bond distance; ${ }^{c} \sigma^{2}$ : Debye-Waller factors; ${ }^{d} \Delta E_{0}$ : the inner potential correction.

$3 \quad R$ factor: goodness of fit. ${ }^{*}$ The experimental EXAFS fit of metal foil by fixing $\mathrm{CN}$ as the known 4 crystallographic value.

5

6 
1 Supplementary Table 4. Raman spectra of different nickel sulfides.

\begin{tabular}{|l|c|c|c|c|c|c|c|c|c|}
\hline & \multicolumn{7}{|c|}{ Raman Peaks (cm $\left.{ }^{-1}\right)$} \\
\hline $\mathrm{NiS}_{2}$ & 274.4 & 284.8 & 479.3 & & & & & & \\
\hline $\mathrm{Ni}_{3} \mathrm{~S}_{2}$ & 187.6 & 202.1 & 223.6 & 303.6 & 324.6 & 350.3 & & & \\
\hline $\mathrm{Ni}_{3} \mathrm{~S}_{4}$ & 223.3 & 286.6 & 337.6 & 380.3 & & & & & \\
\hline$\alpha-\mathrm{NiS}$ & 147.4 & 165.6 & 174.7 & 222.3 & 285.1 & 333.4 & 374.9 & & \\
\hline$\beta-\mathrm{NiS}$ & 143.1 & 178.9 & 206.1 & 221.9 & 244.6 & 283.7 & 297.8 & 349.2 & 370.6 \\
\hline
\end{tabular}

2

3

4

5

6

7

8

9

10

11

12

13

14

15

16

17

18

19

20

21

22

23

24

25

26

27

28 
1 Supplementary Table 5. In-situ Raman spectra of $\mathrm{Ni}_{1-x} \mathrm{Fe}_{x} \mathrm{~S}_{2}$.

\begin{tabular}{|c|c|c|c|c|c|c|c|}
\hline & \multicolumn{7}{|c|}{ Raman Peaks $\left(\mathrm{cm}^{-1}\right)$} \\
\hline$x=0,0.4 \mathrm{~V}$ & 272.9 & 284.1 & 478.4 & & & & \\
\hline$x=0,0.3 \mathrm{~V}$ & 271.5 & 281.2 & 478.4 & & & & \\
\hline$x=0,0.2 \mathrm{~V}$ & 269.3 & 279.7 & 474.2 & & & & \\
\hline$x=0,0.1 \mathrm{~V}$ & 268.6 & 277.0 & 473.5 & & & & \\
\hline$x=0,0.05 \mathrm{~V}$ & 185.5 & 197.6 & 220.1 & 302.2 & 322.1 & 348.3 & 473.2 \\
\hline$x=0,-0.15 \mathrm{~V}$ & 184.8 & 194.0 & 219.0 & 302.1 & 321.1 & 347.2 & \\
\hline$x=0,-0.25 \mathrm{~V}$ & 182.8 & 194.4 & 215.3 & 299.2 & 320.7 & 346.6 & \\
\hline$x=0.1,0.4 \mathrm{~V}$ & 273.5 & 283.2 & 478.9 & & & & \\
\hline$x=0.1,0.3 \mathrm{~V}$ & 271.3 & 282.1 & 476.6 & & & & \\
\hline$x=0.1,0.2 \mathrm{~V}$ & 270.1 & 280.2 & 474.5 & & & & \\
\hline$x=0.1,0.15 \mathrm{~V}$ & 185.1 & 198.5 & 219.2 & 302.1 & 321.9 & 349.2 & 474.4 \\
\hline$x=0.1,0.1 \mathrm{~V}$ & 186.9 & 197.8 & 219.6 & 302.7 & 321.7 & 348.7 & 474.1 \\
\hline$x=0.1,-0.15 \mathrm{~V}$ & 187.4 & 197.8 & 218.9 & 302.6 & 321.3 & 347.8 & \\
\hline$x=0.1,-0.25 \mathrm{~V}$ & 186.5 & 196.7 & 217.6 & 301.4 & 320.4 & 346.8 & \\
\hline$x=0.2,0.4 \mathrm{~V}$ & 274.2 & 285.0 & 479.8 & & & & \\
\hline$x=0.2,0.3 \mathrm{~V}$ & 274.3 & 283.8 & 478.8 & & & & \\
\hline$x=0.2,0.25 \mathrm{~V}$ & 271.3 & 282.5 & 476.5 & & & & \\
\hline$x=0.2,0.2 \mathrm{~V}$ & 181.8 & 195.5 & 216.2 & 297.7 & 320.9 & 345.3 & 476.3 \\
\hline$x=0.2,0.0 \mathrm{~V}$ & 182.4 & 195.5 & 218.7 & 297.7 & 320.3 & 345.3 & 476.1 \\
\hline$x=0.2,-0.15 \mathrm{~V}$ & 184.4 & 198.1 & 218.1 & 299.7 & 320.3 & 347.9 & \\
\hline$x=0.2,-0.25 \mathrm{~V}$ & 182.3 & 195.6 & 217.9 & 300.4 & 320.5 & 347.1 & \\
\hline$x=0.25,0.4 \mathrm{~V}$ & 276.2 & 285.9 & 480.8 & & & & \\
\hline$x=0.25,0.3 \mathrm{~V}$ & 272.9 & 282.6 & 478.3 & & & & \\
\hline$x=0.25,0.25 \mathrm{~V}$ & 271.6 & 281.9 & 476.9 & & & & \\
\hline$x=0.25,0.2 \mathrm{~V}$ & 181.1 & 194.7 & 216.7 & 298.4 & 319.8 & 345.3 & 476.5 \\
\hline$x=0.25,0.0 \mathrm{~V}$ & 182.9 & 195.3 & 217.3 & 298.4 & 318.6 & 345.3 & 476.3 \\
\hline$x=0.25,-0.15 \mathrm{~V}$ & 183.9 & 195.1 & 218.9 & 299.9 & 322.4 & 347.6 & \\
\hline$x=0.25,-0.25 \mathrm{~V}$ & 182.1 & 197.4 & 219.7 & 301.1 & 320.5 & 346.8 & \\
\hline$x=0.33,0.4 \mathrm{~V}$ & 273.5 & 283.8 & 478.4 & & & & \\
\hline$x=0.33,0.3 \mathrm{~V}$ & 272.9 & 283.2 & 478.3 & & & & \\
\hline$x=0.33,0.25 \mathrm{~V}$ & 270.6 & 282.1 & 476.0 & & & & \\
\hline$x=0.33,0.2 \mathrm{~V}$ & 182.6 & 197.6 & 218.7 & 301.1 & 321.0 & 346.1 & 475.4 \\
\hline$x=0.33,0.0 \mathrm{~V}$ & 187.2 & 200.1 & 220.2 & 301.9 & 322.1 & 347.1 & \\
\hline$x=0.33,-0.15 \mathrm{~V}$ & 185.1 & 198.2 & 219.7 & 300.5 & 320.5 & 347.1 & \\
\hline$x=0.33,-0.25 \mathrm{~V}$ & 181.1 & 197.2 & 220.2 & 301.1 & 321.4 & 347.4 & \\
\hline
\end{tabular}


1 Supplementary Table 6. The DFT calculated energy of Ni $3 d$ band center and $\mathrm{S} 3 p$ band center of $\mathrm{Ni}_{1-x} \mathrm{Fe}_{x} \mathrm{~S}_{2}$

$2(x=0.0,0.1,0.2$ and 0.33$)$ relative to Fermi level.

\begin{tabular}{|c|c|c|c|}
\hline & $\mathbf{N i} \mathbf{3}(\mathbf{e V})$ & $\mathbf{S ~ 3} \boldsymbol{p}(\mathbf{e V})$ & $\mathbf{N i} \mathbf{d}-\mathbf{S} \mathbf{3} \boldsymbol{p}(\mathbf{e V})$ \\
\hline$x=0.0$ & -2.204 & -5.232 & 3.028 \\
\hline$x=0.1$ & -2.245 & -4.888 & 2.643 \\
\hline$x=0.2$ & -2.318 & -4.856 & 2.538 \\
\hline$x=0.33$ & -2.384 & -4.788 & 2.404 \\
\hline
\end{tabular}

3

4

5

6 Supplementary Table 7. The sulphur vacancy formation enthalpy $\Delta \mathrm{Hf}$, Vs of $\mathrm{Ni}_{1-x} \mathrm{Fe}_{x} \mathrm{~S}_{2}(x=0.0,0.1,0.2$ 7 and 0.33$)$.

\begin{tabular}{|c|c|c|c|}
\hline & Energy (eV) & $\boldsymbol{\mu}_{\mathbf{i}}(\mathbf{e V})$ & $\boldsymbol{\Delta} \mathbf{H f}, \mathbf{V s}(\mathbf{e V})$ \\
\hline $\mathrm{NiS}_{2}$ & -289.10 & & \\
\hline $\mathrm{NiS}_{2}-\mathrm{V}_{\mathrm{S}}$ & -284.12 & -4.12 & 0.86 \\
\hline $\mathrm{Ni}_{0.9} \mathrm{Fe}_{0.1} \mathrm{~S}_{2}$ & -295.69 & & \\
\hline $\mathrm{Ni}_{0.8} \mathrm{Fe}_{0.2} \mathrm{~S}_{2}-\mathrm{V}_{\mathrm{S}}$ & -290.74 & -4.12 & 0.83 \\
\hline $\mathrm{Ni}_{0.8} \mathrm{Fe}_{0.2} \mathrm{~S}_{2}$ & -302.33 & & 0.75 \\
\hline $\mathrm{Ni}_{0.8} \mathrm{Fe}_{0.2} \mathrm{~S}_{2}-\mathrm{V}_{\mathrm{S}}$ & -297.46 & -4.12 & \\
\hline $\mathrm{Ni}_{0.67} \mathrm{Fe}_{0.33} \mathrm{~S}_{2}$ & -309.07 & & 1.19 \\
\hline $\mathrm{Ni}_{0.67} \mathrm{Fe}_{0.33} \mathrm{~S}_{2}-\mathrm{V}_{\mathrm{S}}$ & -303.76 & -4.12 & \\
\hline
\end{tabular}


Supplementary Table 8. The formation energy of $\mathrm{Ni}_{1-x} \mathrm{Fe}_{x} \mathrm{~S}_{2}(x=0.0$ and 0.2$)$ for reconstruction

\begin{tabular}{|c|c|c|c|c|c|c|}
\hline Structure & $\mathbf{N i S}_{2}$ & $\mathbf{N i}_{3} \mathbf{S}_{2}$ & $20 \% \mathrm{Fe} @ \mathrm{NiS}_{2}$ & $4 \% \mathrm{Fe} @ \mathrm{Ni}_{3} \mathrm{~S}_{2}$ & $\mathrm{FeS}_{2}$ & $\mathbf{S}$ \\
\hline Formula & $\mathrm{Ni}_{4} \mathrm{~S}_{8}$ & $\mathrm{Ni}_{9} \mathrm{~S}_{6}$ & $\mathrm{Fe}_{4} \mathrm{Ni}_{16} \mathrm{~S}_{40}$ & $\mathrm{FeNi}_{23} \mathrm{~S}_{16}$ & $\mathrm{Fe}_{2} \mathrm{~S}_{4}$ & $\mathrm{~S}_{32}$ \\
\hline Energy (eV) & -58.207 & -80.422 & -304.213 & -216.76 & -36.139 & -131.949 \\
\hline $\begin{array}{c}\text { Normalization } \\
(\mathrm{eV})\end{array}$ & -14.552 & -26.807 & -15.217 & -27.095 & -18.070 & -4.123 \\
\hline $\begin{array}{l}\text { Formation } \\
\text { Energy }(\mathrm{eV})\end{array}$ & & $\begin{array}{c}0.059 \mathrm{eV} \\
\left(\mathrm{E}_{\mathrm{fl}}\right) \\
0.025 \mathrm{eV} \\
\left(\mathrm{E}_{\mathrm{f} 3}\right)\end{array}$ & & $\begin{array}{c}0.036 \mathrm{eV} \\
\left(\mathrm{E}_{\mathrm{f} 2}\right)\end{array}$ & & \\
\hline
\end{tabular}

2

3

$4 \quad \mathrm{NiS}_{2}=1 / 3 \mathrm{Ni}_{3} \mathrm{~S}_{2}+4 / 3 \mathrm{~S}$

5

6

7

$\mathrm{E}_{\mathrm{f} 3}=0.025 \mathrm{eV}$

$\mathrm{Fe}_{0.2} \mathrm{Ni}_{0.8} \mathrm{~S}_{2}=4 / 15 \mathrm{Ni}_{3} \mathrm{~S}_{2}+1 / 5 \mathrm{FeS}_{2}+16 / 15 \mathrm{~S}$

$\mathrm{E}_{\mathrm{f3}}{ }^{\prime}=4 / 15 \mathrm{E}\left(\mathrm{Ni}_{3} \mathrm{~S}_{2}\right)+1 / 5 \mathrm{E}\left(\mathrm{FeS}_{2}\right)+16 / 15 \mathrm{E}(\mathrm{S})-\mathrm{E}\left(20 \% \mathrm{Fe} @ \mathrm{NiS}_{2}\right)=0.050 \mathrm{eV}$

This result is a value normalized to $\mathrm{NiS}_{2}$ or $\mathrm{Fe}_{0.2} \mathrm{Ni}_{0.8} \mathrm{~S}_{2}$. For convenience of expression, the result normalized to a single sulphur atom as $E_{\mathrm{fn}}=\mathrm{E}_{\mathrm{fn}}{ }^{\prime} / 2$.

The reconstruction process is discussed in three cases. The first case is the $\mathrm{NiS}_{2}$ phase transition to generate $\mathrm{Ni}_{3} \mathrm{~S}_{2}$ with the sulphur leaching, as shown in Equation 1. For $\mathrm{Fe}_{0.2} \mathrm{Ni}_{0.8} \mathrm{~S}_{2}$, the segregation process (D. J. Vaughan and J. R C. Mineral chemistry of metal sulfides. Cambridge University Press, 1978, 62-66) exists in the phase transition process. Therefore, it is difficult to accurately 
1 measure the Fe content in the final products with suitable characterization methods. We assume 2 that there are two cases in which all $\mathrm{Fe}$ is segregated into $\mathrm{FeS}_{2}$ (as shown in equation 3), and 3 eventually retain some Fe, so proceed according to equation 2 .

4 According to the test results of the EDS element ratio and XPS results, it can be known that 5 with the extension of the test time, the Fe element will correspondingly leach with the phase 6 transition process, and it will eventually stabilize at about $4 \%$ in the new reconstructed structure 7 in $100 \mathrm{~h}$ long-term operation. Because the loss of sulphur is large, we assume that during the $8 \mathrm{Fe}$ loss process, it is extracted from the phase of $\mathrm{Ni}_{0.8} \mathrm{Fe}_{0.2} \mathrm{~S}_{2}$ is in the form of $\mathrm{FeS}_{2}$ to forming new reconstructed structure, and the phase transition reaction are shown in equation (2) and (3). As $\mathrm{E}_{\mathrm{f} 3}(0.025 \mathrm{eV})$ or $\mathrm{E}_{\mathrm{f} 2}(0.036 \mathrm{eV})<\mathrm{E}_{\mathrm{f} 1}(0.059 \mathrm{eV})$, so we have the result that Fe substitution can facilitate the phase transition to form the finalized structure. 
1 Supplementary Table 9. In-situ Raman spectra of $\alpha$-NiS, $\beta$-NiS and $\mathrm{Ni}_{3} \mathrm{~S}_{4}$.

\begin{tabular}{|l|c|c|c|c|c|c|c|}
\hline & \multicolumn{7}{|c|}{ Raman Peaks $\left(\mathbf{c m}^{-1}\right)$} \\
\hline$\beta-\mathrm{NiS}, 0.4 \mathrm{~V}$ & 181.1 & 198.5 & 222.2 & 242.8 & 297.8 & 348.2 & 368.5 \\
\hline$\beta-\mathrm{NiS}, 0.2 \mathrm{~V}$ & 176.4 & 193.4 & 222.7 & 242.8 & 296.4 & 346.8 & 368.1 \\
\hline$\beta-\mathrm{NiS}, 0.15 \mathrm{~V}$ & 173.3 & 192.5 & 221.9 & 242.8 & 296.5 & 346.8 & 368.1 \\
\hline$\beta-\mathrm{NiS}, 0.1 \mathrm{~V}$ & 178.8 & 193.0 & 215.0 & 237.3 & 296.7 & 319.1 & 343.8 \\
\hline$\beta-\mathrm{NiS},-0.15 \mathrm{~V}$ & 178.1 & 194.6 & 215.3 & 299.7 & 319.4 & 343.8 & \\
\hline$\beta-\mathrm{NiS},-0.25 \mathrm{~V}$ & 180.7 & 195.7 & 216.1 & 297.5 & 320.4 & 344.6 & \\
\hline$\alpha-\mathrm{NiS}, 0.4 \mathrm{~V}$ & 164.9 & 175.7 & 221.9 & 285.4 & 347.8 & & \\
\hline$\alpha-\mathrm{NiS}, 0.2 \mathrm{~V}$ & 175.2 & 220.9 & 284.4 & 346.9 & & & \\
\hline$\alpha-\mathrm{NiS}, 0.1 \mathrm{~V}$ & 170.8 & 220.4 & 284.2 & 345.6 & & & \\
\hline$\alpha-\mathrm{NiS}, 0.05 \mathrm{~V}$ & 182.2 & 195.2 & 217.1 & 299.1 & 319.2 & 346.1 & \\
\hline$\alpha-\mathrm{NiS},-0.15 \mathrm{~V}$ & 179.8 & 194.5 & 216.0 & 298.4 & 320.4 & 346.8 & \\
\hline$\alpha-\mathrm{NiS},-0.25 \mathrm{~V}$ & 181.5 & 195.8 & 217.1 & 297.9 & 321.0 & 346.9 & \\
\hline $\mathrm{Ni}_{3} \mathrm{~S}_{4}, 0.4 \mathrm{~V}$ & 223.1 & 286.3 & 338.5 & 381.5 & 480.9 & & \\
\hline $\mathrm{Ni}_{3} \mathrm{~S}_{4}, 0.2 \mathrm{~V}$ & 222.1 & 285.3 & 337.1 & 380.8 & 478.2 & & \\
\hline $\mathrm{Ni}_{3} \mathrm{~S}_{4}, 0.1 \mathrm{~V}$ & 220.1 & 284.2 & 335.6 & 379.1 & 477.6 & & \\
\hline $\mathrm{Ni}_{3} \mathrm{~S}_{4}, 0.05 \mathrm{~V}$ & 183.5 & 196.2 & 217.9 & 301.6 & 318.7 & 346.2 & \\
\hline $\mathrm{Ni}_{3} \mathrm{~S}_{4},-0.15 \mathrm{~V}$ & 184.1 & 196.5 & 219.4 & 300.2 & 320.3 & 346.5 & \\
\hline $\mathrm{Ni}_{3} \mathrm{~S}_{4},-0.25 \mathrm{~V}$ & 185.1 & 197.9 & 219.9 & 302.0 & 322.4 & 348.4 & \\
\hline & & & & & & & \\
\hline
\end{tabular}

2

3

4

5

6

7

8

9

10

11

12

13

14

15 
Figures

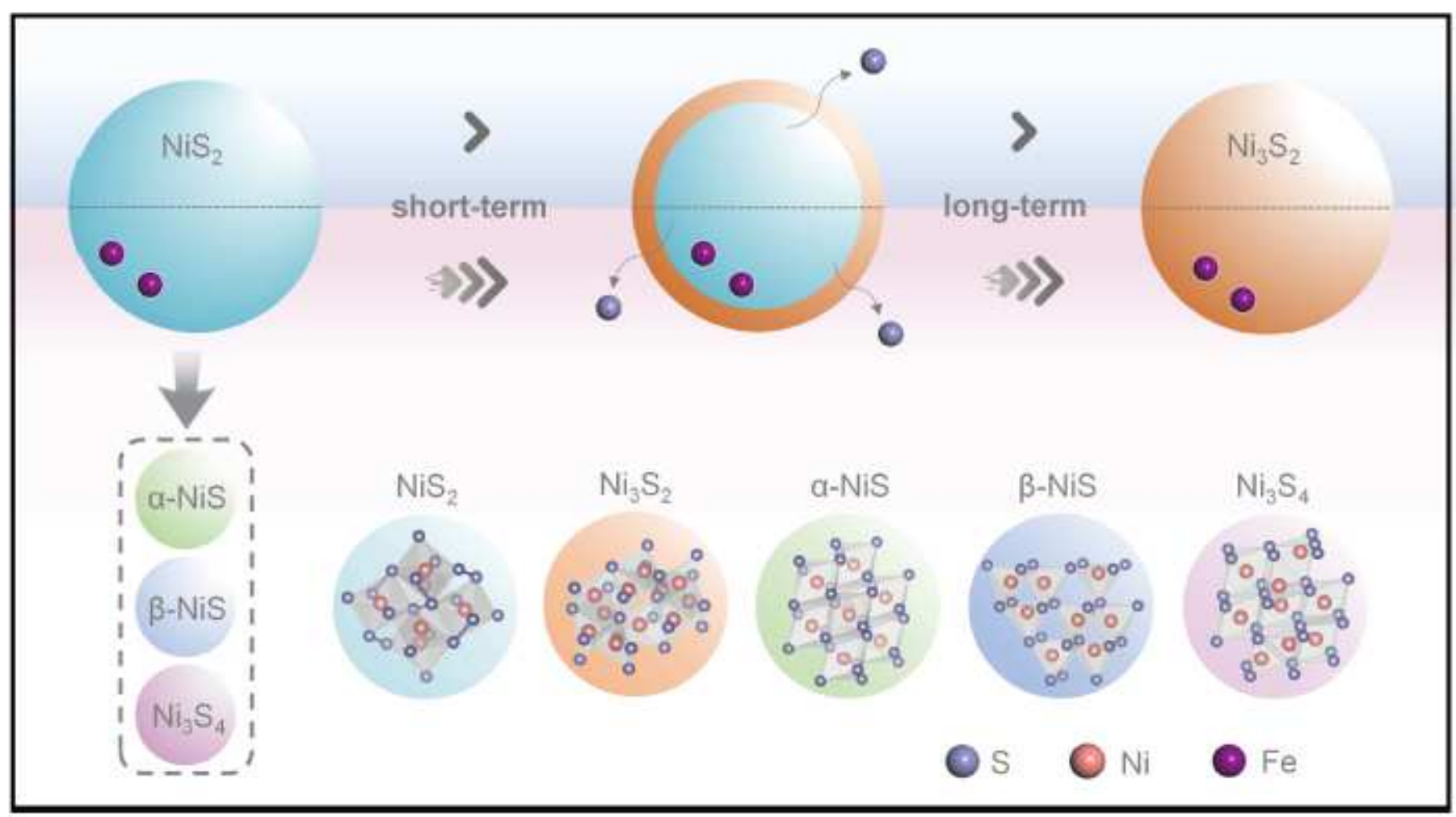

Figure 1

Schematic illustration of dynamic reconstruction of multivalent nickel sulfide HER catalysts. 

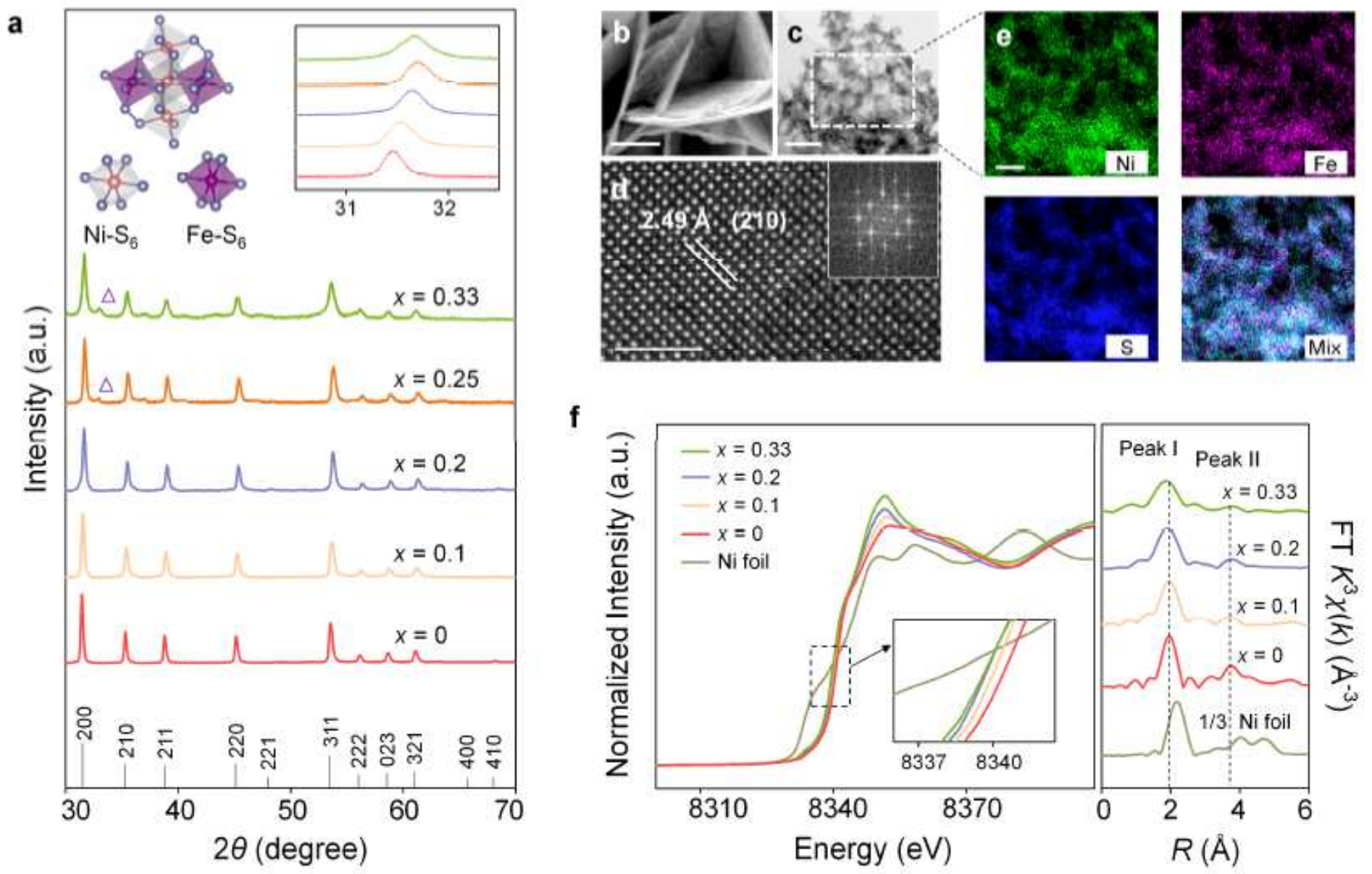

Figure 2

Structural characterizations of as-prepared Ni1-xFexS2 catalysts. a, Powder XRD patterns of synthesized Ni1-xFexS2 ( $x \approx 0 \sim 0.33)$ samples. Inset, schematics of the composition of Fe substituted nickel disulfides and the magnified XRD patterns in the range between 30 and 33 . The triangle symbols represent diffraction peak of FeS2 structure. b, Top-view SEM image of the Ni0.8Fe0.2S2. Scale bar, $1 \mu \mathrm{m}$. c, TEM image of Ni0.8Fe0.2S2. Scale bar, $100 \mathrm{~nm}$. d, High-resolution TEM image of Ni0.8Fe0.2S2. Scale bar, 2 $\mathrm{nm}$. The fast Fourier transform is shown in the inset of (d) confirms the crystalline nature of the bulk material. e, The corresponding EDS elemental mappings of $\mathrm{Ni}$, Fe, S and the mixed elemental mapping. Scale bar, $50 \mathrm{~nm}$. f, Normalized Ni K-edge XANES analysis (left axis) of Ni1-xFexS2 samples with Ni foil as reference, as well as the corresponding k3-weighted Fourier transform (FT) Ni K-edge EXAFS spectra (right axis). Inset, Magnified pre-edge XANES region. Peaks I and II in the FT-EXAFS plots are assigned to $\mathrm{Ni}-\mathrm{S}$ and Ni-Ni radial distances, respectively. 

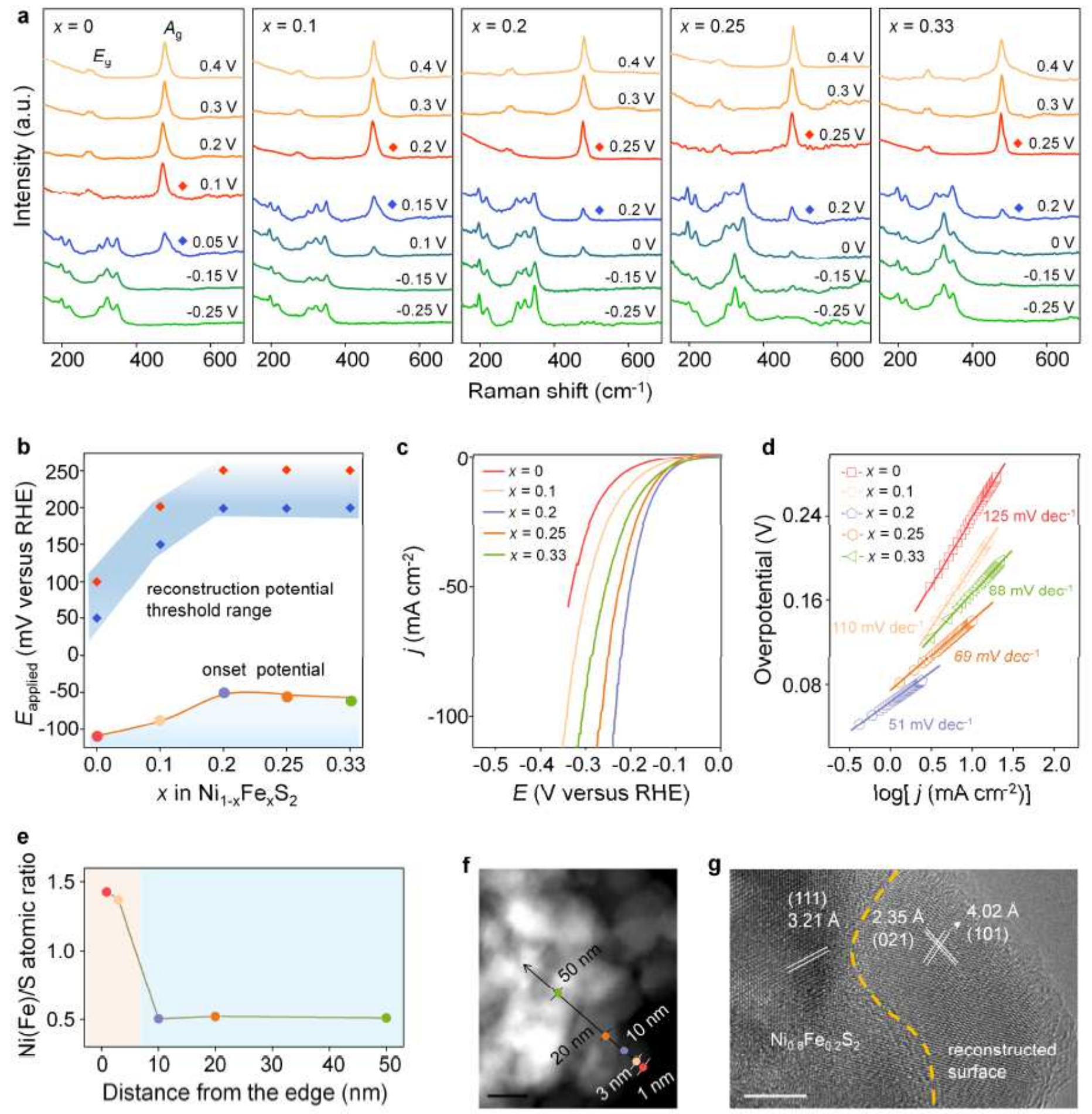

\section{Figure 3}

In-situ investigation of dynamic surface reconstruction process and HER performances of catalysts. a, Insitu Raman spectra of Ni1-xFexS2 $(x \approx 0 \sim 0.33)$ samples at the potentials of $0.4 \sim-0.25 \mathrm{~V}$ versus reversible hydrogen electrode (vs. RHE) in $1 \mathrm{M} \mathrm{KOH}$. b, The surface reconstruction potential threshold range for $\mathrm{Ni1}$ $x F e x S 2(x \approx 0 \sim 0.33)$ samples, and the corresponding onset potentials of hydrogen evolution are plotted to show the dynamic correlation of structure-activity. The red diamond dots represent the final potential of existence for Raman peaks of Ni1-xFexS2 structures, and the blue diamond dots stand for the 
potential of emerging of Ni3S2 Raman peaks. c, HER polarization curves of Ni1-xFexS2 catalysts on carbon fiber paper in N2-saturated $1 \mathrm{M} \mathrm{KOH}$ at a scan rate of $5 \mathrm{mV} \mathrm{s}-1, \mathrm{~d}$, Corresponding HER Tafel plots derived from the polarization curves. e, $\mathrm{f}$, Elemental composition of post-electrolysis Ni0.8Fe0.2S2 determined from EDS at a series of spots along a line from the crystallite edge to the bulk reveals the variation in $\mathrm{Ni}(\mathrm{Fe})$ : $\mathrm{S}$ composition across the crystallite, the marked points in (f) denote the scanning distance along the pathway in $\mathrm{nm}$. g, HRTEM image of post-electrolysis Ni0.8Fe0.2S2. The scale bars are $20 \mathrm{~nm}$ in (f), $5 \mathrm{~nm}$ in (g).
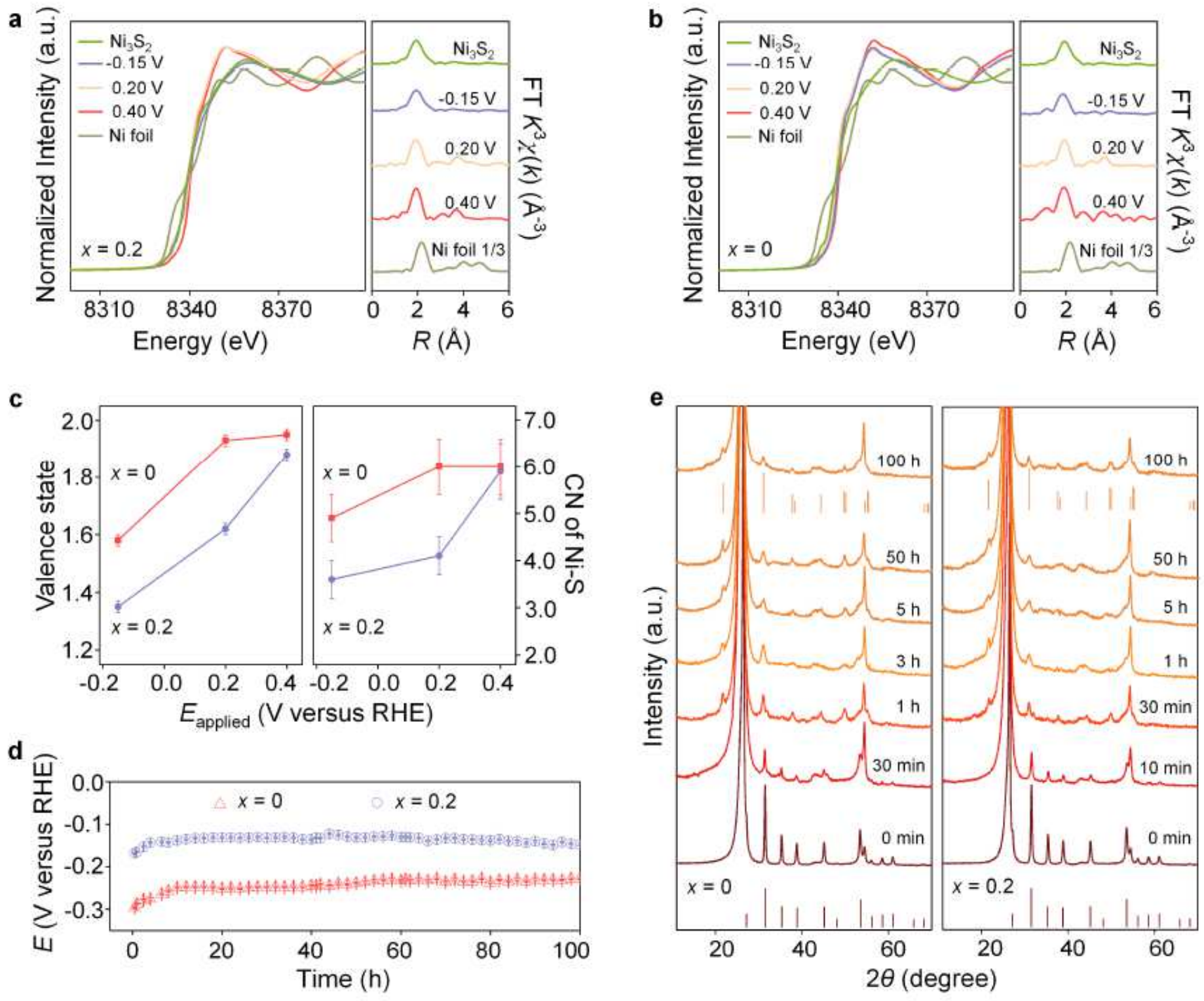

\section{Figure 4}

Operando XAFS spectra and long-term operation characterization of catalysts. a, b, Normalized operando Ni K-edge XANES analysis (left axis) at 0.40, 0.20, and - $0.15 \mathrm{~V}$ (vs. RHE) with Ni Foil and standard Ni3S2 powder (Alfa Aesar) as reference, as well as the corresponding operando FT k3-weighted Ni K-edge EXAFS (right axis): Ni0.8Fe0.2S2 (a) and NiS2 (b). c, Left axis, the fitted average valence states of nickel element from XANES spectra for NiS2 and Ni0.8Fe0.2S2. Error bars represent the standard deviation from 
at least three independent measurements. The right axis show the changes of coordination number (CN) for Ni-S corresponding to the applied potentials. d, Chronopotentiometric curves obtained with $\mathrm{Ni0.8Fe} 0.2 \mathrm{~S} 2$ and NiS2 at constant current density of $10 \mathrm{~mA} \mathrm{~cm}-2$. e, XRD patterns of catalysts after the operation of HER instantly at $10 \mathrm{~mA} \mathrm{~cm}-2$ during $100 \mathrm{~h}$. The $2 \theta$ peaks of $\sim 26.5^{\circ}$ and $54.5^{\circ}$ stand for the carbon fiber paper substrates.

a
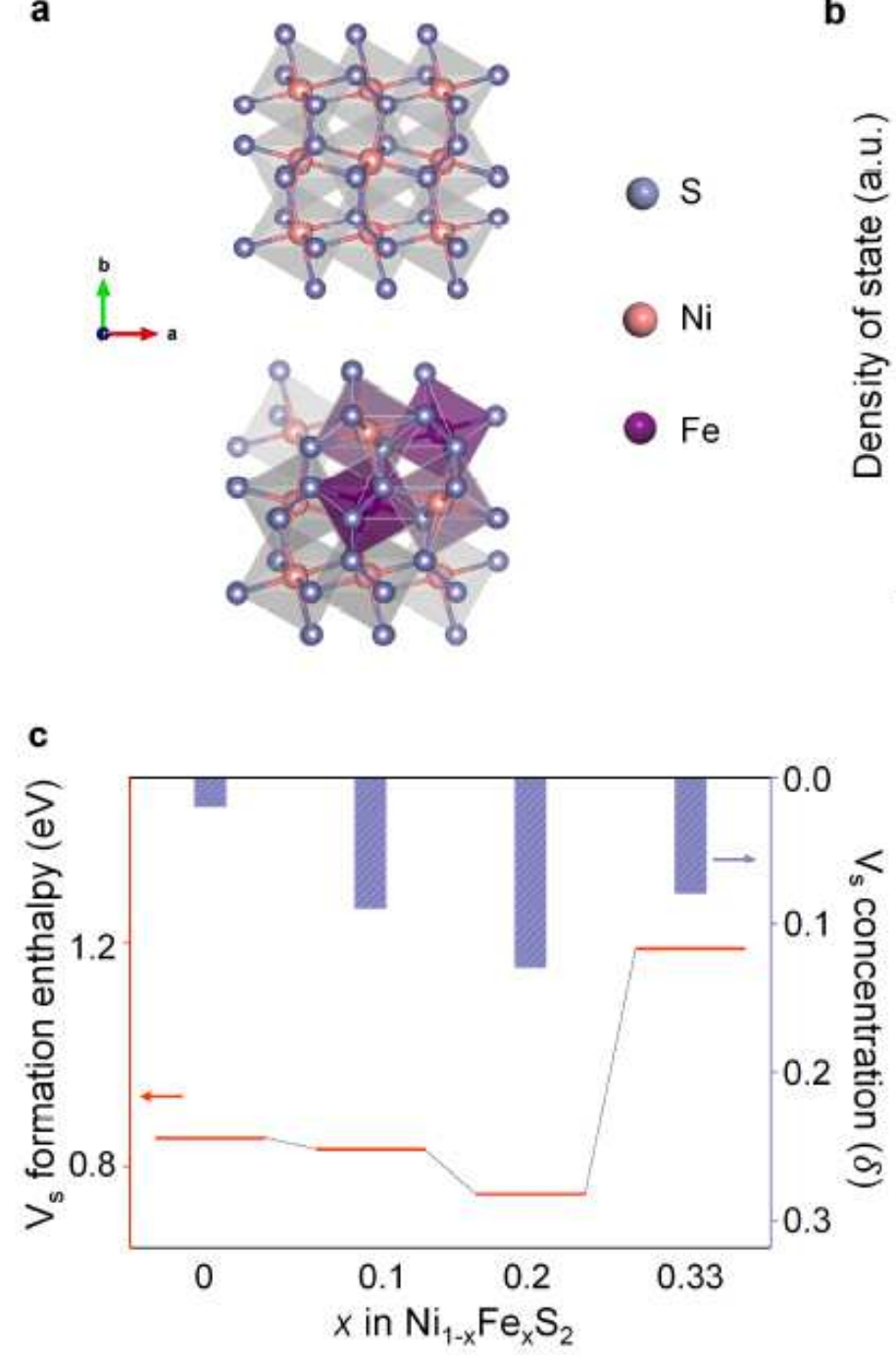
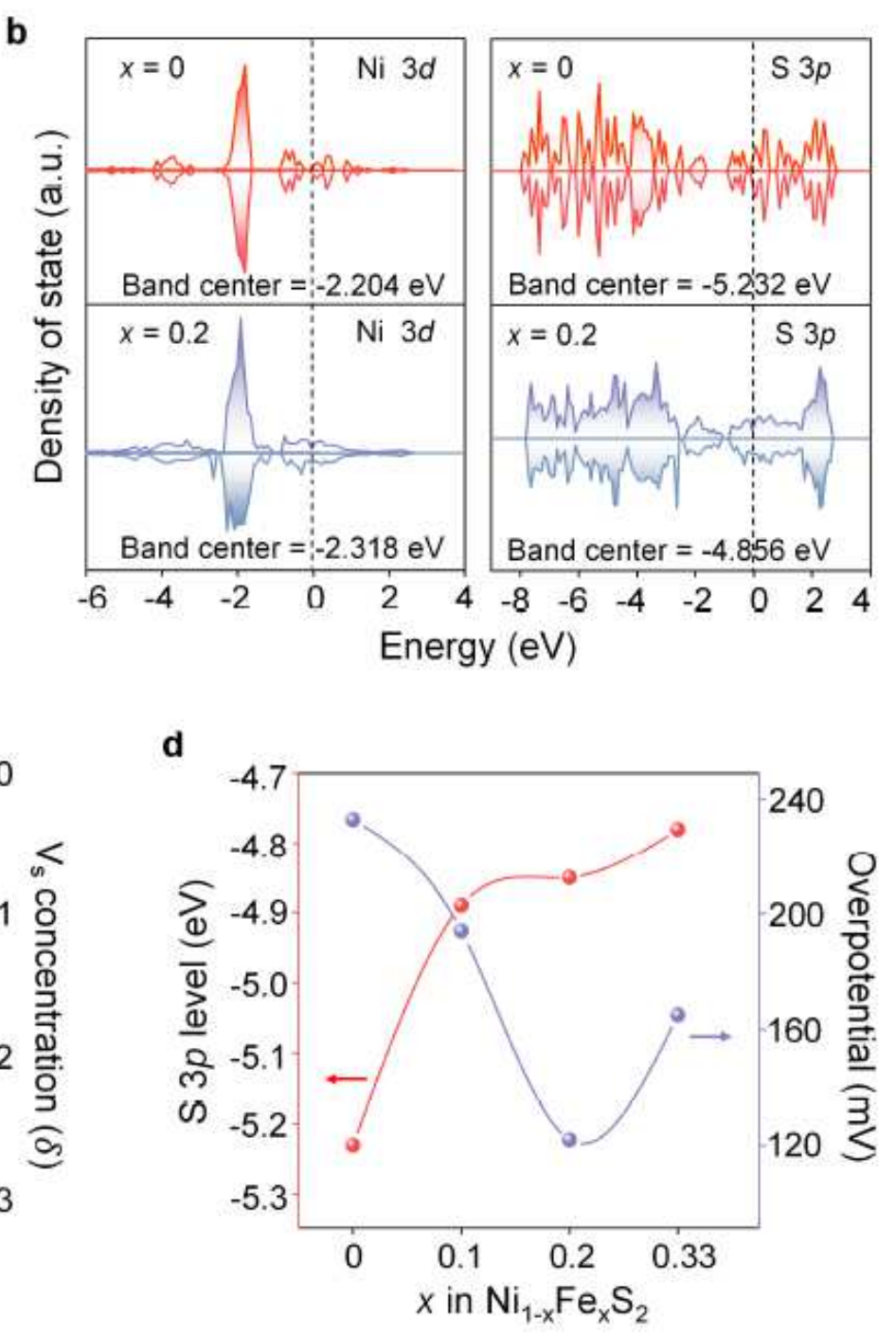

Figure 5

Electronic interpretation of the effect of Fe substitution on catalyst evolution. a, Computational models of Ni1-xFexS2: top, $x=0$; bottom, $x=0.2$. b, Computed Ni 3d, S 3p PDOS of Ni1-xFexS2 ( $x=0.0,0.2)$. c, Calculated sulphur vacancy (VS) formation enthalpy and sulphur vacancy concentration $(\delta)$ of the samples for Ni1-xFexS2 $(x=0.0,0.1,0.2,0.33)$. $d$, Computed S 3p PDOS related to the overpotential of Ni1-xFexS2 ( $x=0.0,0.1,0.2,0.33) @ 10 \mathrm{~mA}$ cm-2. 

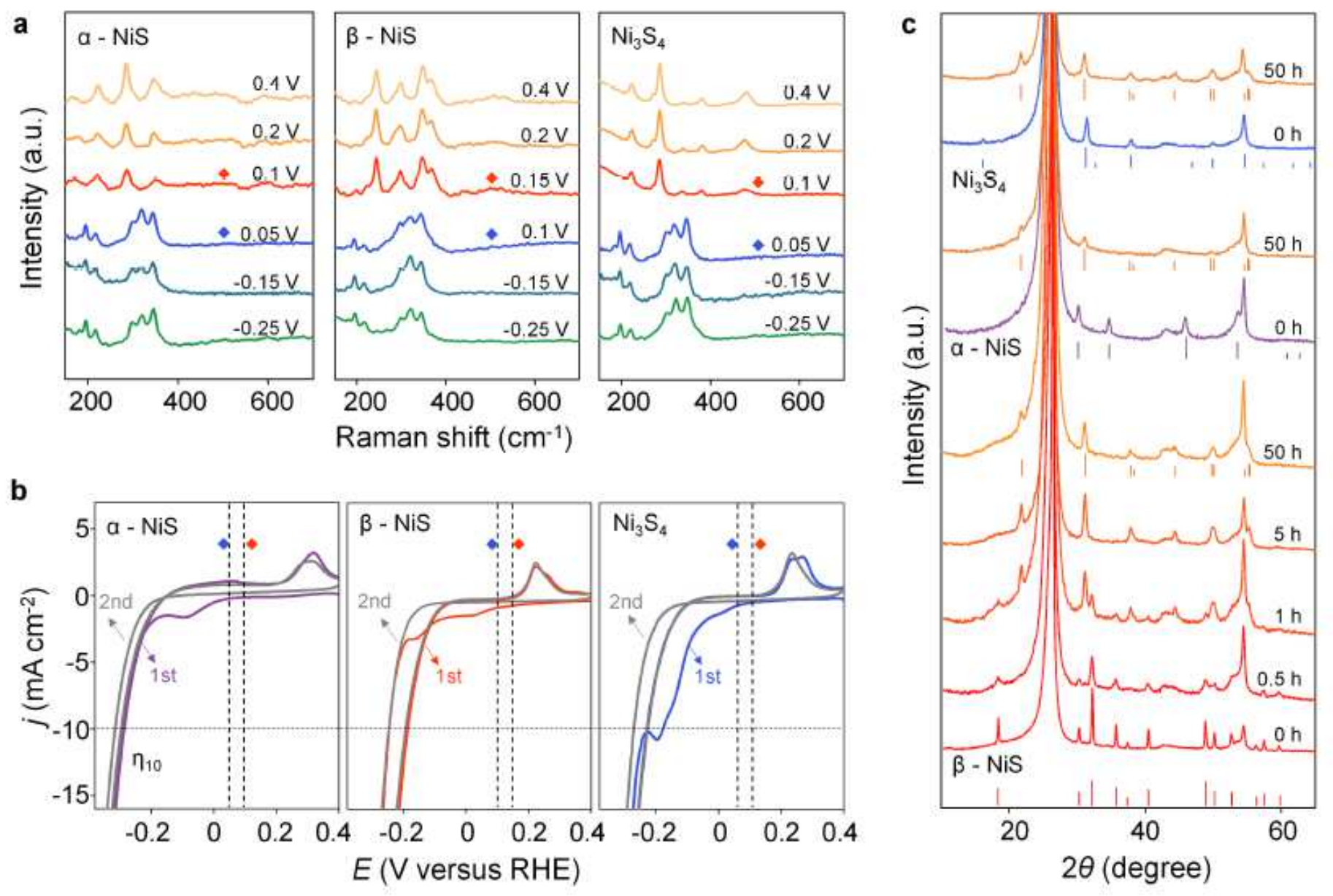

Figure 6

Dynamic structural evolution characterization of a-NiS, $\beta$-NiS and Ni3S4 catalysts. a, In-situ Raman spectra of nickel sulfides at the potentials of $0.4 \sim-0.25 \mathrm{~V}$ (vs. RHE) in $1 \mathrm{M} \mathrm{KOH}$ for a-NiS, $\beta-\mathrm{NiS}$ and Ni3S4. b, Cyclic voltammetry curves of a-NiS, $\beta$-NiS and Ni3S4 in N2-saturated $1 \mathrm{M} \mathrm{KOH}$ with a scan rate of $2 \mathrm{mV}$ s-1 between 0.4 and $-0.4 \mathrm{~V}$ (vs. RHE). The red diamond dots represent the final potential of existence for a-NiS, $\beta$-NiS and Ni3S4 Raman peaks, and the blue diamond dots stand for the potential of emerging of Ni3S2 Raman peaks. c, XRD patterns of catalysts after the operation of HER instantly at constant current density of $10 \mathrm{~mA} \mathrm{~cm}-2$. 